\title{
ASSESSMENT OF IN-STREAM PROCESSES IN URBAN STREAMS FOR DEVELOPMENT OF SEDIMENT TOTAL MAXIMUM DAILY LOADS
}

\author{
A Thesis \\ Presented to \\ The Academic Faculty \\ by \\ Joshua Lee Robinson

\begin{abstract}
In Partial Fulfillment
of the Requirements for the Degree

Master of Science in Civil Engineering
\end{abstract}

Georgia Institute of Technology

May 2005 


\section{ASSESSMENT OF IN-STREAM PROCESSES IN URBAN STREAMS FOR DEVELOPMENT OF SEDIMENT TOTAL MAXIMUM DAILY LOADS}

Approved by:

Dr. Terry W. Sturm, Chair School of Civil and Environmental Engineering Georgia Institute of Technology

Dr. Thomas N. Debo School of Architecture

Georgia Institute of Technology

Dr. Marc Stieglitz

School of Civil and Environmental Engineering Georgia Institute of Technology

Date Approved: January 13, 2005 


\section{ACKNOWLEDGEMENTS}

I would like to thank Dr. Sturm for his support and guidance throughout this project. I would also like to extend my gratitude to Dr. Debo and Dr. Stieglitz for their contributions to this thesis. I would finally like to thank Andrew Udell for his advice and assistance during my research. 


\section{TABLE OF CONTENTS}

ACKNOWLEDGEMENTS .iii

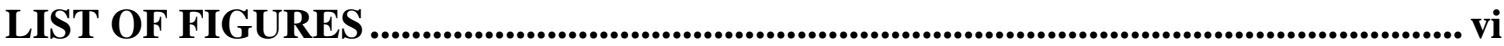

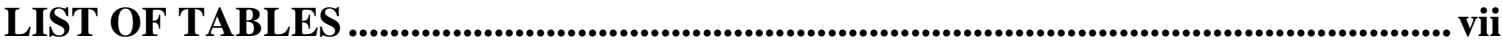

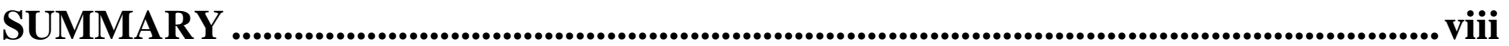

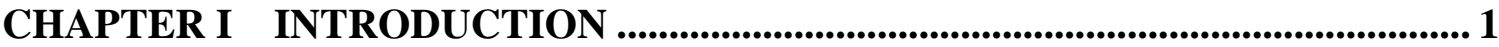

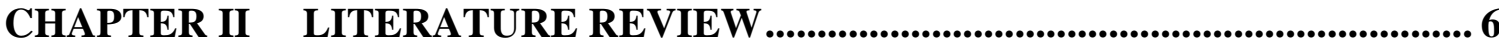

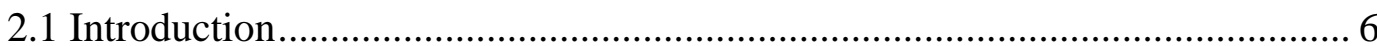

2.2 Importance of Suspended Sediment Monitoring ......................................... 6

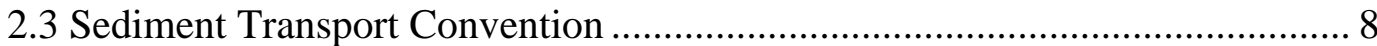

2.4 Suspended Sediment Load Calculations ......................................................... 10

2.5 Suspended Sediment Load Measuring Techniques ..................................... 13

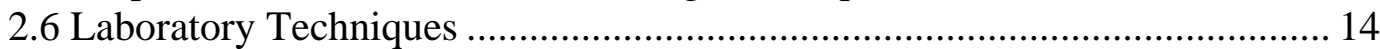

2.7 Suspended Sediment Surrogate Technologies ............................................ 16

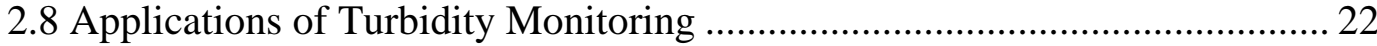

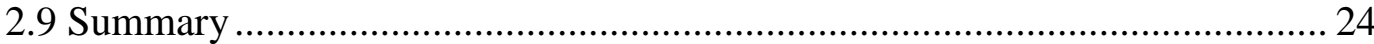

CHAPTER III EXPERIMENTAL METHODS ...................................................... 26

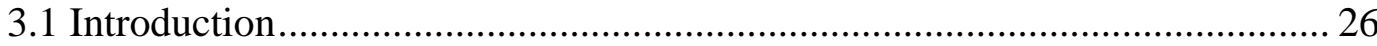

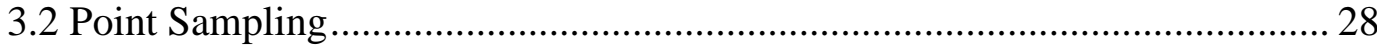

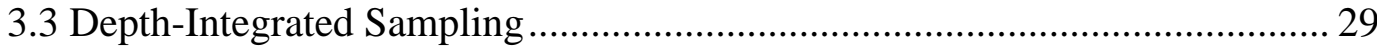

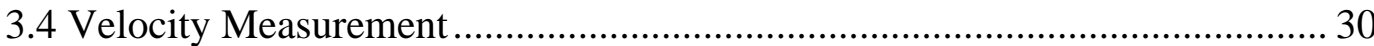

3.5 Sediment Sample Collection.................................................................... 31

3.6 Suspended Sediment Concentration (SSC) Measurement............................. 31

3.7 Percent Fine Sediment Measurement......................................................... 32

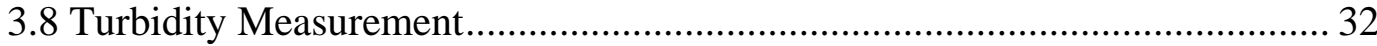

3.9 Particle Size Analysis ................................................................................ 33

CHAPTER IV RESULTS AND ANALYSIS .................................................... 35

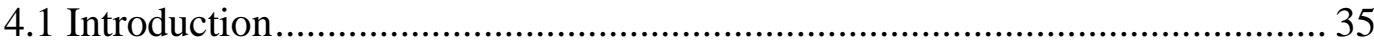

4.2 Constructing a Sediment-Rating Curve by Point Sampling .......................... 35

4.3 Relative Sources of Sediment in Point Samples ............................................. 38

4.4 Using Turbidity to Locate Sources of Washload........................................... 39

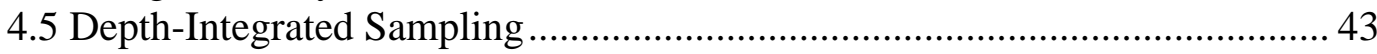

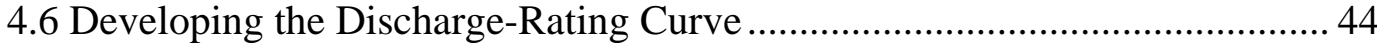

4.7 Suspended Sediment-Rating Curve ............................................................. 46

4.8 Vertical Extrapolation of Point Samples..................................................... 47

4.9 Cross-sectional Extrapolation of Point Samples........................................... 51 
4.10 Effects of Energy Grade Line Slope on Point Samples ............................. 57

4.11 Implementation of Research Findings .......................................................... 61

CHAPTER V CONCLUSIONS AND RECOMMENDATIONS ............................. 65

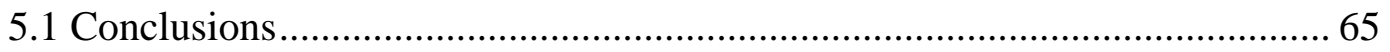

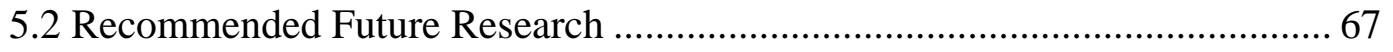

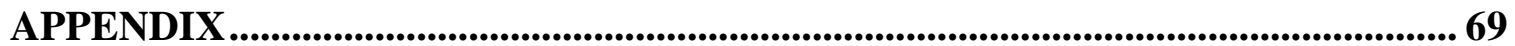

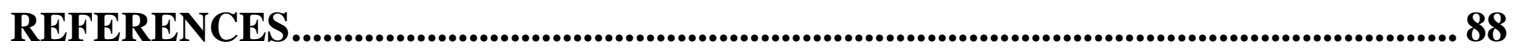




\section{LIST OF FIGURES}

Figure 2.1 Rouse vertical distribution of suspended sediment concentration .................. 12

Figure 3.1 Sampling location: North Fork Peachtree Creek at Century Blvd ................. 27

Figure 4.1 May 22, 2004 storm hydrograph and point sampled SSC data ...................... 36

Figure 4.2 Log-log plot of paired stage and point sampled SSC data ........................... 37

Figure 4.3 Grain size distribution of bed sediment.................................................. 38

Figure 4.4 Log-log plot of $\mathrm{SSC}_{\text {fines }}$ and turbidity for multiple storm events................... 40

Figure 4.5 Log-log plot comparing turbidity signatures of sediment samples ............... 42

Figure 4.6 Log-log plot of paired stage and depth-integrated SSC data.......................... 44

Figure 4.7 Discharge-rating curve at sampling cross-section .................................... 45

Figure 4.8 Suspended sediment-rating curve from depth-integrated samples ................. 46

Figure 4.9 Turbidity comparison of suspended sediment concentration samples ........... 49

Figure 4.10 Measured sediment discharge at single vertical from depth-integrated samples and from integrated Isco point samples ................................................ 51

Figure 4.11 Lateral variation in measured sediment discharge from depth-integrating

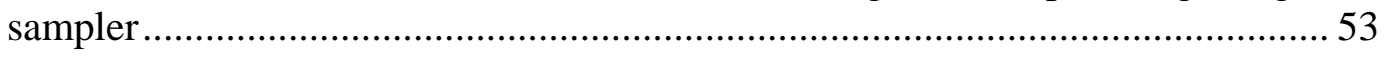

Figure 4.12 Measured sediment discharge of entire cross-section ................................. 54

Figure 4.13 Suspended sediment discharge using integrated point samples $\left(G_{s}\right)$ and measured sediment discharge from depth-integrated samples $\left(G_{m}\right) \ldots \ldots \ldots \ldots \ldots \ldots \ldots . . . . .55$

Figure 4.14 Suspended sediment discharge using averages of integrated point samples and measured sediment discharge from depth-integrated samples......................56

Figure 4.15 EGL slope fluctuation during storm event on May 22, 2004 ...................... 57

Figure 4.16 Rouse number fluctuation during storm event on May 22, 2004 ................. 58

Figure 4.17 Twenty percent depth with increasing discharge .................................... 59 


\section{LIST OF TABLES}

Table 4.1 Regression equations of turbidity signatures and grain size information ......... 42 


\section{SUMMARY}

The Clean Water Act requires the establishment of Total Maximum Daily Loads (TMDLs) for quantifying allowable pollutant loads for stream reaches in which the biological integrity of the stream is threatened. Sediment TMDLs in urban streams are particularly difficult to establish because they require (1) reliable measurement of sediment loads and (2) the ability to locate sediment sources. This research has attempted to address these challenges through a field study of North Peachtree Creek located in DeKalb County, Georgia, which has been sampled at the Century Boulevard crossing through automatic point sampling and depth-integrated sampling. Storm events from October 2003 through October 2004 provided a field record of sediment concentration and turbidity data over a wide range of storm events. Bed and bank sediment samples were collected for comparison with the point samples and depthintegrated samples. A methodology is presented whereby point sampling is used to calculate suspended sediment discharge and turbidity analysis is used to locate and characterize sediment sources. Point samples provide the boundary condition in the Rouse solution for the vertical distribution of suspended sediment to obtain suspended sediment discharge, which is then calibrated through comparison with depth-integrated sampling. The computer model HEC-RAS (U.S. Army Corps of Engineers, 1998) was applied to the stream reach to calculate the energy grade line slope throughout each storm event for input into the sediment discharge calculations. A favorable relationship between turbidity and suspended fine sediment was found at the sampling cross-section

and, through comparison with bed and bank sediment samples, was used to identify the contribution of eroded bank sediment to the total sediment discharge. 


\section{CHAPTER I \\ INTRODUCTION}

The North Peachtree Creek drainage basin located in DeKalb County, Georgia, has been subject to rapid urban development over the last several decades and suffers impaired water quality as a consequence. Streams experience the initial effects of the urbanization process when large pulses of sediment are delivered into the stream as land is cleared for construction. The resulting disturbed land is highly vulnerable to sheet and rill erosion and yields a large amount of sediment during each rainfall event. Because the stream cannot transport the increased sediment load, deposition occurs in the channel and the stream conveyance function becomes impaired by sediment. This process of sediment deposition in the stream system may occur for decades until urbanization reaches its capacity in terms of density. As construction activities decrease, completed developments introduce their own destructive effects on urban streams. Impervious parking lots and manicured landscapes replace natural areas and consequently reduce the travel time and rate of infiltration of stormwater, thereby increasing runoff volume and peak discharge. These impervious areas also prevent the vital process of watershed erosion, thus drastically reducing sediment supply to the stream. As a result, sedimentstarved runoff constitutes much of urban streamflow and contributes to subsequent stream bank erosion that may continue for several decades beyond the end of urbanization as the stream adjusts itself to a new geomorphic equilibrium.

Previous research on the relative contribution of sediment sources in Peachtree Creek revealed that in the 1970s and 1980s, when the Atlanta area was experiencing 
rapid urbanization, approximately 53 percent of the sediment discharge was due to erosion of the watershed, while 47 percent was due to erosion of the channel and floodplain (Weber, 2000). By the 1990s, when urbanization had decreased, 44 percent of the sediment discharge was due to erosion of the watershed and 56 percent of the sediment discharge was due to channel and floodplain erosion. The total sediment discharge was 75,500 tons/year in the 1970 s, 88,400 tons/year during the 1980 s, and 74,200 tons/year in the 1990s. The changes in sediment yield and the relative contribution of sediment sources were due to the changes in land use in the Peachtree Creek Basin.

The urbanization process permanently alters the hydrologic and hydraulic response of the stream and its watershed. In addition, the fluctuating sediment supply results in a loss of equilibrium in the stream sediment regime. This imbalance in the sediment regime, along with the increased peak and reduced time-to-peak of the urban runoff hydrograph, collectively produce instability in the stream form and function. The stream seeks a more stable state by modifying its dimensions and planform relative to the watershed conditions. This produces increased bank erosion and associated lateral migration of the stream, along with sediment aggradation and degradation. Specific ancillary effects of urbanization include impairment and loss of aquatic habitat and spawning areas, inhibition of photosynthesis due to turbidity in the water column, increased water treatment costs, loss of storage capacity in water supply reservoirs, and transport of contaminants associated with the fine-grained silt- and clay-sized sediment.

Such impairment of water quality is addressed by Section 303(d) of the Clean Water Act, which requires the establishment of TMDLs (total maximum daily loads) for 
quantifying allowable pollutant loads for stream reaches in which the biological integrity of the stream is threatened. Load can be defined as the amount of a substance that passes a particular point in the stream over a specified time interval. However, the development of TMDLs for sediment is complex because upstream sources of eroded sediment and various in-stream processes such as bank erosion both contribute to sediment loads. Furthermore, measuring natural sediment loads for comparison with loads in impaired watersheds is not a straightforward process. Because the urban stream can never be returned to its natural state, comparison of a natural watershed to an urban one is a tenuous proposition. Rather, it has to be transformed into a new geomorphic form capable of transporting the water and sediment discharges imposed upon it after urbanization. In addition, sediment moves both from upland watershed sources and within the stream system during large storm events according to the stream geomorphic response to urbanization, and then is redeposited so that it becomes a potential source for resuspension in succeeding storm events. For these reasons, locating sediment sources and measuring sediment loads in urban streams are challenging problems that require solutions for effective establishment of sediment TMDLs and sediment source controls.

Currently, the measurement of sediment loads in streams involves the use of:

(1) programmable point samplers that pump water samples (for later measurement of sediment concentration) at specified time intervals from the stream with simultaneous measurement of stage;

(2) manual depth-integrating samplers that collect samples over several stream verticals to obtain the average cross-sectional, discharge-weighted suspended sediment concentration; 
(3) velocity meters for establishing the stage-discharge relationship for the stream at the sampling cross-section;

(4) sensors for the continuous measurement of turbidity as a surrogate measure of sediment concentration.

These techniques may be used in a combined effort to calculate sediment loads. Average annual sediment loads can be measured using a combination of depth-integrated sampling and discharge measurement along with streamflow frequency data. However, individual storm-event sediment loads may be more important in determining sediment TMDLs, especially in urban watersheds in which significant quantities of sediment are transported by large, infrequent storm events. In this case, a programmable point sampler or continuous measurement of turbidity in combination with discharge measurement may be required. These methods introduce the problems of (1) transforming a point measurement of suspended sediment concentration to a cross-sectional average so that sediment loads can be accurately calculated; and (2) calibrating the correlation between sediment concentration and turbidity.

This study focuses on field data collection using existing technology but in an expanded and more comprehensive manner for resolving some of the longstanding problems associated with the measurement of sediment discharge and sediment loads in streams for the purpose of establishing sediment TMDLs and sediment controls. A field sampling site at Century Boulevard in DeKalb County, Georgia, located in metro Atlanta has been established and equipped with an Isco 6700 automatic water quality sampler that has provided a field record of automatically-sampled point samples over a wide range of storm events with respect to magnitude and time distribution. Depth-integrated 
samples have been collected during several storm events in order to develop an empirical relationship between suspended sediment discharge and the point measurements of suspended sediment concentration from the point sampler. Samples collected using both methods have been analyzed for sediment concentration, along with turbidity and grain size distribution in particular cases. Sediment samples from the stream bed and banks in the vicinity of the automatic sampler and in upstream locations have been collected and analyzed.

The samples were analyzed to sequentially investigate three research objectives: 1) the relationship between stage and sediment concentration in the point samples; 2) the correlation of point measurements of sediment concentration with cross-sectional depthintegrated measurements of suspended sediment discharge; and 3) the potential for using turbidity measurement in some capacity to improve the accuracy of sediment discharge calculation by supplementing point and depth-integrated sampling.

Chapter II is a review of the current literature related to field measurement of sediment discharge and use of turbidity in making these calculations. Field sampling techniques and experimental laboratory procedures are given in Chapter III. Results and discussion are found in Chapter IV, and the final chapter provides conclusions and recommendations. 


\section{CHAPTER II}

\section{LITERATURE REVIEW}

\subsection{Introduction}

Accurate measurement of sediment transport is necessary for effectively establishing sediment TMDLs or otherwise assessing the geomorphic and environmental health of a stream. When large and infrequent storm events dominate annual sediment loads as in highly urbanized systems, low-flow sampling is insufficient and thus samples taken during storm events become necessary. Reliable storm event samples are difficult to collect, however, because sediment concentration and velocity distribution vary temporally during the storm hydrograph and spatially in the stream cross-section. As a result, sediment transport measurements vary depending on the collection equipment and deployment procedures. Surrogate measurements of stream parameters that correlate to sediment concentration may also offer satisfactory results, and many technically advanced devices are available that operate using measurement principles such as differential density, optical transmission, laser diffraction, and acoustic backscatter intensity. Turbidity is one of the most notable surrogates because it can be measured continuously at a low comparative cost.

\subsection{Importance of Suspended Sediment Monitoring}

Sediment affects every aspect of a riparian environment. Although sediment transport is a normal function of streams, lack of equilibrium between sediment supply and sediment transport in a stream system causes geomorphic instabilities that lead to erosion and deposition of sediment. Erosive processes can destroy a stream channel and 
cause property damage or loss. Furthermore, sediment deposition decreases flood storage volume in streams and reservoirs and otherwise alters their hydraulic function. Consequently, measuring sediment transport in streams is necessary for monitoring stream health and predicting future stream function. Over the last two decades suspended sediment data have been used in such fields as contaminated sediment management, stream restoration, environmental quality, and geomorphic classification (Gray, 2002).

The environmental concerns associated with suspended sediment are such that the U.S. Environmental Protection Agency (1998) identifies sediment as the single most widespread cause of impairment in the Nation's streams, rivers, lakes, reservoirs, ponds, and estuaries (Gray et al., 2000). Fine sediment, classified as particles of diameter less than $64 \mu \mathrm{m}$, contributes turbidity that harms biological activities. By reducing light penetration in the water column, suspended sediment impairs photosynthesis and limits spawning areas. In addition to biological impacts, sediment also acts as a vehicle for carrying harmful chemicals and trace elements downstream (Grayson et al., 1996; Faye et al., 1978). These concerns initiated the Total Maximum Daily Load (TMDL) program, set forth by the EPA. This program, established by the Clean Water Act, section 303, regulates the total amount of pollutant that a body of water can receive from all sources and still meet water quality standards. Compliance with the TMDL program requires accurate measurements of suspended sediment discharge.

The TMDL program also involves allotment of a particular pollutant to each contributing point and non-point source. Accordingly, monitoring sediment transport is very helpful in establishing the sediment's origin. Stream bank erosion and lateral migration can be examined during peak periods of sediment transport to identify causes 
of erosion and establish preventive measures for future erosion (Green et al., 1999). Fluvial sediment is the result of both watershed and bank erosion, and the balance is dictated by land use. Urban areas are characterized by impervious surfaces and storm drainage systems that channelize stormwater and significantly reduce infiltration. In addition, any exposed land is highly maintained, thereby minimizing its absorptive potential. The result is a series of large point discharges that significantly reduce strormwater travel time. These effects drastically affect the storm hydrograph by increasing the magnitude of peak discharges and reducing the time to peak in the runoff hydrograph. The channel adjusts to these modifications by widening and incising into its bed through erosive processes. In contrast to the channel erosion that dominates urban streams, sediment found in rural streams is produced mostly by watershed erosion. The exposed land associated with cultivation, livestock feeding areas, grazing pastures, and fields of row crops is highly susceptible to sheet erosion during storm events. This process contributes to sediment loads in nearby streams but causes only minimal channel erosion (Faye et al., 1978). This diversity in sediment origin emphasizes the difficulty in allocating contributing sources of erosion for stream remediation and establishing TMDLs.

\subsection{Sediment Transport Convention}

Sediment transport is often expressed in terms of sediment load, which is calculated as the dry weight of sediment that passes a specific point in the stream over a particular time interval. A related quantity is sediment discharge, which is the crosssectional sediment concentration weighted with water discharge to produce an 
instantaneous sediment flux. Accurate presentation and meaningful comparisons of sediment transport data require the establishment of specific terminology. The total sediment load transported by streamflow can be thought of in one of three ways: by the type of movement, by the source of sediment, or by the method of measurement (Julien, 1995).

Sediment transport understood by type of movement divides the total sediment discharge by weight $G_{T}$ into the bedload discharge $G_{b}$ and the suspended sediment discharge $G_{s}$. Bedload refers to sediment particles that are carried near the bed and frequently remain in contact with the bed through rolling, sliding, and hopping of individual particles (Sturm, 2001). Suspended sediment discharge consists of particles that are lifted and kept in suspension by turbulence and are not in frequent contact with the bed as they are transported downstream. The resulting total sediment discharge is given by

$$
G_{T}=G_{b}+G_{s}
$$

Sediment transport classification by source of sediment equates the total sediment discharge $G_{T}$ to the washload discharge $G_{w}$ plus the bed-material discharge $G_{b m}$. Washload discharge refers to the particles not found in large quantities in the bed that are therefore limited by the available supply from upstream sources. Although washload does not have any direct relation to sediment grain size, it often corresponds to the silts and clays in sand-bed streams. The bed-material sediment discharge, on the other hand, is a function only of the streamflow and its capacity to transport the grain sizes found in the bed. The total sediment discharge in this classification then becomes

$$
G_{T}=G_{w}+G_{b m}
$$


Lastly, sediment transport defined by method of measurement specifically refers to the inherent inability of depth-integrating samplers to sample within a range of approximately six inches above the bed surface. As a result, total sediment discharge $G_{T}$ consists of the measured suspended sediment discharge $G_{m}$ and the unmeasured sediment discharge $G_{u}$, composed of unmeasured suspended sediment discharge and bedload discharge, as given by

$$
G_{T}=G_{m}+G_{u}
$$

\subsection{Suspended Sediment Discharge Calculations}

Sediment discharge calculations can be accomplished using a number of empirical formulas that involve grain size and hydraulic variables. Sediment grain fall velocity is fundamental in these calculations, particularly since it plays a very important role in differentiating between bedload discharge and suspended sediment discharge (Sturm, 2001). An exact solution for sediment grain fall velocity $w_{f}($ Julien, 1995) is given as

$$
w_{f}=\frac{8 v}{d}\left[\sqrt{1+0.0139 d_{*}^{3}}-1\right]
$$

in which $v$ = kinematic viscosity of the fluid; $d=$ grain diameter; and $d_{*}=$ dimensionless grain size number. The dimensionless grain size number is given as

$$
d_{*}=\left[\frac{\left(\frac{\gamma_{s}}{\gamma}-1\right) g d^{3}}{v^{2}}\right]^{1 / 3}
$$

in which $\gamma_{\mathrm{s}}=$ specific weight of the grain; $\gamma=$ specific weight of the fluid; and $g=$ gravitational acceleration. 
Another important parameter in sediment discharge calculations is shear velocity $u$ * shown below as given by Sturm (2001) from the uniform flow equation in which the gravitational force down the slope is just balanced by the resisting shear force:

$$
u_{*}=\sqrt{g y_{0} S}
$$

where $\mathrm{y}_{0}=$ water depth; and $S=$ energy grade line slope.

Rouse (1937) derived an equation whereby the vertical distribution of suspended sediment concentration can be determined from the solution of the simplified mass transport equation for steady uniform flow with equilibrium sediment transport. The boundary condition is a single point measurement of suspended sediment concentration at a known distance above the bed (Vanoni, 1977; Julien, 1995):

$$
\frac{C}{C_{a}}=\left[\frac{\left(y_{0}-z\right)}{z} \frac{a}{\left(y_{0}-a\right)}\right]^{R_{0}}
$$

in which $y_{0}=$ water depth at vertical; $z=$ distance from bed; $C=$ suspended sediment concentration in the vertical at elevation $z$; $C_{a}=$ suspended sediment concentration at $z=$ $a$; and $\mathrm{R}_{0}=w_{f} /\left(\beta \kappa u_{*}\right)$. The von Karman constant $\kappa$ is taken as 0.4 and $\beta=1.0$ (Sturm, 2001). Equation 2.7 is plotted in Figure 2.1 for different values of the Rouse number $R_{0}$. The vertical coordinate in this figure is defined as $(z-a) /\left(y_{0}-a\right)$ in which, arbitrarily, $a=$ $0.05 y_{0}$. 


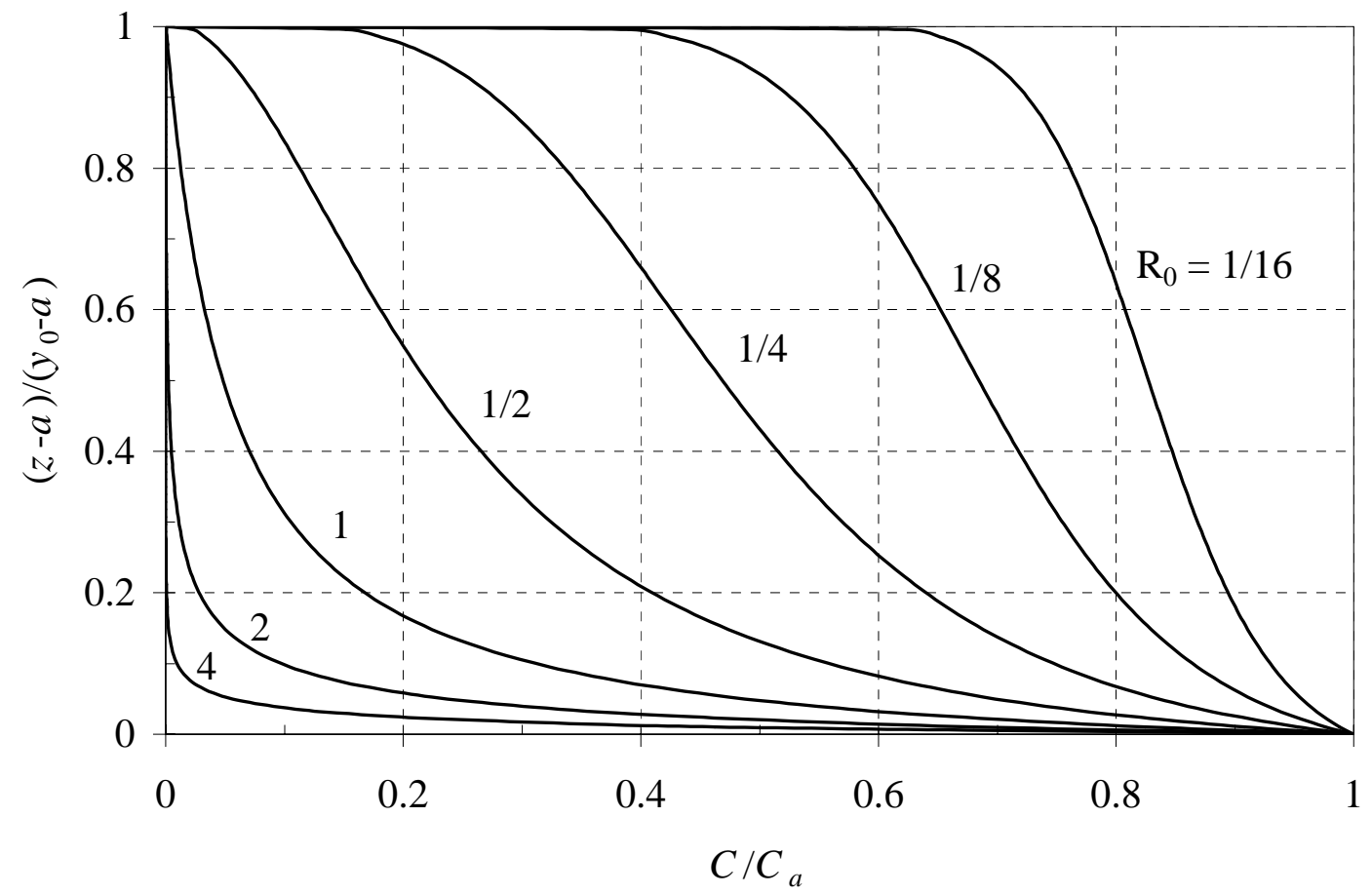

Figure 2.1 Rouse vertical distribution of suspended sediment concentration

Suspended sediment discharge per unit width at a given stream vertical can be determined by integrating the product of the Rouse suspended sediment concentration distribution and the log velocity distribution over the depth. The resulting spatiallyaveraged mean sediment concentration $C_{m}$ is then given symbolically by

$$
\frac{C_{m}}{C_{a}}=f\left(\frac{\kappa V}{u_{*}}, \frac{a}{y_{0}}, R_{0}\right)
$$

in which $\kappa=$ von Karman's constant; $V=$ depth-averaged velocity; $u_{*}=$ shear velocity; $a$ $=$ elevation of point measurement of suspended sediment concentration $C_{a} ; y_{0}=$ flow depth; $\mathrm{R}_{0}=$ Rouse number as defined previously; and $C_{m}=G_{s} / Q$ for a unit width. In 
other words, a single point measurement of suspended sediment discharge concentration can be transformed into a true measure of suspended sediment discharge $G_{\mathrm{s}}$.

\subsection{Suspended Sediment Discharge Measuring Techniques}

Direct sampling of suspended sediment discharge $G_{s}$ is a labor-intensive, costly procedure that is subject to several sources of error. Because suspended sediment concentration varies temporally and spatially in a stream cross-section, single point measurements are not sufficient for quantifying total sediment discharge $G_{T}$. Because point samplers by nature withdraw samples from a fixed distance above the bed, they are in reality measuring only a single point concentration that cannot be immediately extrapolated to give the suspended sediment discharge. This measurement is sometimes erroneously taken to be representative of the entire cross-section and thus used to quantify total sediment discharge by multiplying it by the water discharge. However, point samples are essentially meaningless without a calibration and/or an analytical process that relates point values to measured cross-sectional values. Point samplers are generally implemented to sample near the stream bed so that the sampling intake is submerged even during small storm events, although sediment concentration is greatest in this region. Accordingly, field studies have shown that point measurements made with pumping samplers overestimate total sediment discharge when compared with other methods (Horowitz et al., 1990).

The variability associated with point sampling can be minimized using calibrated depth-integrating samplers, established by the Federal Interagency Sedimentation Project (FISP), which was established by the Subcommittee on Sedimentation that began in 1938 
(Vanoni, 1977). Depth-integrating samplers are lowered and then raised again through the flow depth with the intake nozzle pointed upstream so that the sampling intake velocity equals the stream velocity at every point (Julien, 1995). When the sampler is deployed at several transverse locations in the stream, a representative sample that accounts for vertical and horizontal variation of sediment concentration at a given crosssection can be produced that is then multiplied by water discharge to give sediment discharge. The sampling procedure is difficult to conduct, however, as it requires sampling during periods of high streamflow, which coincide with storm events. Flashy urban streams are particularly difficult to sample since the storm hydrograph may only last for a few hours. The sampling equipment is heavy and unwieldy and the sampling procedures require a team of trained staff for proper implementation. The samples produced require extensive laboratory analysis, making reliable data costly to produce. However, even when sampling is conducted successfully, a portion of the suspended sediment discharge near the bed is omitted due to the inherent inability to sample within a range of approximately six inches above the bed surface as described above. In spite of their deficiencies, depth-integrating samplers provide the most reliable data and have thus been used to gauge the accuracy of other measurement techniques or of surrogate measurement devices.

\subsection{Laboratory Techniques}

The laboratory analyses that follow field sampling can also introduce error in sediment transport calculations. A common error lies in the discrepancy between the two methods used for measuring sediment concentration in a sample. The Total Suspended 
Solids (TSS) procedure, set forth by the American Public Health Association, American Water Works Association, and the Water Pollution Control Federation (1995), was designed for analyzing wastewater effluent samples but has also been used for measuring sediment concentration in stream samples. The procedure involves filtering an aliquot of the sample under the assumption that it is representative of the entire sample. Withdrawal of the representative aliquot is often difficult, particularly when large particles that settle quickly constitute much of the sediment in the sample. This inherent bias in the TSS procedure produces unreliable results that do not accurately represent the concentration of sediment within a sample. In comparison, the Suspended Sediment Concentration (SSC) test presented by the American Society of Testing and Materials involves measuring the entire sample to obtain total sediment mass. This is accomplished through evaporation, filtration, or wet-sieve filtration, and produces reliable results that are a true measure of the concentration of solid material in a stream sample. Because the entire sample is measured, the SSC procedure is not affected by particle size and related settling velocities of particles. The U.S. Geological Survey (2000) analyzed this discrepancy by comparing 3,235 paired TSS and SSC data taken from many different regions in the United States. The study found that the TSS method was essentially unreliable for analyzing natural water samples because TSS values demonstrated particle size bias by underestimating the sediment concentration when the sand-sized material exceeded about a quarter of the total sediment dry weight. The study concluded that the SSC method should be used exclusively for measuring sediment concentration in naturalwater samples to prevent error in laboratory analyses (Gray et al., 2000). Many have 
commonly used the terms TSS and SSC interchangeably, an oversight that has produced data that does not truly represent the intended measurements.

\subsection{Suspended Sediment Surrogate Technologies}

Several surrogate measurements are commonly employed to avoid the difficult and costly procedure of sampling suspended sediment directly. Conventional surrogates such as stream discharge in a regression relationship with suspended sediment concentration offer somewhat acceptable results but can suffer from large uncertainties in predicted suspended sediment concentration, especially if fine sediment is a significant proportion of the total size distribution. Emerging technologies such as laser diffraction and acoustic backscatter measurements show promise but are costly and are yet to experience widespread use.

Sediment-rating curves that relate suspended sediment concentration and stream discharge with a power function have been used for more than 60 years (Horowitz, 2002). This relationship can be used in conjunction with the stage-discharge relationship of a particular reach (Kennedy, 1984), allowing sediment discharge predictions to be made from water surface elevation measurements or average annual sediment loads to be predicted with the aid of a flow-duration curve. Intensive calibration of a particular river section can yield acceptable results so that stage can be used to predict sediment loads and grain size distributions. Once the calibrations are established, the method is essentially free of cost. For this reason it is often used with other surrogates as a comparison or for filling in potential gaps in data sets caused by equipment failure (Green et al., 1999). In general, however, this approach underestimates highs and overestimates 
lows (Horowitz, 2002). As a result, when precision is required, stream discharge is not a suitable measurement. Thus, rating curves are more useful in analyzing portions of storm events rather than entire events (Lewis, 2002).

The ideal surrogate technology would involve a direct relationship with suspended sediment and/or particle size distribution that could be monitored and recorded automatically in a fashion representative of the entire cross-section for any river in any flow situation (Gray, 2002). Two of the most promising instruments involve laser diffraction and acoustic backscatter intensity, respectively. Both apparatuses have been field tested and yielded effective results in certain situations.

Laser diffraction devices, unlike many other instruments, remain unaffected by changes in grain-size or particle color and refractive index. The apparatus uses technology based on the Mie theory model for light scattering physics by generating a collimated beam and collecting the reflected beam with a receiving lens. As a particle passes through this beam and blocks light waves, some waves enter the particle while others are diffracted around it. The angular scattering caused by the particle leaves a distinctive silhouette that appears identical to an aperture of the same diameter. This diffractive signature can be used to indicate the grain-size. As this process occurs at a stream gauging station, streamflow passes through the instrument such that the summation of the analysis of each particle gives the grain-size distribution and the suspended sediment concentration in the streamflow. This can be accomplished using a recently developed low drag vehicle that encloses a laser diffraction instrument. The unit uses pressure transducers to record sampling depth. It also measures free-stream velocity and adjusts withdrawal rates using an internal pump (Agrawal and Pottsmith, 2002). 
The Grand Canyon Monitoring and Research Center tested one such instrument in the Colorado River beginning July 19, 2001. The particular unit was designed to detect particles over a size range of 1.3 to $250 \mu \mathrm{m}$. Investigators made 720 point measurements with the device and collected 13 samples using depth-integrating samplers integrated across the cross-section. Preliminary results indicated that the laser diffraction instrument accurately tracked the sand concentration and its variance with increasing flow. Median grain size data from the two sample sets were also in good agreement (Melis et al., 2002). The comprehensiveness that laser diffraction instruments offer reinforces the advantage of continuous monitoring. A common limitation among optical sensors is their vulnerability to biological fouling, which is a substantial concern in the stream environment.

Acoustic instruments have been widely used for measuring in-stream flow velocity and have recently been employed for measurement of sediment concentration using acoustic backscatter intensity. These devices apply the principles of sound scattering from small particles for estimation of suspended sediment concentration. Calculations include adjustments for sampling volume, source level, two-way transmission loss, and volume scattering strength, a parameter affected by particle shape, size, density, rigidity, compressibility, and acoustic wavelength. The transmission loss of the water is based on the water's acoustic frequency, salinity, temperature, and pressure. However, since surrogate measurements are intended to simplify sediment monitoring, measurement of all characteristics is not practical. A reduced form of the calculations involves a simplified exponential equation that relates sediment concentration to relative backscatter. The major limitation of this technology is its inaccurate response to changes 
in concentration and particle size distribution, a restraint common to single-frequency instruments. An inherent mismatch of frequency versus particle size also exists. Although the limiting effects can be minimized through extensive calibration, acoustic sensors are most sensitive to large particles and do not respond well to the frequency range that corresponds to clay-sized particle distributions. In spite of its response to certain particle sizes, acoustic backscatter technology has the advantage of providing a data profile rather than a point measurement. The measurement process is also much less intrusive to the stream environment than are many other instruments. Like all surrogate measurements, significant calibration must be conducted before accurate predictions can be made (Gartner, 2002).

A final surrogate that has been used successfully is turbidity measurement. The relationship between suspended sediment concentration and turbidity is based on the assumption that the cloudiness of a water sample is directly related to the concentration of sediment particles suspended in the sample. Accordingly, turbidity meters quantify suspended sediment by measuring the scattering or attenuation of a beam of light through a water sample and using this measure by relating it to suspended sediment concentration of a particular suspended material. Using turbidity measurement as a surrogate for suspended sediment concentration is a process that, like other surrogates, requires significant calibration. Site-specific regression analyses produce relationships that can be used for prediction of sediment loads. Turbidity measurement can be accomplished in several ways. Grab samples can be taken and subsequently analyzed in a laboratory for turbidity and suspended sediment concentration. This process can be used for calibrating the site such that after calibration the sediment concentration tests can be replaced with 
turbidity measurements (Wass and Leeks, 2002). A more advanced procedure involves in situ turbidity probes that continuously monitor turbidity. A data logger records the turbidity measurements, which are converted to sediment concentration using the predetermined regression relationships. In situ turbidity probes require considerable maintenance since they can often be rendered ineffective by debris flowing downstream and are highly susceptible to biological fouling (Lewis, 2002). Both methods have been used extensively and, coupled with discharge measurements, can provide very accurate sediment load estimations.

There are two major types of turbidity meters. Attenuation turbidimeters measure the loss of intensity of a light beam across a known distance of a sample. Nephelometric turbidimeters measure scattered light by detecting the beam at an angle from its origin. Turbidimeters are standardized with a substance of known turbidity, with the most common being formazine. However, in spite of standardization, the two types of instruments respond differently when measuring the turbidity caused by suspended sediment particles. Fluvial sediment is a mixture of grain sizes originating from various minerals, and this aggregation responds differently than formazine (Gippel, 1995). As a result, most turbidity measurements are instrument-specific (Pfannkuche and Schmidt, 2003).

While the use of turbidity as a surrogate for suspended sediment concentration has yielded successful results in numerous studies, it has limitations. As mentioned previously, the relationship between turbidity and suspended sediment is site-specific. Organic particles also contribute to turbidity in the water column and can skew suspended sediment data derived from turbidity measurements (Weigel, 1984). In 
addition, background water color unrelated to sediment can contribute as much as ten percent error, although a light source light near infrared wavelengths can minimize this problem (Gippel, 1995). However, the predominant limitations to accurate turbidity measurement involve the shape, size, and color of suspended particles. Each mineral that is represented in a particular stream sample has distinctive optical properties that respond differently to a light source. This combination of sediment properties emphasizes the importance of developing site-specific relationships between turbidity and suspended sediment since each site has its own unique sediment characteristics.

The most important limitation in turbidity measurement is particle size. The relationship between turbidity and suspended sediment is based on the principle that each individual sediment particle contributes to the overall cloudiness of a sample. Fine sediment causes high light attenuation in turbidity measurements (Brasington and Richards, 2000), but when coarse sediment particles (> $64 \mu \mathrm{m})$ constitute a significant portion of a sample, turbidity measurement becomes difficult since these large particles settle very quickly and therefore do not adequately contribute to turbidity readings. And, as sediment concentration measurement involves the weight of sediment within a sample volume and large particles constitute a considerable fraction of the sediment weight, omission of large particles substantially skews sediment concentration data. For this reason, application of turbidity as a surrogate is most appropriate when fine clay-sized sediment particles compose most of the sample. 


\subsection{Applications of Turbidity Monitoring}

The development of site-specific calibration curves for use in relating turbidity and suspended sediment concentration is the most important part of successfully using turbidity as a surrogate. Although the relationship is mostly uniform during periods of low flow, suspended sediment flux is highly variable in space and time and is difficult to quantify with single point measurements. In fact, during periods of high flow, turbidity varies for a given suspended sediment concentration. For this reason, numerous events during varying flow conditions must be incorporated into the data set. Storm events that yield the highest variation in sediment flux should be especially targeted. Turbidity data should be scrutinized to identify possible errors and periods of extended fouling should be omitted. Secondary relationships, such as between flow rate and suspended sediment concentration, can serve as a check and, when turbidity data are missing, be used to form a piecewise model (Lewis, 2002).

More than two decades ago, a U.S. Geological Survey report noted that turbidity values should not be used to determine numeric values for suspended sediment concentration (Faye et al., 1978). Since then, however, further research has shown that under certain conditions turbidity can be used successfully once its limitations are understood and taken into account. Turbidity measurement has been utilized for measuring stream-bank erosion, nutrient and contaminant transport, and sediment loads. One study of the Namoi River in New South Wales, Australia measured flow rate and turbidity at continuous 15-minute intervals at 12 monitoring stations for predicting sediment concentrations and loads related to stream bank erosion (Green et al., 1999). Britain's Land-Ocean Interaction Study (LOIS) included establishing site-specific 
relationships of suspended sediment and turbidity in ten major tributaries of the River Humber. Least-squares linear regression analyses yielded correlation coefficients between 0.827 and 0.917 . The success of this relationship can be partly attributed to the favorable conditions present for turbidity monitoring, namely that fine sediment constituted 96.4 percent of the total sediment. The turbidity measurements were made in conjunction with depth-integrated sampling. The turbidity vs. suspended-sediment relationship was well established and provided sufficient data for estimating sediment loads and sediment flux (Wass and Leeks, 1999).

The German Federal Institute of Hydrology investigated the relationship between suspended particulate matter and turbidity along the Elbe River (Pfannkuche and Schmidt, 2003). This study involved a total of 1405 measurements of turbidity, suspended particulate matter, and flow rates taken between June 1996 and February 2001. The measurements were adversely affected by large stream bed particles and water color, and measurement error was found to increase with increasing flow rate.

The effectiveness of turbidity as a surrogate was also demonstrated in an investigation of the Kansas River and Little Arkansas River in which twenty samples were collected at eight stream-gauging stations between 1998 and 2001 (Christensen et al., 2002). The Kansas River sites yielded a coefficient of determination of 0.987 between the two parameters, and the relationship between suspended sediment and turbidity in the Little Arkansas River allowed prediction of sediment loads within six percent accuracy. It is crucial to note that in The Kansas River samples the median particle size for the test sites was 95 percent fines, a very favorable condition for turbidity measurement. 
Contaminated sediment can also be traced using turbidity data. The Ecuadorian Meteorological Institute investigated metal contamination in the Puyango River Basin in southern Ecuador (Tarras-Wahlberg and Lane, 2003). Forty-four samples were used to develop a calibration curve of nephelometric turbidity versus suspended solids with a coefficient of determination of 0.98 . This study included investigations of the turbidity profile that concluded the difference between near-bottom samples and surface samples only varied from six to eight percent. Grayson et al. (1996) investigated the Latrobe River in southeast Australia for suspended sediment concentration and total phosphorous using turbidity measurements during storm events. The research was motivated by the poor correlation between river discharge and suspended sediment concentration and fine sediment was presumed to be key in the transport of phosphorous. Turbidity, sediment concentration, and total phosphorous data were collected during storm events of varying intensities. Although the in situ turbidity sensors detected that peaks in stage and sediment concentration were sometimes out of phase, the study revealed that turbidity and sediment concentration were linearly related and that turbidity probes were effective for estimating transported material with predictive capabilities generally greater than eighty percent.

\subsection{Summary}

Field methods for sampling suspended sediment loads are difficult to conduct and are subject to various sources of error. Flashy urban streams are especially difficult to sample. A comprehensive approach to sampling suspended sediment is the most effective method, and in some cases turbidity measurement has been a contributor to this 
approach. Using turbidity as a surrogate for suspended sediment concentration in some cases can be more effective than the relationship between discharge and suspended sediment concentration (Christensen et al., 2002; Grayson et al., 1996). In particular, when fine sediment constitutes a significant portion of transported sediment, turbidity offers high correlation to sediment concentration and can effectively supplement other sampling methods. 


\section{CHAPTER III \\ EXPERIMENTAL METHODS}

\subsection{Introduction}

The data for this research were obtained through field sampling and subsequent laboratory analysis. Field sampling was conducted at Century Boulevard in DeKalb County, Georgia, located in metro Atlanta. The North Fork Peachtree Creek at this bridge crossing, shown in Figure 3.1, is approximately 50 feet wide with a bank-full depth of approximately 8 feet. Storm-event samples were collected at this location using an automatic point sampler and a depth-integrating sampler. Laboratory analyses of storm samples included the measurement of the concentration of sediment in a water sample, the turbidity of the sample caused by the sediment particles in suspension, and the relative percent of fine sediment in the sample. Bed and bank sediment samples were collected at multiple locations in the immediate vicinity of the sampling equipment as well as at several upstream sites. These samples were analyzed to find the grain size distribution and the turbidity contributed by the sediment when suspended in water at various concentrations. 


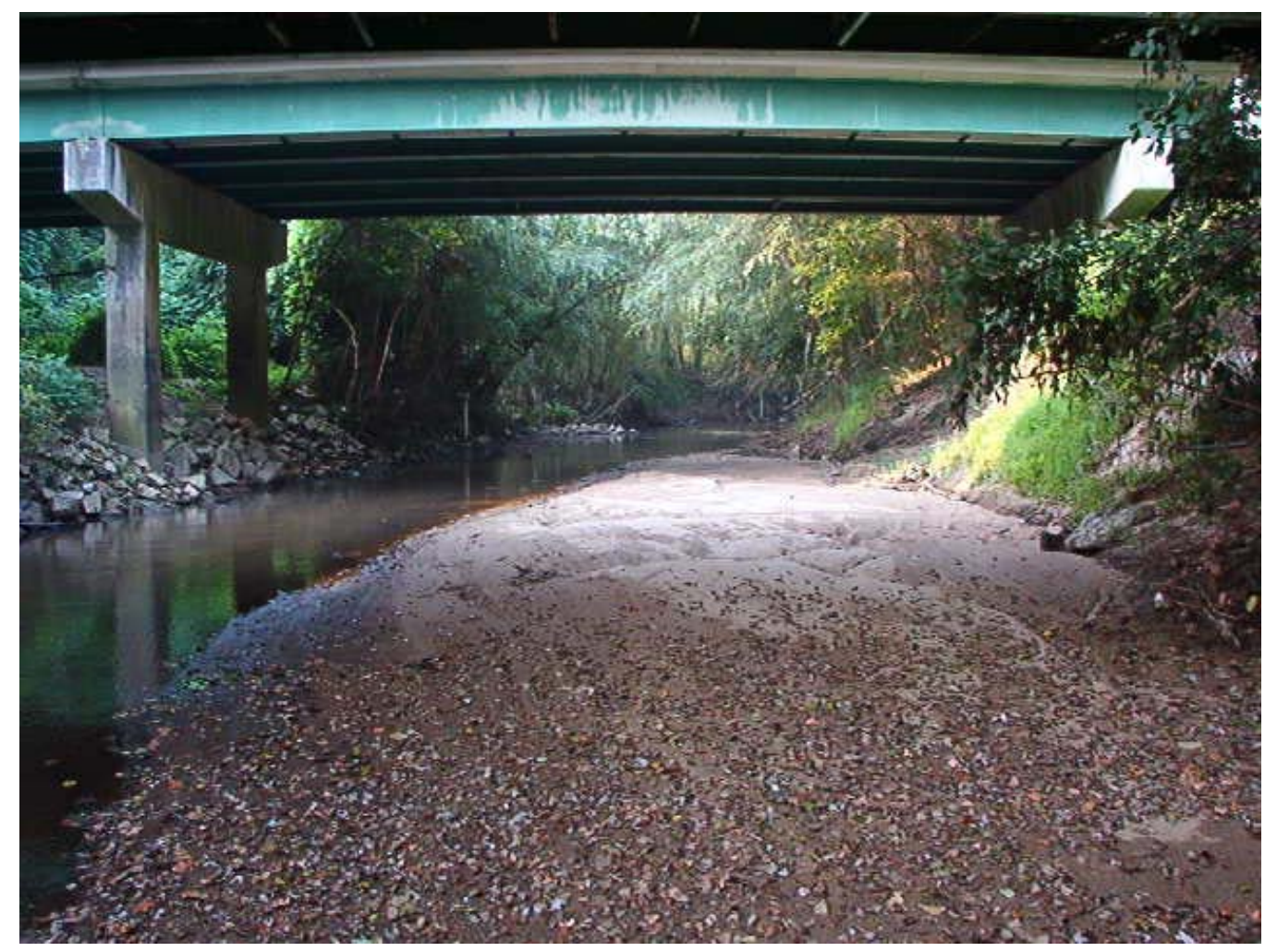

a) Sampling cross-section shown at base flow. Image taken looking downstream.

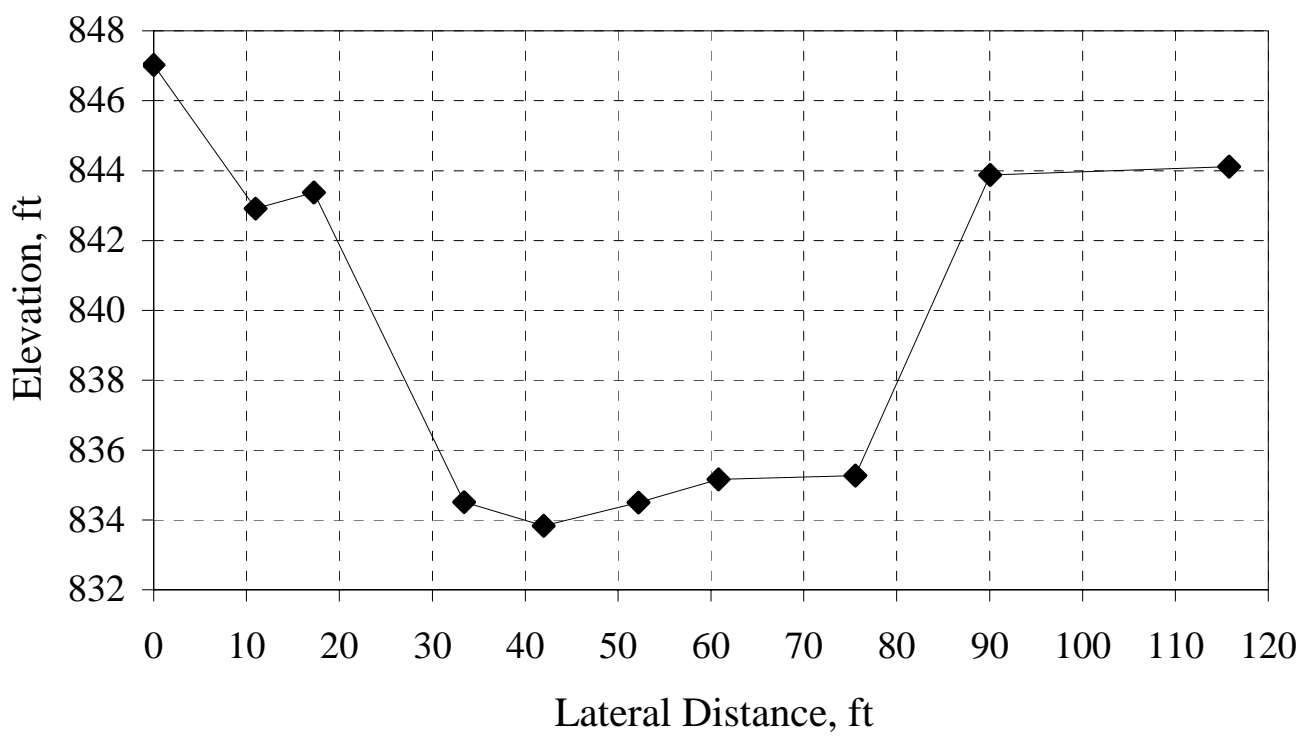

b) Surveyed cross-section at sampling location looking downstream.

Figure 3.1 Sampling location: North Fork Peachtree Creek at Century Blvd. 


\subsection{Point Sampling}

Point sampling was performed using a portable water quality sampler manufactured by Isco, Inc. (6700 series, full-size portable unit). The programmable unit, which includes a pumping device and distributor with 24 one-liter bottles, was positioned in the floodplain on the earthen embankment beneath the bridge as shown in Figure 3.1 a). The liquid suction line used by the sampler to withdraw water samples was fastened to the ground on the floodplain and stream bank using aluminum stakes. The end of the suction line was attached to a straining device that was fixed at a height of $1 \mathrm{ft}$ above the stream bed in the deepest point of the cross-section. Stage was measured directly above the strainer using an ultrasonic device cantilevered over the water surface and attached to a bridge pier. The Isco unit continuously logged stage data at 5-minute intervals and was triggered to pump water samples by the occurrence of an increase in stage of $1 \mathrm{ft}$ above the base level. After being activated, the sampler withdrew water samples at a time interval specified as 15 or 30 minutes, with volumes ranging from $500-1000 \mathrm{~mL}$ and deposited each individual sample sequentially in one of the 24 bottles located within the sampling unit. Sampling continued at the specified time interval until the stage decreased below $1 \mathrm{ft}$ or until the 24 sampling bottles were filled, providing the potential for a maximum of 12 hours of sampling.

Following a storm event, the filled sample bottles were retrieved from the unit and replaced with empty bottles. An Isco 581 rapid transfer device was used to download data from the Isco unit. This information was then transferred to a laboratory computer and written to a spreadsheet. The stage and time data were used to construct a storm hydrograph, and the time data were used to establish the timing of each sample relative to 
the hydrograph. The water samples subsequently underwent a variety of laboratory tests that provided information regarding the characteristics of the sediment present in the samples. In most applications, the contents of each sampling bottle were analyzed individually; in specific cases, however, samples were combined based on their relative locations in the storm hydrograph to provide fewer samples of larger volumes.

\subsection{Depth-Integrated Sampling}

Depth-integrated sampling was used to acquire water samples representative of the entire stream cross-section. A US D-77 depth-integrating suspended sediment sampler was utilized for collecting such samples. The sampler was equipped with a 5/16inch intake nozzle attached to a 3-liter sampling bottle. The sampler was deployed into North Fork Peachtree Creek from the Century Boulevard bridge crossing. This was accomplished using a specially designed apparatus constructed in the Georgia Institute of Technology hydraulics laboratory, which used a telescoping boom and winch attached to a service vehicle truck ladder rack. The selected sampling scheme, as described in the ASCE Sedimentation Engineering Manual No. 54 (Vanoni, 1977), involved collecting depth-integrated samples at equally spaced stream verticals in the cross-section. Lateral stations at 10 - $\mathrm{ft}$ intervals, beginning at $10 \mathrm{ft}$ from the toe of the left bank, were established and marked on the concrete bridge railing directly above the sampling crosssection. Extensive woody vegetation prevented sampling closer to the stream bank. This scheme provided four verticals for depth-integrated sampling. The same transit velocity was used for all verticals and was kept uniform within each vertical. This method allowed the sample volume to be determined only by the stream velocity and the 
corresponding depth at each vertical. A separate sampler bottle was used at each vertical, and the representative discharge-weighted cross-section samples resulted from combining the partial samples collected at each vertical.

\subsection{Velocity Measurement}

Velocity measurements were made in conjunction with depth-integrated sampling during storm events. These measurements were used in estimating stream discharge, and when coupled with discharge-weighted sediment concentration measurements, enabled estimation of sediment discharge. Velocity was measured using the Model 2000 portable Flo-Mate magnetic flowmeter manufactured by Marsh-McBirney, Inc. Fixed Point Averaging (FPA) was used to average the velocities measured at a single point over a one-minute duration. This setting produced consistent and reliable velocity measurements by taking into account large-scale turbulent bursts that may have adversely affected measurements taken over shorter durations. Velocity measurements were made at the four verticals previously established for depth-integrated suspended sediment sampling. The flashy hydrology of the watershed and the resultant rapid changes in stage required that one velocity measurement be made at each vertical so that velocities could be measured quickly, minimizing error associated with changing stage. Each measurement was made at sixty percent of the water depth below the water surface at each vertical as prescribed by the U.S. Geological Survey (USGS) (Buchanan and Somers, 1969). 


\subsection{Bed and Bank Sediment Sample Collection}

Bed and bank sediment samples were taken at several upstream locations. Stream banks experiencing active erosion were first identified. A sample was then taken above the elevation of the base flow water surface at each location. The samples were approximately $150 \mathrm{~g}$ in mass and were taken to the laboratory in individual resealable plastic bags. Photographs of each location were also taken to aid in identifying each sample.

\subsection{Suspended Sediment Concentration (SSC) Measurement}

Suspended sediment concentration (SSC) analyses were performed in accordance with standard test method ASTM D 3977-97 Test Method B. The procedure consisted of measuring the volume of the sample and then filtering the entire sample through a glassfiber filtration disk. The entire sample volume was measured using a $1000 \mathrm{~mL}$ graduated cylinder. After the sample was transferred to the graduated cylinder, the sediment was permitted to settle so that the overlying water could be used to thoroughly rinse the Isco sampler bottle. The entire sample was then filtered through a Whatman type 934-AH glass-fiber disk with $1.5 \mu \mathrm{m}$ pore spaces and a diameter of $22 \mathrm{~mm}$. Filtration was assisted by a vacuum system. After the entire sediment-water sample was filtered through the filtration disk, the disk and remaining sediment were oven-dried and then weighed. Calculation of suspended sediment concentration of the sample in $\mathrm{mg} / \mathrm{L}$ was accomplished using the measured volume of the sample and the dry mass of sediment obtained from the measured weights of the filtration disk before and after filtration. 


\subsection{Percent Fine Sediment Measurement}

The process of measuring percent fine sediment in the suspended sediment samples is identical to the above procedure for measuring suspended sediment concentration with an additional step. After measuring the volume of the sample, the sample was passed through an ASTM standard number 230 sieve (63 $\mu$ m mesh openings) and collected in a container beneath the sieve. The sediment remaining on the sieve was thoroughly rinsed and the rinse water was also collected in the underlying container. The remaining coarse sediment was then rinsed from the sieve into a separate container. Both containers were then filtered through separate glass-fiber disks. This enabled calculation of fines-only SSC and total SSC, both in mg/L.

\subsection{Turbidity Measurement}

Turbidity was measured using an HF Scientific, Inc. Micro 100 laboratory turbidimeter equipped with a pour-through apparatus that enables turbidity measurement of a water sample of any volume. The original concentration of the storm samples was scrupulously maintained and no rinse water was added when transferring between containers. The coarse sediment was first removed by pouring the entire sample through an ASTM standard number 230 sieve (63 $\mu \mathrm{m}$ mesh openings) and collecting the resulting mixture of water and fine sediment. This resultant mixture was used to rinse the sediment remaining on the sieve to ensure that all fine particles were separated from the coarse sediment. The sample of fine sediment and water was thoroughly agitated before and during the process of pouring into the turbidimeter receptacle. The turbidity value associated with the fine sediment was recorded after the turbidimeter reading stabilized. 


\subsection{Particle Size Analysis}

Particle size analysis was conducted in accordance with standard test method ASTM D 422-63. For storm event samples and bed sediment control samples, only the sieve analysis portion of the test was performed. For several control samples conducted with upstream soil samples, hydrometer analysis was also performed to provide a more exact and complete grain size distribution.

Sieve analysis was performed on various sediment samples. The test requires a dry sediment sample of a known weight and a nest of sieves that encompass the range of sediment sizes in the sample. The smallest sieve size used was the ASTM standard number 230 sieve (63 $\mu \mathrm{m}$ mesh openings) which separates coarse and fine sediment. The weight of each sieve is measured and recorded before stacking the sieves in ascending order of size. The entire sediment sample is then poured into the top of the nest, the lid and pan are secured, and the nest is placed in a shaking device that jars and agitates the sieves for approximately ten minutes. Following shaking, each sieve is weighed so that the weight of sediment retained on each sieve can be determined. This data can then be plotted to provide information regarding the distribution of sediment sizes within the sample, and it leads to calculation of important sediment transport variables such as median grain size. Hydrometer analysis of the fine sediment fraction was performed using an ASTM 152H hydrometer conforming to the requirements enumerated in Specifications E 100. Hydrometer analysis identifies the grain size distribution of fine sediment by relating the settling velocity of sediment particle sizes in suspension to their contribution to water density. Hydrometer readings over time are then converted to percent finer distribution by relating the decreasing water density to settling particle 
sizes. A dispersing-agent solution of sodium hexametaphosphate and distilled water was used to minimize the presence of interparticle bonds during the hydrometer analysis. The fine sediment was isolated by performing sieve analysis and collecting the sediment that passed the ASTM number 230 sieve. The fine sediment was then thoroughly mixed with dispersing-agent in the $1000 \mathrm{~mL}$ sedimentation cylinder, and the hydrometer was immediately placed in the sample. Hydrometer readings were taken at time intervals of 2, 5, 15, 30, 60, 250, and 1440 minutes. 


\section{CHAPTER IV \\ RESULTS AND ANALYSIS}

\subsection{Introduction}

The data displayed and discussed in this chapter were collected from October 2003 through October 2004. During the period of October 2003 through May 2004, automatic point sampling of storm events was conducted and sediment samples from the bed and banks were collected and analyzed. The period of June 2004 to November 2004 involved both automatic point sampling and depth-integrated sampling during a variety of storm events. As stated in Chapter I, the various types of samples were analyzed with respect to three main research objectives: (1) development of a sediment-rating curve for the cross-section; (2) the correlation of point measurements of sediment concentration with cross-sectional depth-integrated measurements of sediment discharge; and (3) the potential for using turbidity measurement in some capacity to improve the accuracy of sediment discharge calculations by supplementing point and depth-integrated sampling.

\subsection{Constructing a Sediment-Rating Curve by Point Sampling}

Automatic point sampling produced a field record of point measurements of suspended sediment concentration (SSC) taken during storm events along with stage measurement. Because the Isco intake strainer samples at a point located $1 \mathrm{ft}$ above the bed surface, the point samples of sediment concentration are not necessarily representative of the entire suspended sediment discharge and do not sample bedload discharge. Figure 4.1 illustrates the stage hydrograph and SSC measurements from a storm event on May 22, 2004. 


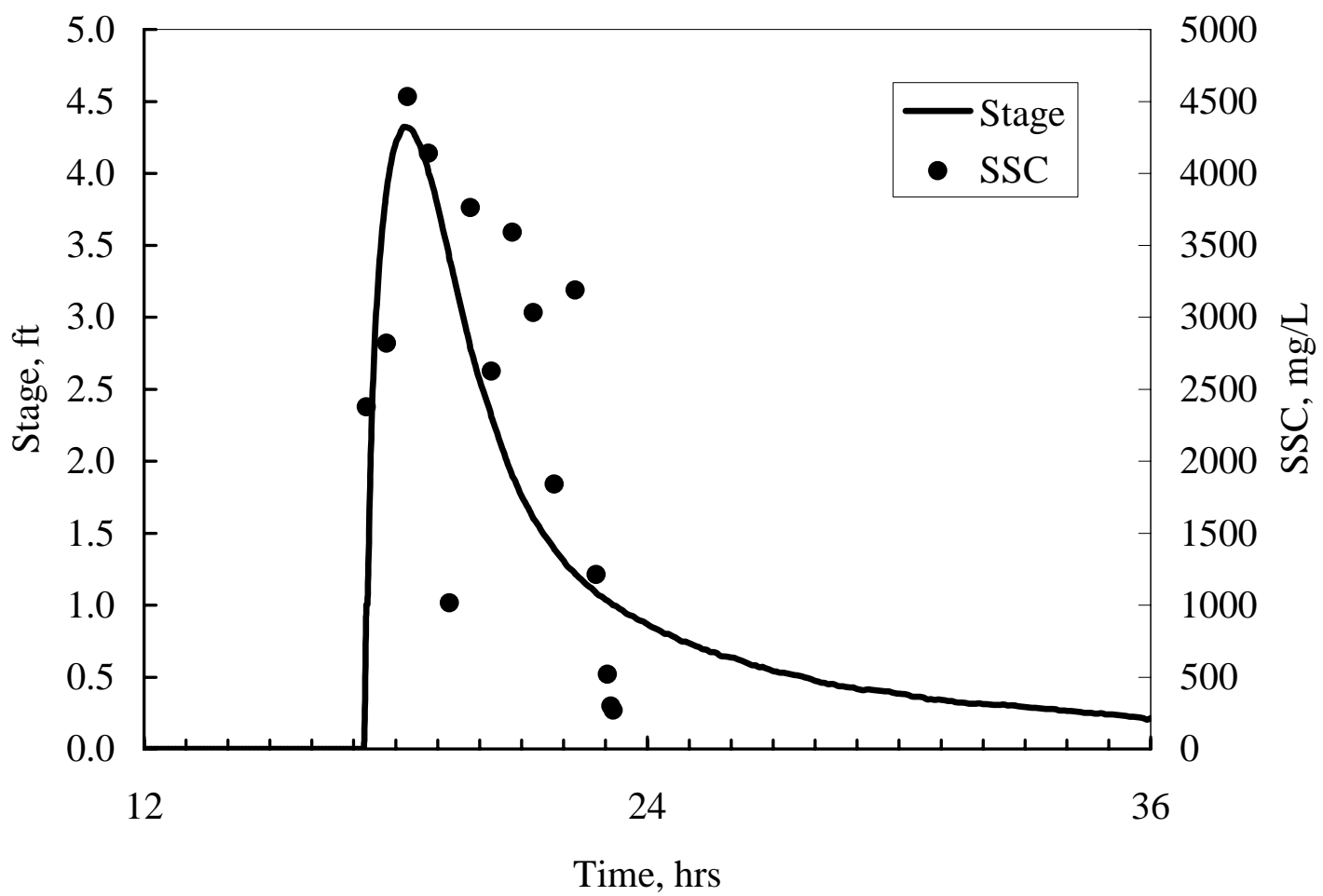

Figure 4.1 May 22, 2004 storm hydrograph and point sampled SSC data

The first research objective was approached using the point samples collected during the first six storm events of the study, shown in the Appendix as Figure A.1 Figure A.6. Although the first two storm events were sampled with a sampling interval of $15 \mathrm{~min}$, the interval was increased to $30 \mathrm{~min}$ after the second storm so that sampling during subsequent storms could capture a greater range of the storm hydrograph. The data collected from these six storm events were used to construct a sediment-rating curve relating SSC of the point samples with stage. This rating curve, displayed below as Figure 4.2, exhibits a poor relationship between stage and SSC of the point samples. The tenuous relationship demonstrates that point measurements of sediment concentration alone cannot effectively predict sediment transport at the cross-section. This also reveals 
the high degree of error associated with assuming point samples to be representative of the sediment concentration in the entire stream cross-section. In addition, this proves that suspended sediment concentration is a function not only of stage, but of a suite of variables. Other variables of interest include sediment grain size distribution, water velocity and discharge, and energy grade line slope of the flow. Additional sediment sampling techniques, such as depth-integrated sampling, along with supplementary parameter measurements, such as bed sediment sampling and velocity measurement, can provide the additional variables needed to make point sampling data more meaningful. These variables are discussed in detail in the sections that follow.

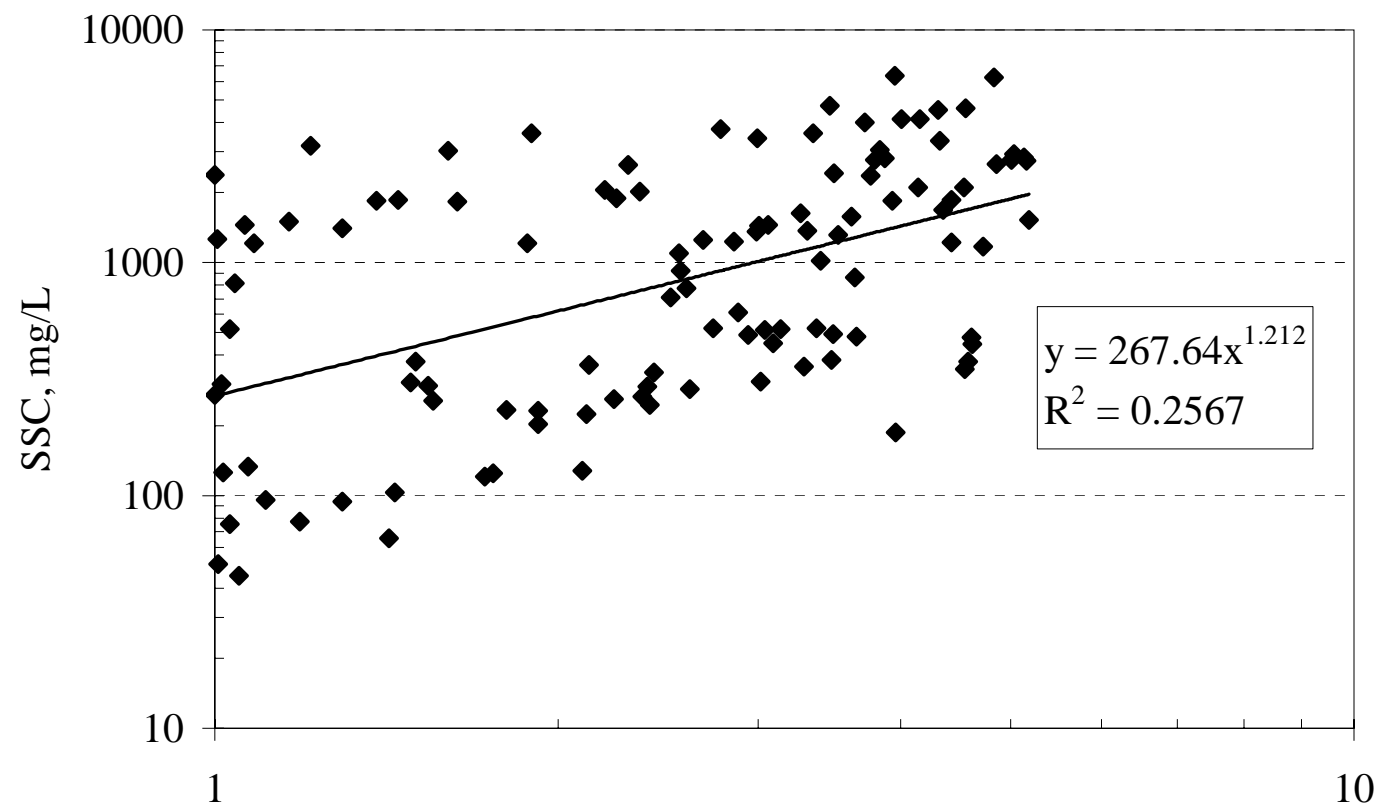

Stage, $\mathrm{ft}$

Figure 4.2 Log-log plot of paired stage and point sampled SSC data 


\subsection{Relative Sources of Sediment in Point Samples}

As mentioned above, the knowledge of the grain size distribution of the sediment collected in the point samples would provide helpful information for improving the point sampling technique. However, the majority of the point samples did not include the required weight of dry sediment to accurately conduct sieve analysis. Proper identification of the sources of sediment that contribute to the point samples can minimize this shortfall, however, and provide helpful grain size information. The bed was sampled in the upstream vicinity of the point sampler intake strainer as a first step in identifying the contribution of bed-material to the point samples. Several bed samples were taken and grain size analysis revealed that the median grain size of the bed sediment $d_{50}$ is approximately $0.63 \mathrm{~mm}$. The distribution also shows that the bed contains less than one percent fine sediment $(<63 \mu \mathrm{m})$. A lognormal plot of the results of the grain size analysis is shown below as Figure 4.3.

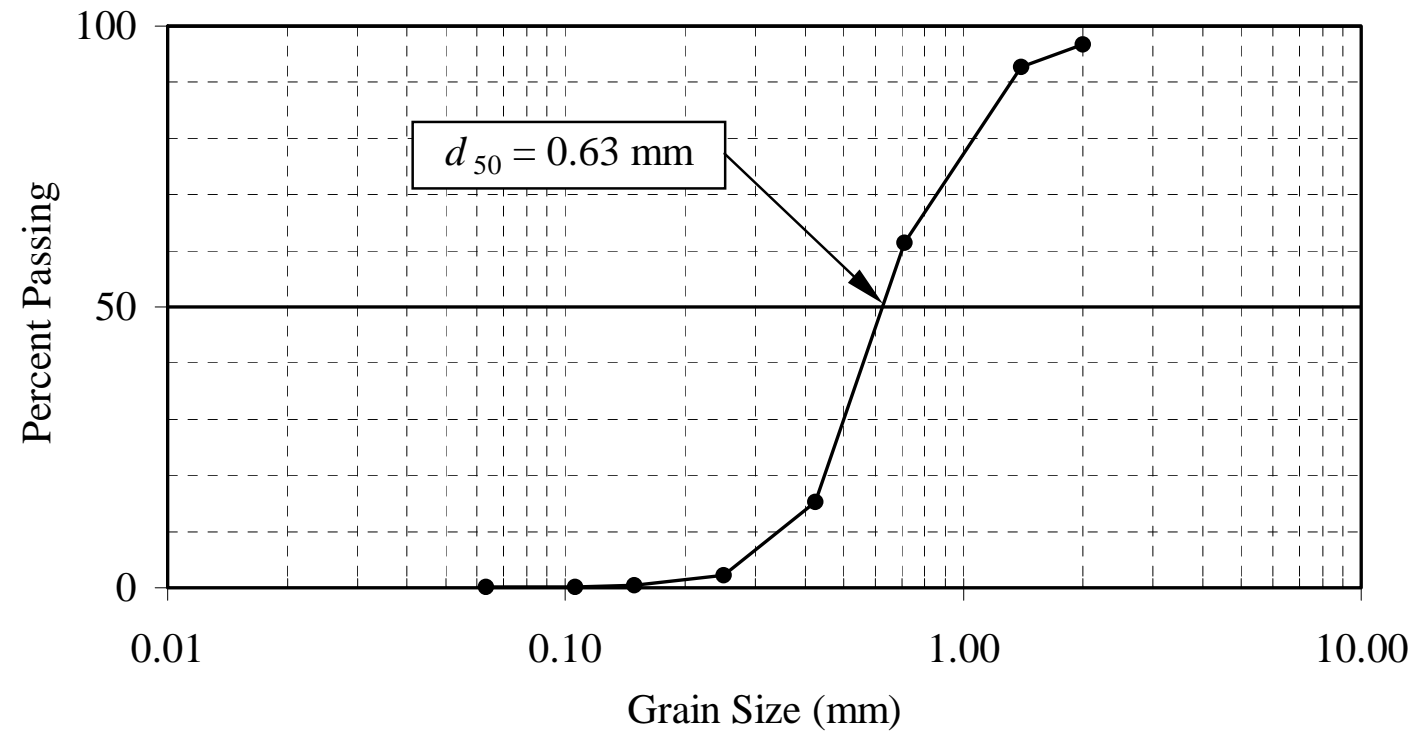

Figure 4.3 Grain size distribution of bed sediment 
A method was then needed for comparing the sediment in the point samples with the sediment sampled from the bed. Comparing the two types of samples in terms of median grain size $d_{50}$ was determined impractical since the point samples did not contain enough sediment to conduct grain size analysis through sieving. However, because the point samples visibly contained a significant portion of fine sediment, comparing the samples by their relative percentage of coarse and fine sediment was identified as an appropriate method of comparison. Point samples from eight storm events, shown in the Appendix as Figure A.4 - Figure A.11, were then analyzed for percent fine sediment in addition to SSC analysis. Storm event samples from the latter five storm events were grouped based on their relative location in the storm hydrograph to produce a greater mass of sediment for the analyses. The results revealed that the average percent fine sediment of the seventy-three point samples from the eight storm events was thirty percent fine sediment by weight. As discussed in Chapter II, Julien (1995) describes washload as fine particles that are easily carried by the streamflow and whose grain size accounts for less than ten percent of the bed-material $\left(d_{\mathrm{s}}<d_{10}\right)$. He adds that although washload does not have any direct relation to sediment grain size, it often corresponds to the silts and clays in sand-bed streams. This understanding provides evidence that the coarse sediment present in the point samples was bed-material sediment and that the vast majority of the fine sediment was washload originating from upstream sources.

\subsection{Using Turbidity to Locate Sources of Washload}

Upstream bank erosion was identified as a potential source of the washload, so sediment samples from the bed and banks upstream of the sampling site were collected 
for comparison with the sediment in the point samples. A review of related literature provided the concept of using turbidity as a means of comparison by creating suspensions with each sediment sample and measuring the turbidity each produced (Brasington and Richards, 2000). This method was adopted and the coarse sediment (>63 $\mu \mathrm{m})$ was removed from each sample so that the fine sediment could be isolated. First, the Isco point samples from the eight storm events used for percent fines analysis were also analyzed for the turbidity contributed by the fine sediment in suspension. These eight storm events provided a graphical relationship between concentration of fine sediment $\mathrm{SSC}_{\text {fines }}$ and turbidity. This relationship is shown below as Figure 4.4. The favorable relationship $\left(\mathrm{R}^{2}=0.9711\right)$ indicates the strong correlation between $\mathrm{SSC}_{\text {fines }}$ and turbidity at the sampling cross-section.

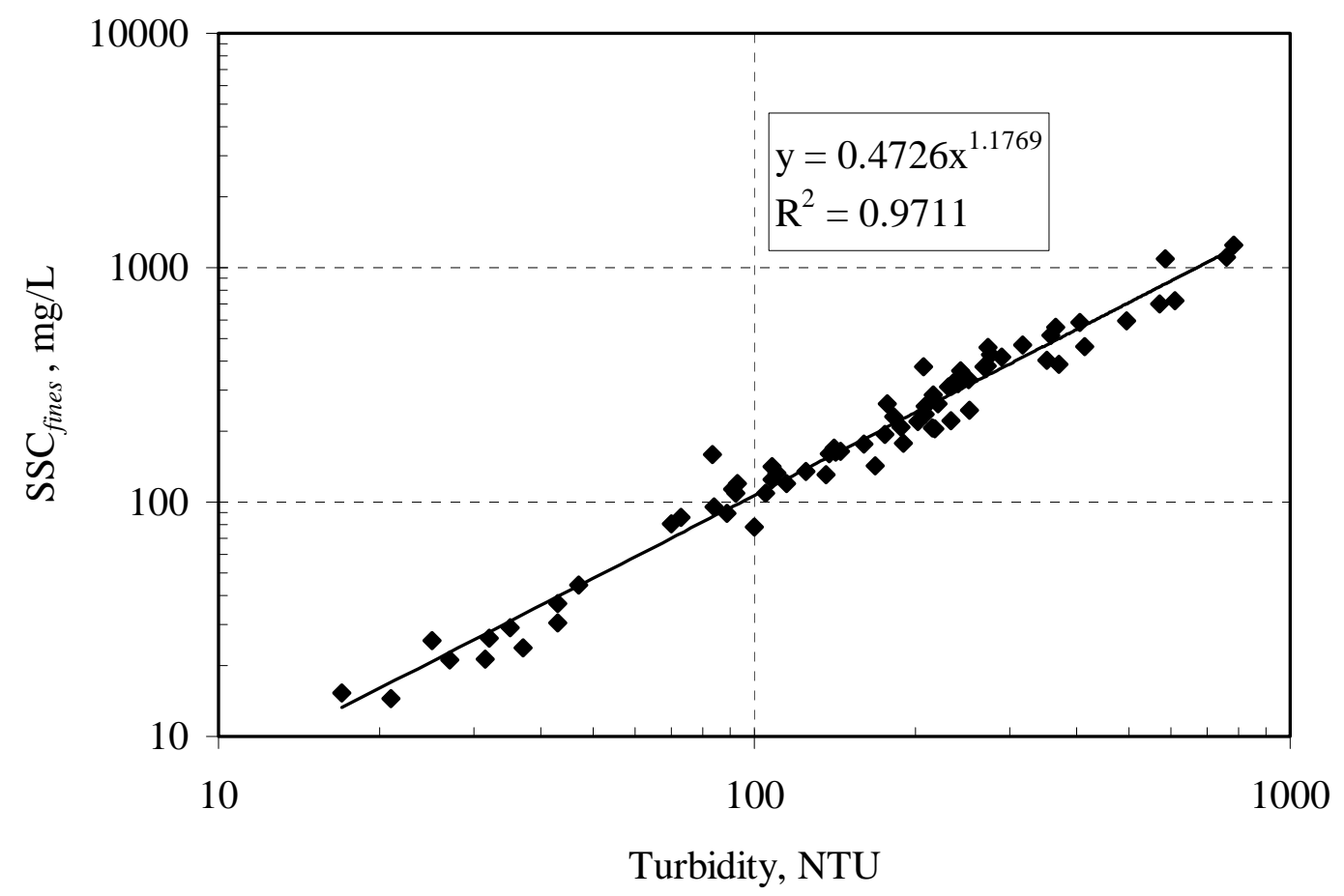

Figure 4.4 Log-log plot of $\mathrm{SSC}_{\text {fines }}$ and turbidity for multiple storm events 
Sediment bed and bank samples were collected from several sites just upstream of the sampling location and at a site approximately one mile upstream where severe bank erosion is actively occurring and presumably contributes significantly to the washload. The grain size distribution of the bed and bank samples was found through sieve analysis in order to determine the median grain size and percent fines of each type of sediment. The fine sediment in each sample was used to create suspensions for which turbidity in nephelometric turbidity units (NTU) and suspended sediment concentration of the fines ( SSC $_{\text {fines }}$ ) were measured and correlated. Comparing all of the sediment samples as shown in Figure 4.5 and Table 4.1 indicates that each type of sediment exhibits a unique relationship or "signature" between $\mathrm{SSC}_{\text {fines }}$ and turbidity.

Comparing the turbidity signature of the fine sediment contained in the Isco point samples with that of the fine sediment sampled from the bed in Figure 4.5 shows that the two sediments are dissimilar and thus reinforces the supposition that the fine sediment in the bed only constitutes a negligible fraction of the fine sediment in the point samples. Yet, as Figure 4.5 demonstrates, neither of the bank samples matches the turbidity relationship for the fine sediment found in the point samples. However, the eroding bank sediment is most similar, particularly in the upper portion of the relationship. This similarity suggests that it is contributing significantly to the washload. The slight difference is likely due to winnowing that takes place as the eroded sediment travels downstream. 


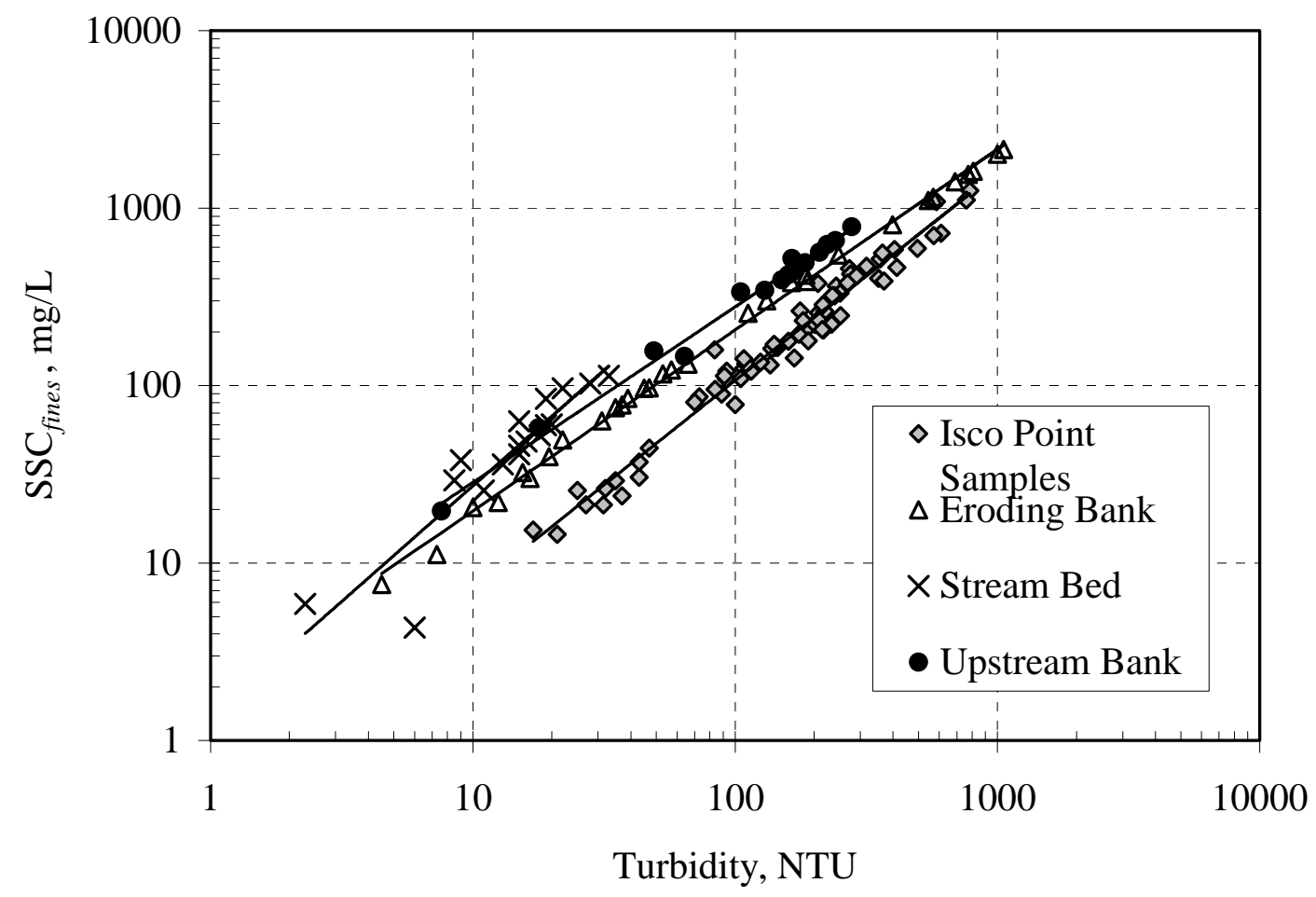

Figure 4.5 Log-log plot comparing turbidity signatures of sediment samples

Table 4.1 Regression equations of turbidity signatures and grain size information

\begin{tabular}{c|cccc}
\hline $\begin{array}{c}\text { Type of } \\
\text { Sample }\end{array}$ & $d_{50}$ & $\begin{array}{c}\text { Percent } \\
\text { Fines }\end{array}$ & Regression Equation & $\mathrm{R}^{2}$ \\
\hline Isco Point Samples & - & $30 \%$ & $\mathrm{SSC}_{\text {fines }}=0.472(\mathrm{NTU})^{1.1769}$ & 0.9711 \\
Eroding Bank & $0.15 \mathrm{~mm}$ & $25 \%$ & $\mathrm{SSC}_{\text {fines }}=1.881(\mathrm{NTU})^{1.0193}$ & 0.9974 \\
Upstream Bank & $0.30 \mathrm{~mm}$ & $7 \%$ & $\mathrm{SSC}_{\text {fines }}=2.92(\mathrm{NTU})^{0.988}$ & 0.9904 \\
Stream Bed & $0.63 \mathrm{~mm}$ & $<1 \%$ & $\mathrm{SSC}_{\text {fines }}=1.356(\mathrm{NTU})^{1.3025}$ & 0.832 \\
\hline
\end{tabular}


Turbidity analysis was used to effectively determine that the vast majority of the fine sediment in the point samples originated at an upstream location rather than the bed. Although grain size analysis showed a disproportionate contribution of fine sediment in the point samples, comparison of turbidity signatures identified that the fine sediment found in the bed did not match that in the point samples. Furthermore, this use of turbidity provides a method of identifying potential sources of washload and eliminating others.

\subsection{Depth-Integrated Sampling}

Depth-integrated sampling was performed during six storm events of varying intensities. These storms are displayed in the Appendix as Figure A.12 - Figure A.17. Each deployment provided four individual samples representing each of the four transect verticals. The four samples from each deployment were analyzed individually but used to form a composite SSC measurement by weighting the concentration of each sample with its volume. It is important to reiterate that the samples collected by the depthintegrating sampler represent only the measured sediment discharge and therefore do not include the entire suspended sediment discharge nor the bedload discharge. For this reason, raw SSC data from depth-integrated sampling should not be confused with the point sampling data discussed above. Figure 4.6 is a logarithmic plot of these depthintegrated SSC data with stage. When displayed in this fashion, the correlation between stage and SSC at the sampling cross-section is virtually nonexistent. This underscores the problems associated with developing a relationship between stage and sediment loads, regardless of sampling technique. 


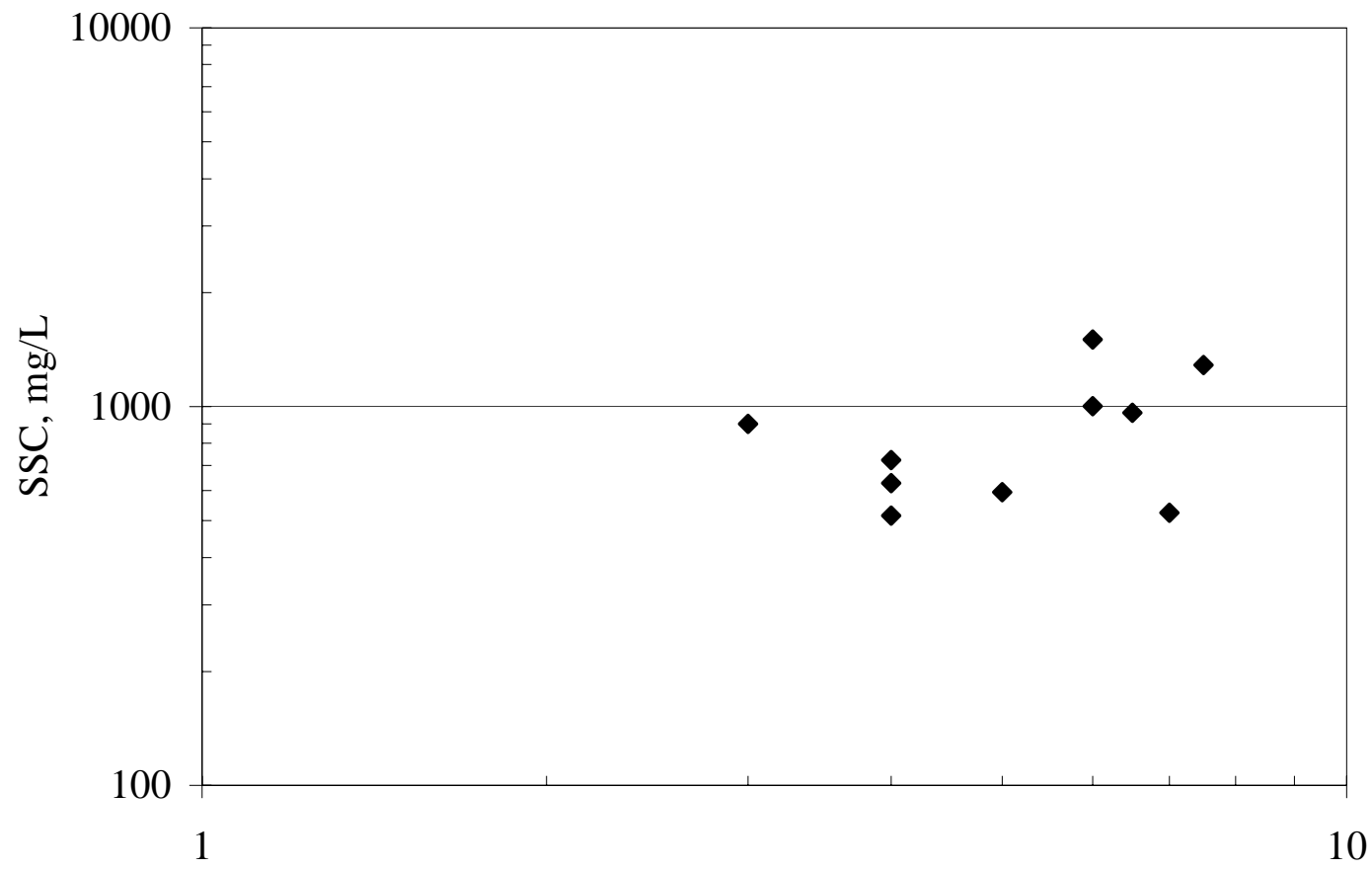

Stage, $\mathrm{ft}$

Figure 4.6 Log-log plot of paired stage and depth-integrated SSC data

\subsection{Developing the Discharge-Rating Curve}

Velocity measurements were made during certain storm events for development of the discharge-rating curve at the sampling cross-section. Velocities were measured at the four stream verticals established for depth-integrated sampling and the cross-sectional velocity average was used with stage measurements and cross-sectional geometry to calculate discharge. The velocity meter apparatus prevented measuring within $3 \mathrm{ft}$ of the bed so that velocity data could not be obtained for smaller stages. To overcome this deficiency, a complete discharge-rating curve was also developed using the HEC-RAS computer model (U.S. Army Corps of Engineers, 1998). A detailed topographic survey of the stream channel was available from previous research conducted within the reach. 
The unsteady module of HEC-RAS was utilized to develop the rating curve using measured stage hydrographs at the sampling cross-section at Century Blvd. as well as simultaneous stage hydrographs measured at a cross-section approximately $5000 \mathrm{ft}$ downstream of Century Blvd. using a submerged pressure transducer connected to another Isco sampler. The storm event used to create the rating curve occurred on March 19, 2000 and is shown in the Appendix as Figure A.18.

The computed results from HEC-RAS are shown in Fig. 4.7, and it can be observed that there is a small hysteresis in the rating curve as expected. The results from the velocity measurements are also shown in Fig. 4.7, and they compare reasonably well with the computed results considering the uncertainty in the field measurements.

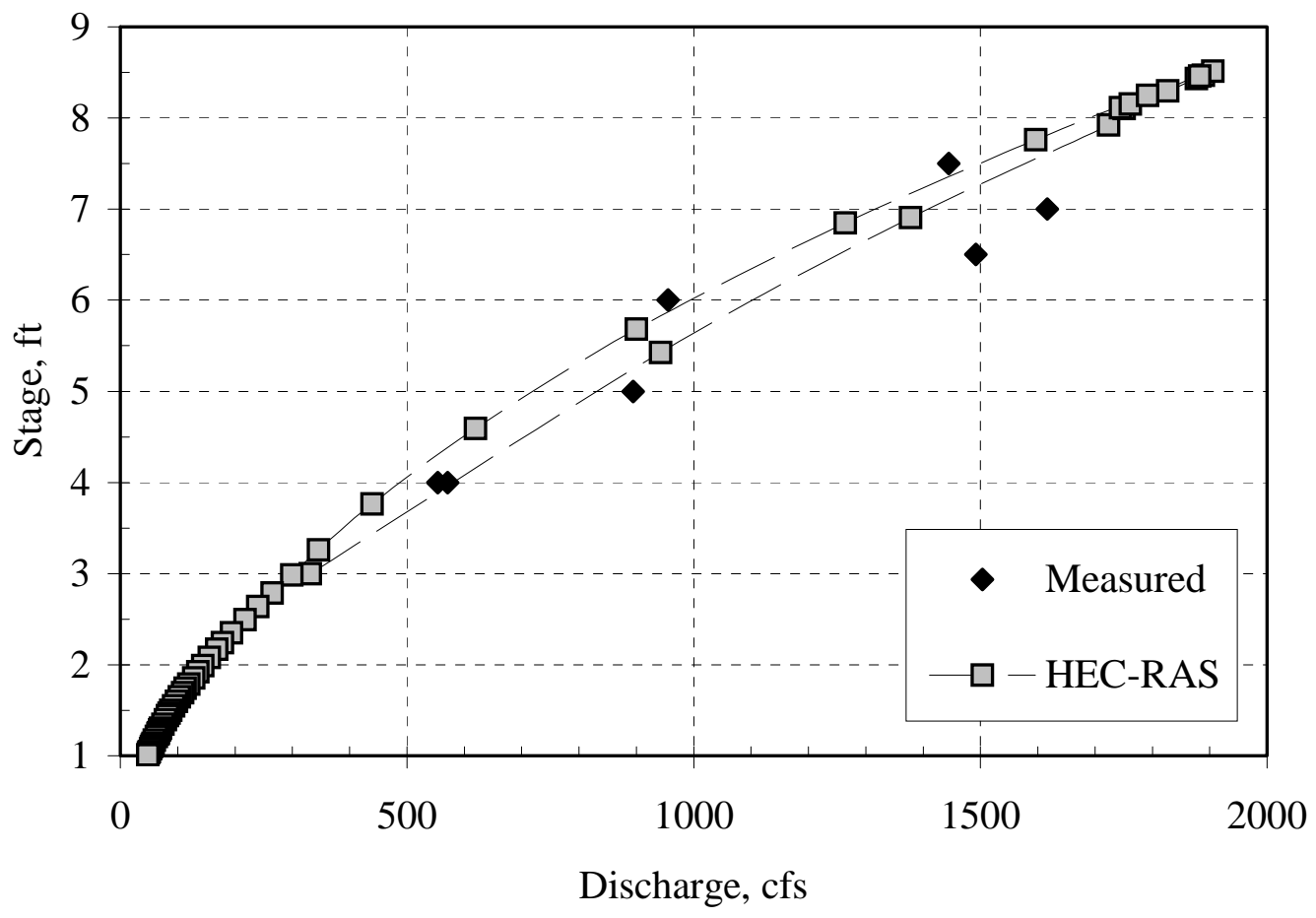

Figure 4.7 Discharge-rating curve at sampling cross-section 


\subsection{Suspended Sediment-Rating Curve}

Sediment rating curves are used to display sediment discharge as a function of water discharge $Q$. Suspended sediment discharge $G_{\mathrm{s}}$ is defined as the cross-sectional average concentration of suspended sediment $C_{\mathrm{s}}$, as determined from depth-integrated sampling, times water discharge $Q$ (Vanoni, 1977). The suspended sediment-rating curve constructed from the depth-integrated samples is shown below as Figure 4.8. Suspended sediment discharge $G_{\mathrm{s}}$ is displayed in $\mathrm{lb} / \mathrm{s}$ but again does not include the suspended sediment transported in the unsampled region. The high degree of variability in the rating curve represents the fluctuating supply of washload sources and indicates that the stream reach is supply-limited by washload (Julien, 1995). This also explains the hysteresis effect caused by the rising and falling limbs of the hydrograph.

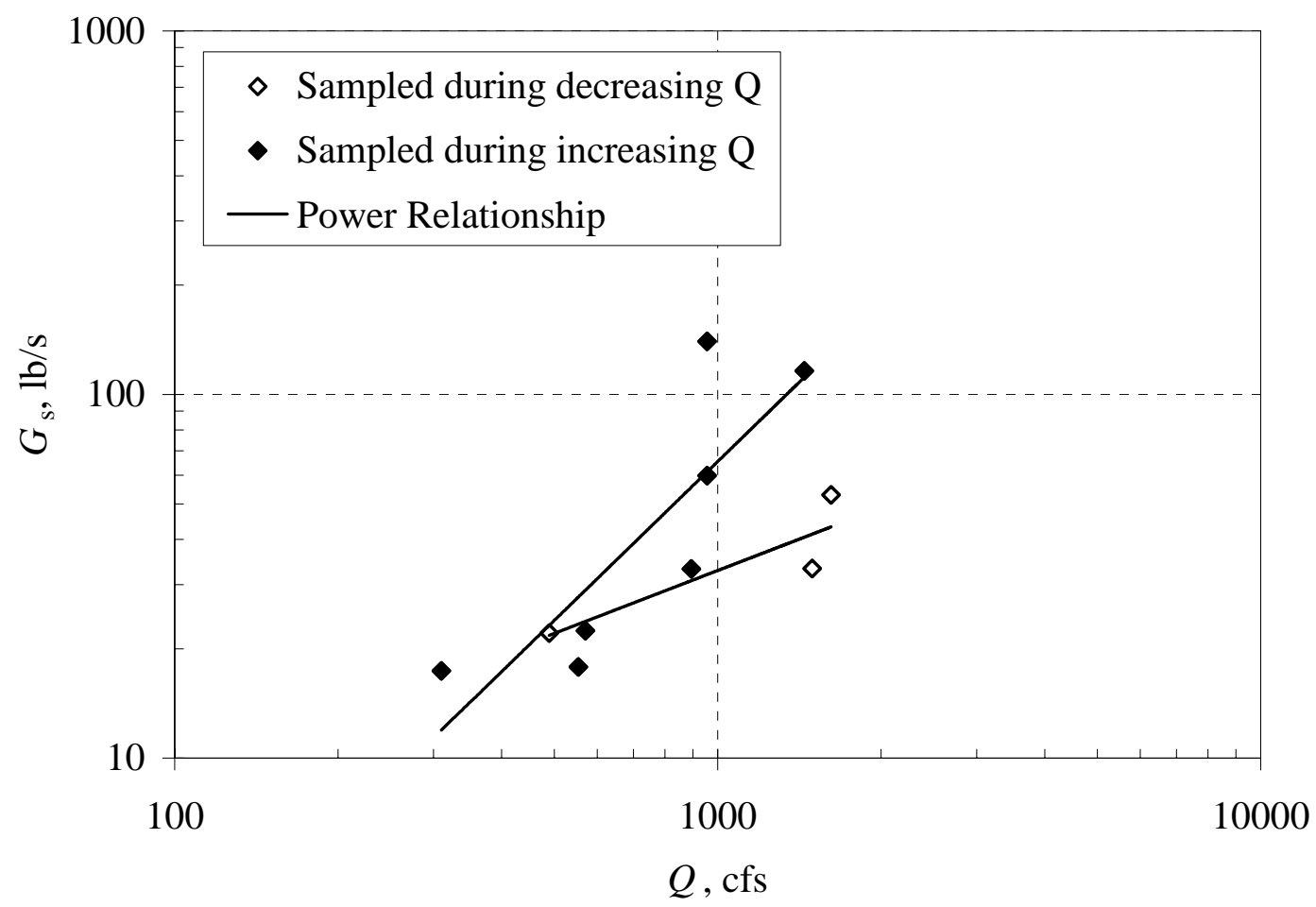

Figure 4.8 Suspended sediment-rating curve from depth-integrated samples 


\subsection{Vertical Extrapolation of Point Samples}

An effective comparison between the point samples and depth-integrated samples requires a method of transforming the point samples of SSC into cross-sectional averages of suspended sediment concentration $C_{\mathrm{s}}$. This presents a particular challenge since sediment concentration varies both vertically and laterally in the cross-section. Depthintegrated sampling accounts for this variation in the two cross-sectional dimensions while point samples theoretically capture only a single point in the two-dimensional plane of the cross-section but with greater detail in the temporal dimension. Comparing the two types of samples first requires a method of extrapolating the point measurements so that they account for variation in the vertical dimension.

The Rouse solution for vertical distribution of suspended sediment concentration as discussed in Chapter II provides a method of calculating a vertical average of suspended sediment concentration using one measured point of suspended sediment concentration at a known vertical location. The Rouse solution is a measure of the capacity of the flow to transport sediment particles and thus inherently assumes that there is no source of sediment in the flow other than the sediment particles on the bed. For this reason, the Rouse solution is useful for calculating the capacity-limited bed-material sediment discharge.

The Rouse solution requires two parameters not supplied by point sampling data alone, namely average water velocity in the vertical and energy grade line EGL slope at the time of sampling to determine the shear velocity. The EGL slope is often estimated as the water surface slope since energy grade line slope is more difficult to calculate (Sturm, 2001). However, the unsteady flow module of HEC-RAS enabled accurate 
calculation of both average water velocity and EGL slope during each storm event. The Isco sampling unit provided the stage hydrographs concurrent with point sampling that were applied as the upstream boundary condition in the computer model. Normal depth far downstream was used as the downstream boundary condition. The HEC-RAS model output provided the quantities of average water velocity and slope of the energy grade line for each point sample as required by the Rouse solution described previously by Equations 2.7 and 2.8.

A numerical model using Visual Basic for Applications was developed to obtain the Rouse solution using the trapezoidal rule of integration. This provided the potential to extrapolate the point samples of suspended sediment concentration into vertical averages of suspended sediment concentration. However, for the Rouse solution to be applied to the point samples it was necessary to isolate the bed-material from the other sources of sediment in the point samples. As discussed previously, grain size and turbidity analysis of the bed sediment and point samples revealed that the fine sediment present in the point samples did not originate in the bed. Therefore, the assumption was made that since the vast majority of the coarse sediment in the point samples originated in the bed, it represented bed-material discharge and could be used with the Rouse solution.

The Rouse solution in general terms also demonstrates that very fine sediment is nearly uniformly distributed vertically in the cross-section. Sampling of the bed and banks, along with percent fines analysis of the point samples, indicated that the washload present in the point samples consisted of very fine particles that could be considered uniformly distributed vertically. Depth-integrated samples were analyzed for percent fine 
sediment and turbidity following the procedure used for point samples. The turbidity caused by the fine sediment in the depth-integrated samples matched the relationship previously established through point sampling. This relationship is shown below in Figure 4.9. The close agreement between the turbidity caused by the fine sediment in the point samples and the depth-integrated samples provides further evidence that the fine sediment found in the point samples represents washload and that it is uniformly distributed in the cross-section. For this reason, the fine sediment concentration in the point samples was considered to be equivalent to the vertical average of fine sediment concentration as measured by the depth-integrating sampler without adjustment.

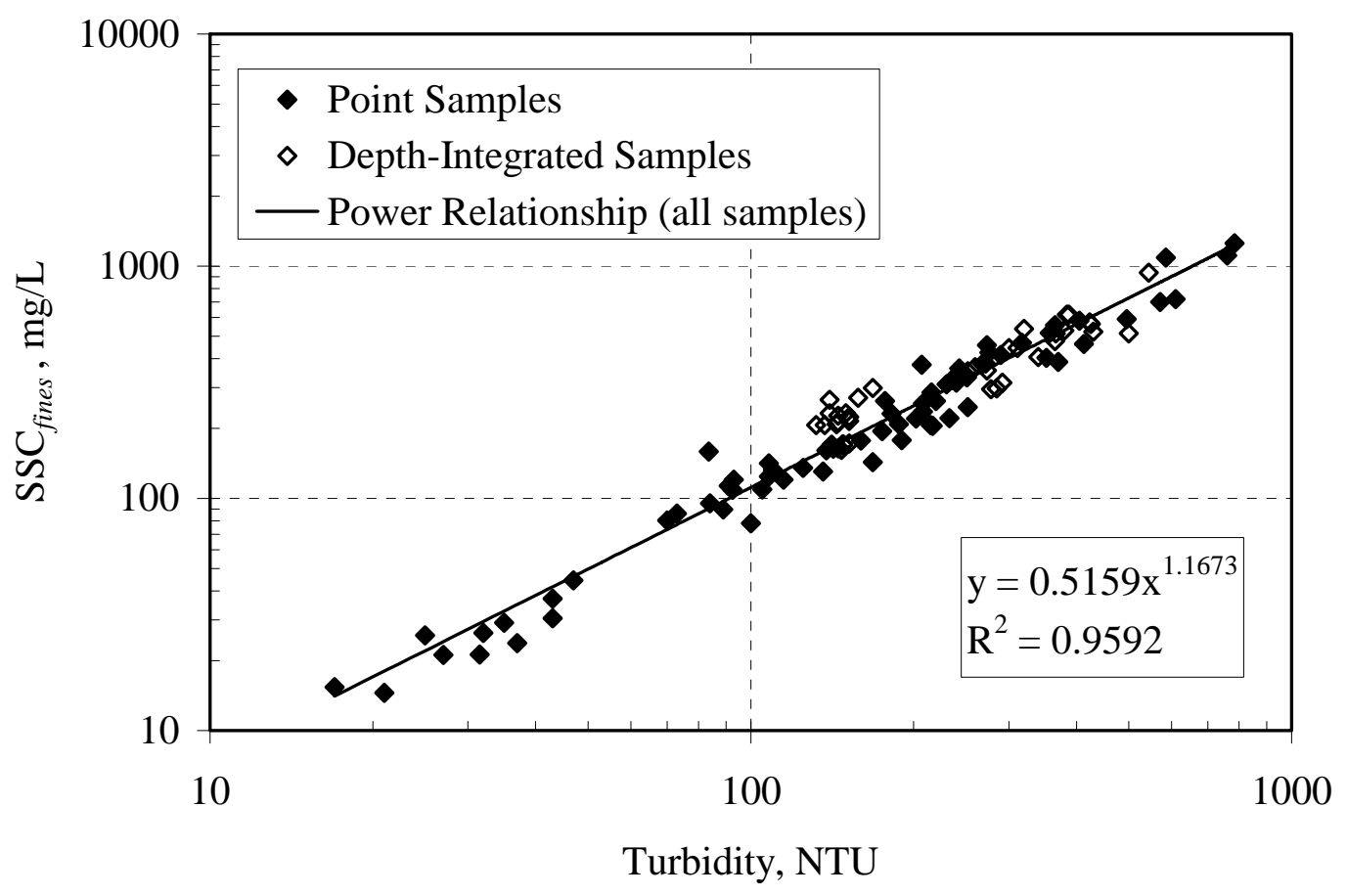

Figure 4.9 Turbidity comparison of suspended sediment concentration samples 
One of the four verticals used for depth-integrated sampling was located directly downstream of the point sampling intake strainer at a distance of approximately $20 \mathrm{ft}$. Depth-integrated samples collected at this vertical are then comparable to the vertical extrapolations of the point measurements using the Rouse solution. As noted earlier, however, the two sampling techniques represent a different portion of the suspended sediment and must be modified for appropriate comparison. Whereas the Rouse solution's vertical extrapolation of the point samples represents the entire vertical distribution of suspended sediment, the depth-integrated samples do not include the suspended sediment carried within 6 in. of the bed. This disparity was overcome by modifying the integration procedure of the Rouse solution so that the bottom limit of integration was equal to 6 in. above the bed, thereby neglecting numerically the sediment transported in the zone not sampled by the depth-integrating sampler. As discussed previously, the Rouse solution was applied only to the bed-material by using the concentration of the coarse fraction of the Isco point sample. Then the fine sediment concentration in the point samples was added to the integrated concentration of bedmaterial without adjustment. This process yields vertically extrapolated point measurements that represent the same vertical distribution of sediment collected by the depth-integrating sampler and provides a means of true comparison between the two sampling methods. Sediment discharge was calculated as measured sediment discharge $G_{m}$ using the product of the cross-sectional water discharge $Q$ from the discharge-rating curve and mean sediment concentration $C_{m}$ over the sampled portion of the single vertical. In the case of the Isco point samples, the mean concentration is calculated by integration while the depth-integrated sampler measures it directly. The favorable 
comparison of the sediment discharges determined by the two methods is shown below as Figure 4.10.

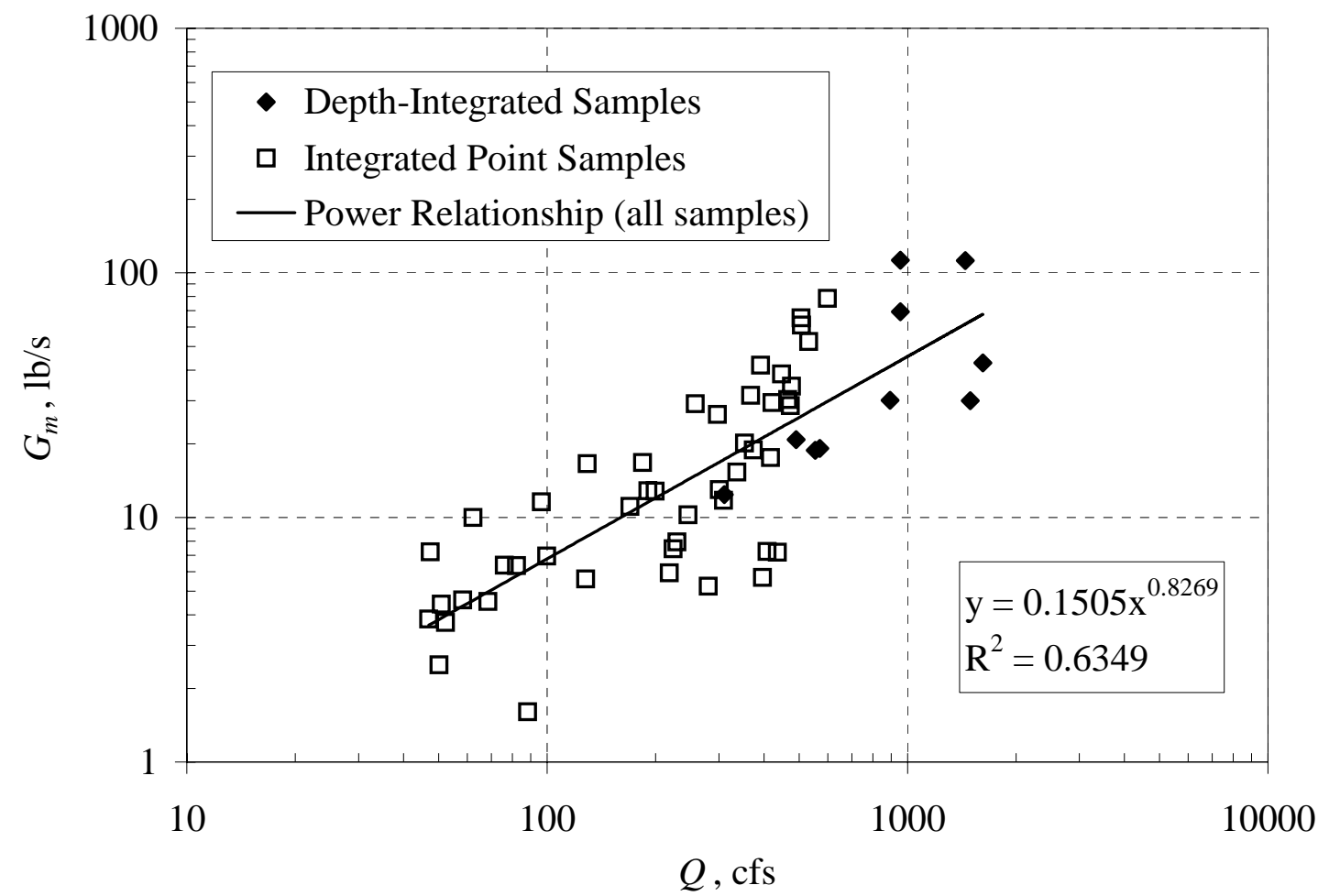

Figure 4.10 Measured sediment discharge at single vertical from depth-integrated samples and from integrated Isco point samples

\subsection{Cross-sectional Extrapolation of Point Samples}

Although vertical extrapolation of the point samples provides sufficient agreement with the depth-integrated samples taken at one vertical, it does not address lateral variation in suspended sediment concentration. The ideal method of making this comparison would be through simultaneously collecting depth-integrated samples and automatically sampled point samples. Comparing the two types of samples would provide a method for scaling the point samples with respect to the cross-sectional average under identical flow conditions. Indeed, this was the sampling scheme envisioned during 
the initial phases of research. However, the summer months of 2004 in the Atlanta area were characterized by drought, followed by severe tropical storm systems in September 2004. The first storm resulted in flooding of infrequent magnitude that damaged the automatic sampling equipment and rendered it ineffective in collecting samples. Additionally, the stream did not recede to base flow before a second storm occurred. As a result, repairs could not be made to the sampling equipment and point samples were not collected following the initial damage.

In spite of equipment failure, lateral comparisons between the field record of point samples and depth-integrated samples can be made. A comparison can first be made, using only depth-integrated samples, which provides an idea of the lateral variation in suspended sediment concentration between the point sampling location and the entire cross-section (Horowitz et al., 1990). This is accomplished by comparing the depthintegrated cross-sectional average of measured sediment discharge with the depthintegrated value collected only at the vertical that coincides with the point sampling strainer as shown in Figure 4.10. This relationship is plotted below as Figure 4.11. 


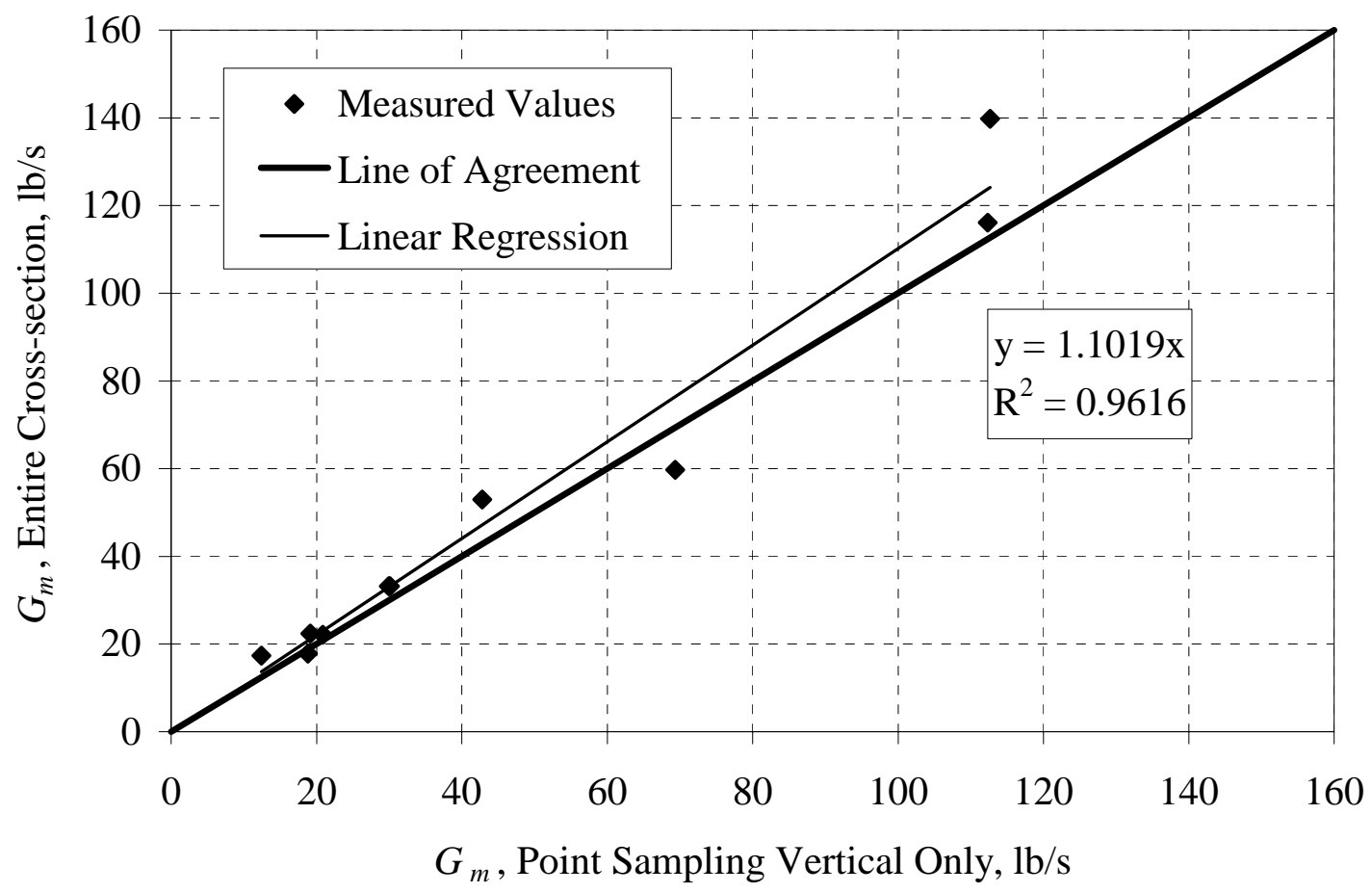

Figure 4.11 Lateral variation in measured sediment discharge from depthintegrating sampler

The linear regression shown in Figure 4.11 demonstrates that the cross-sectional measured sediment discharge is approximately ten percent greater than measured sediment discharge at the location of the point sampling vertical only. The reliability of this agreement $\left(\mathrm{R}^{2}=0.9616\right)$ indicates that this approach is sufficient for estimating lateral variation of measured sediment discharge in the cross-section. An initial comparison can be made that utilizes this understanding by comparing measured sediment discharge of the extrapolated point samples with the cross-sectional average computed from all four depth-integrated sampling verticals. These two data sets are shown below graphically as Figure 4.12, in which the depth-integrated samples represent the entire cross-section and the point samples have been increased by ten percent to reflect the lateral variation revealed by Figure 4.11. 


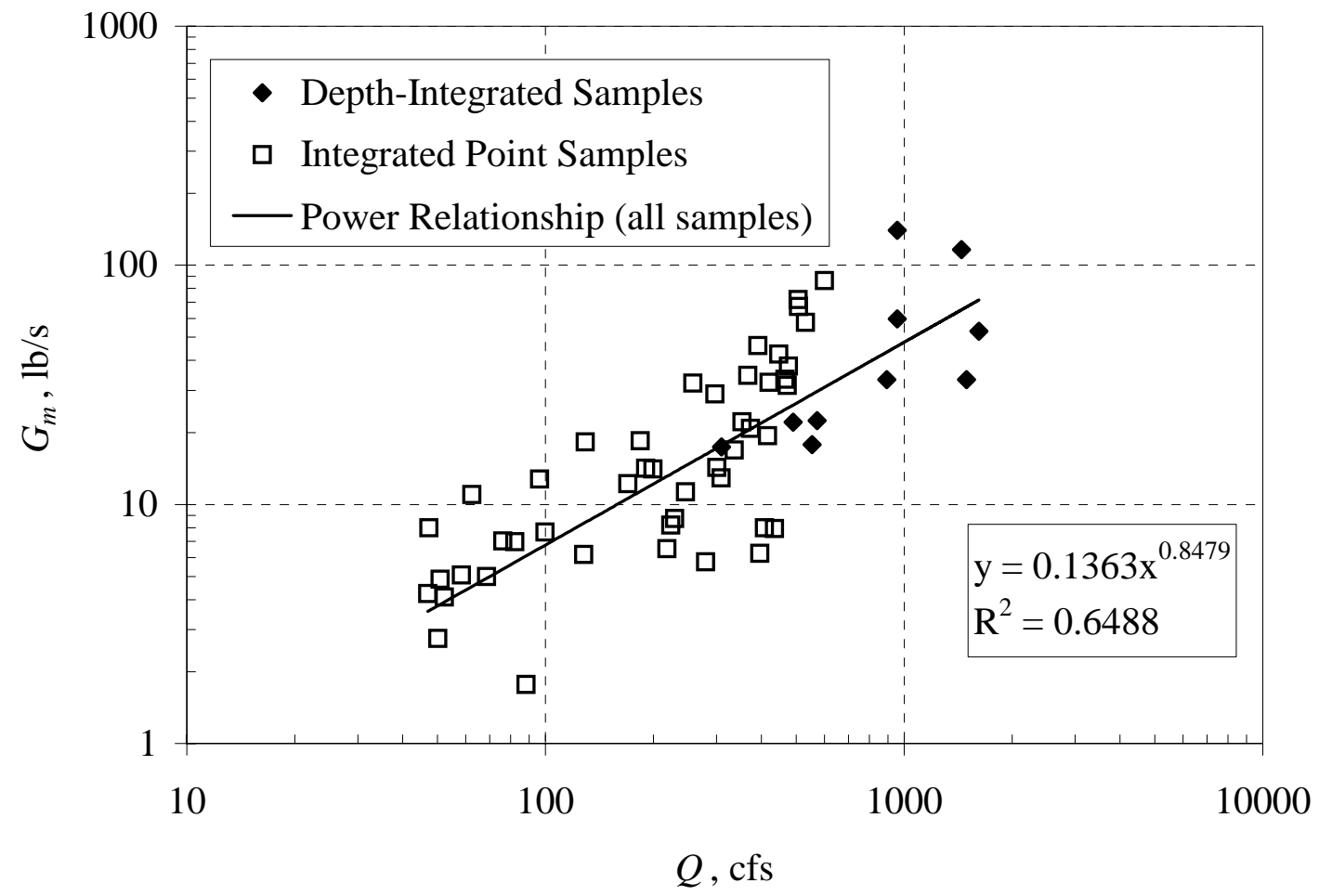

Figure 4.12 Measured sediment discharge of entire cross-section

This understanding also provides the appropriate basis for presenting the entire vertical extrapolation of point measurements including the unsampled region that has so far been neglected. This was accomplished using the entire Rouse solution, which vertically extends from the water surface to the stream bed at the point where velocity equals zero. Figure 4.13 displays the suspended sediment discharge $G_{\mathrm{s}}$ calculated with the vertically extrapolated point measurements without the ten percent lateral adjustment, along with the cross-sectional depth-integrated measurements as previously displayed in Figure 4.12, which again do not included the unsampled region. 


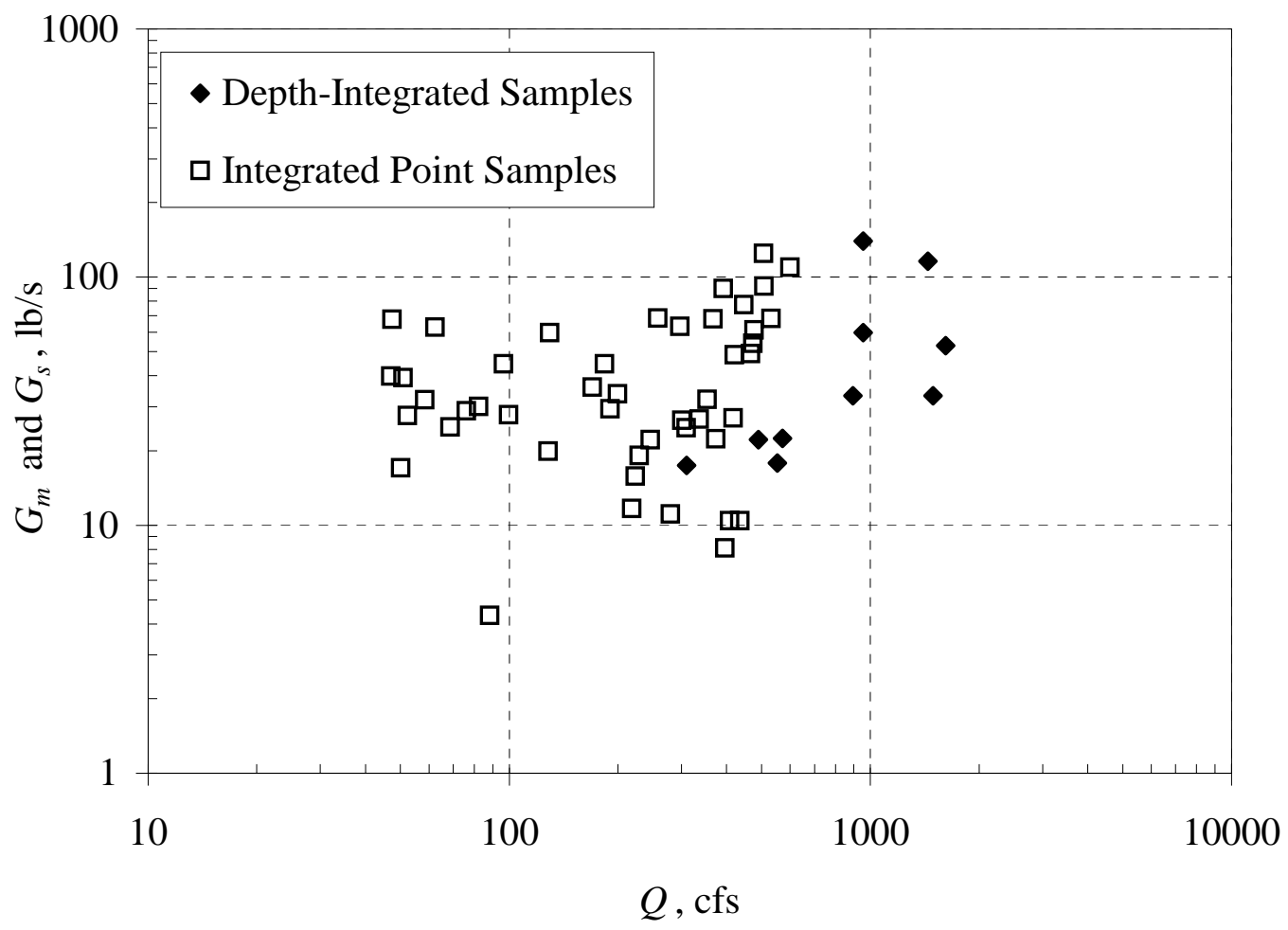

Figure 4.13 Suspended sediment discharge using integrated point samples $\left(G_{s}\right)$ and measured sediment discharge from depth-integrated samples $\left(G_{m}\right)$

Figure 4.13 makes obvious the disparity introduced by including the unsampled zone in the vertical extrapolation of the point measurements. Julien (1995) suggests that when sediment concentration data are widely scattered, better results can be obtained by subdividing the discharge into small increments and calculating the average value of sediment concentration of the measurements in each increment. This method was applied to the point sampling data by designating discharge increments of $100 \mathrm{cfs}$ and averaging the calculated values of suspended sediment discharge $G_{\mathrm{s}}$ and $Q$ within each increment. The resultant sediment-rating curve of average values is plotted below as Figure 4.14. 


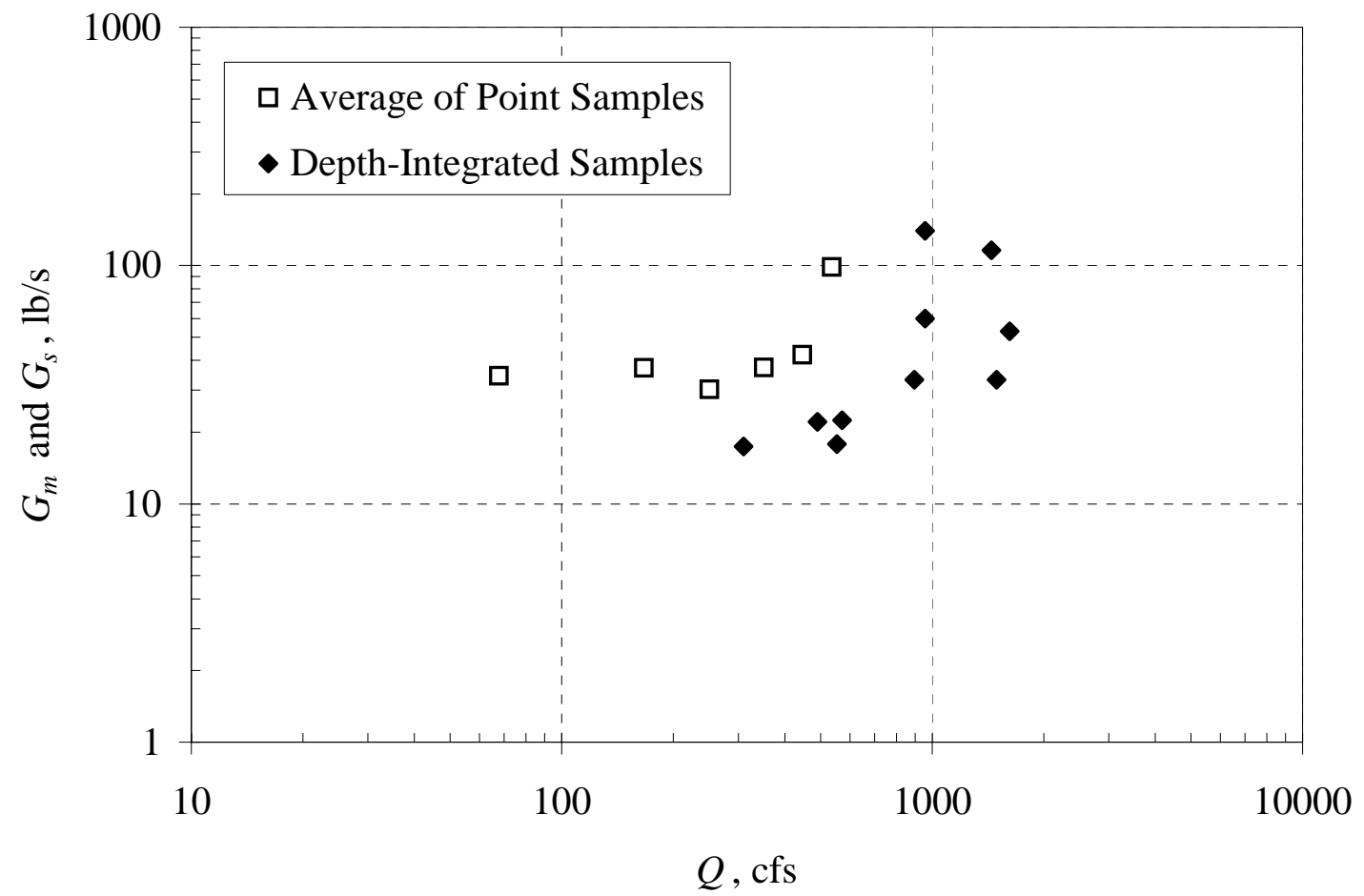

Figure 4.14 Suspended sediment discharge using averages of integrated point samples and measured sediment discharge from depth-integrated samples

Although this relationship does not provide a method of improving the tenuous sediment-rating relationship exhibited by the point samples, it does reveal that the discrepancy lies in the region between base flow water discharge and 200 cfs. Point sampling data corresponding to water discharge exceeding $200 \mathrm{cfs}$ follow the general trend exhibited by depth-integrated data and reveal the difference in magnitude between suspended sediment discharge $G_{\mathrm{s}}$ and measured suspended sediment discharge $G_{m}$. This difference represents the contribution of unmeasured sediment discharge $G_{\mathrm{u}}$. 


\subsection{Effects of Energy Grade Line Slope on Point Samples}

Application of the Rouse solution to point measurements of suspended sediment concentration provides a unique approach for improving the reliability of point sampling. However, when applied to point samples collected during flashy urban storms, the effects of the rapidly changing EGL slope are particularly evident. Because the Rouse solution is dependent upon the EGL slope, rapid fluctuations in the slope affect the calculations of vertical distribution of suspended sediment. Figure 4.15 shows the EGL slope relative to the stage hydrograph for the storm event on May 22, 2004 as previously displayed in Figure 4.1.

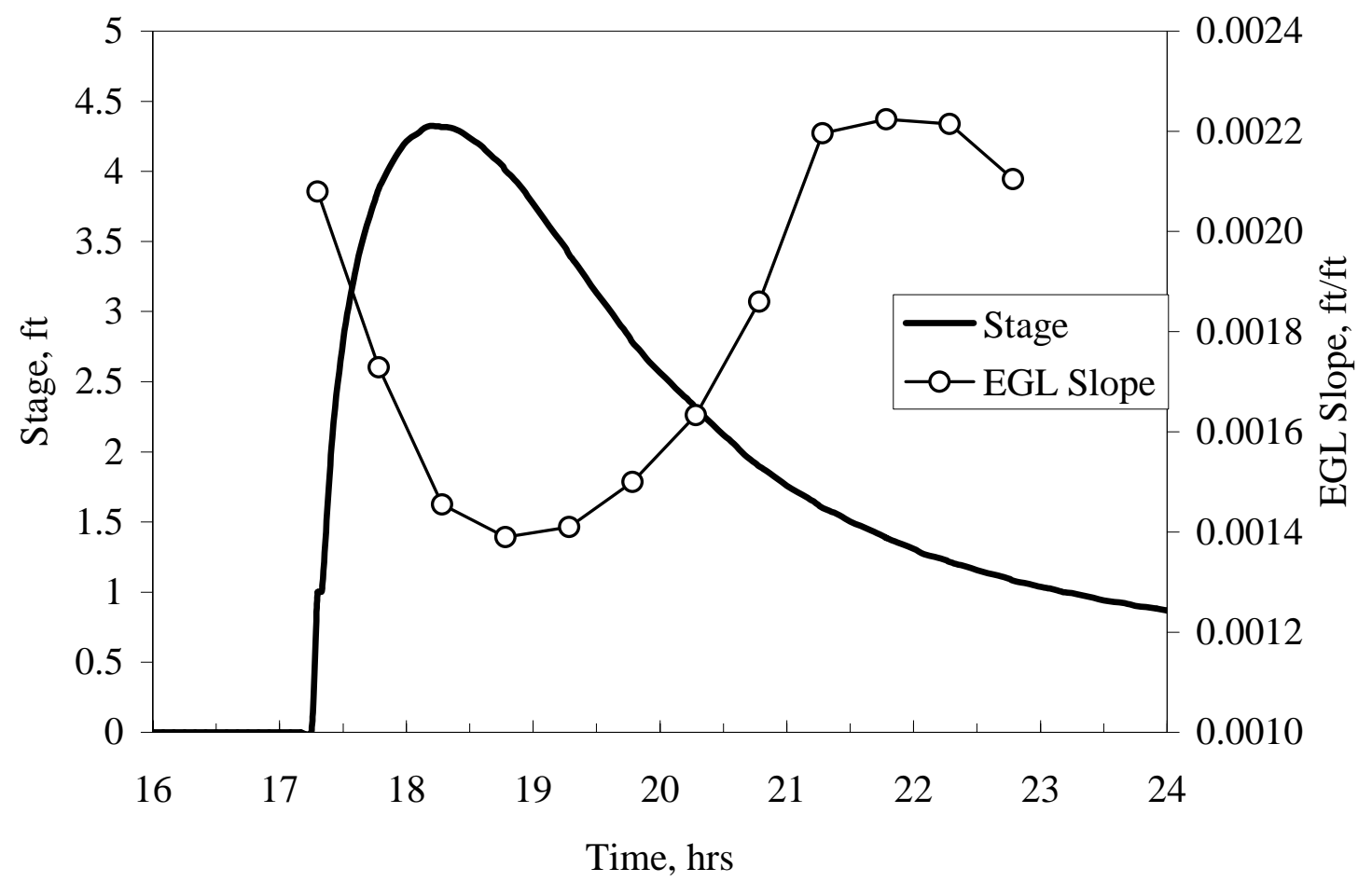

Figure 4.15 EGL slope fluctuation during storm event on May 22, 2004 
The EGL slope is employed in the Rouse solution in the calculation of the Rouse number $\mathrm{R}_{0}$, defined as $\mathrm{R}_{0}=w_{\mathrm{f}} /(\beta \kappa \mathrm{U} *)$ as previously presented in Chapter II. In particular, the EGL slope is involved in estimating shear velocity $u *$ from a uniform flow formula as $\left(g \mathrm{y}_{0} S\right)^{0.5}$. Sturm (2001) notes that this assumption of uniform flow introduces errors since river flows are seldom uniform. This is effectively demonstrated in Figure 4.15 by the nonuniformity of the flow portrayed in the drastic fluctuations in EGL slope. When applied to suspended sediment concentration distributions, the value of the Rouse number determines the gradient in the vertical distribution. Figure 2.1 provides a graphical display of variation in Rouse number in nondimensional terms and its effects on the concentration distribution. Figure 4.16 below shows fluctuations in $\mathrm{R}_{0}$ during the storm event on May 22, 2004.

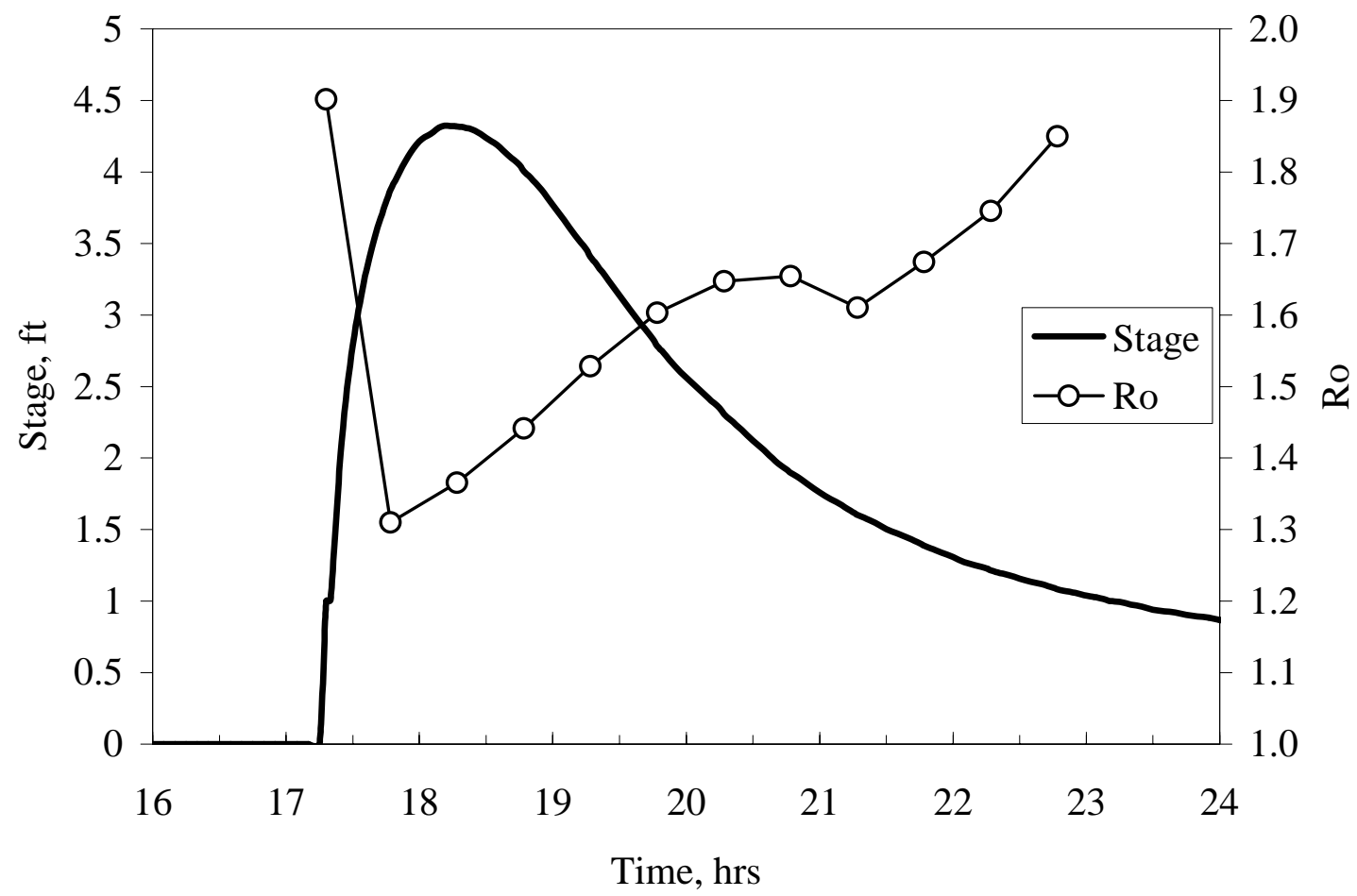

Figure 4.16 Rouse number fluctuation during storm event on May 22, 2004 
Figure 4.16 shows that $\mathrm{R}_{0}$ fluctuates between approximately 1.3 and 1.9 , with the most drastic variation with time occurring as the stage rapidly ascends at the beginning of the storm. Figure 2.1 reveals that the concentration distribution in this range of $\mathrm{R}_{0}$ is heavily weighted in the lower 20 percent of water depth. Figure 4.17 below is a modified discharge-rating curve, similar to Figure 4.7, which shows water depth $y_{0}$ on the vertical axis and 20 percent of the water depth on a second vertical axis relative to discharge. Recall that the disparity in the sediment-rating curve as shown in Figure 4.14 lies in the region between base flow and 200 cfs. Figure 4.17 reveals that when water discharge $Q$ equals $200 \mathrm{cfs}$, water depth $y_{0}$ equals $3.2 \mathrm{ft}$ and 20 percent of that depth is $0.64 \mathrm{ft}$. Also recall that the depth-integrating sampler is unable to sample within 6 in. of the bed.

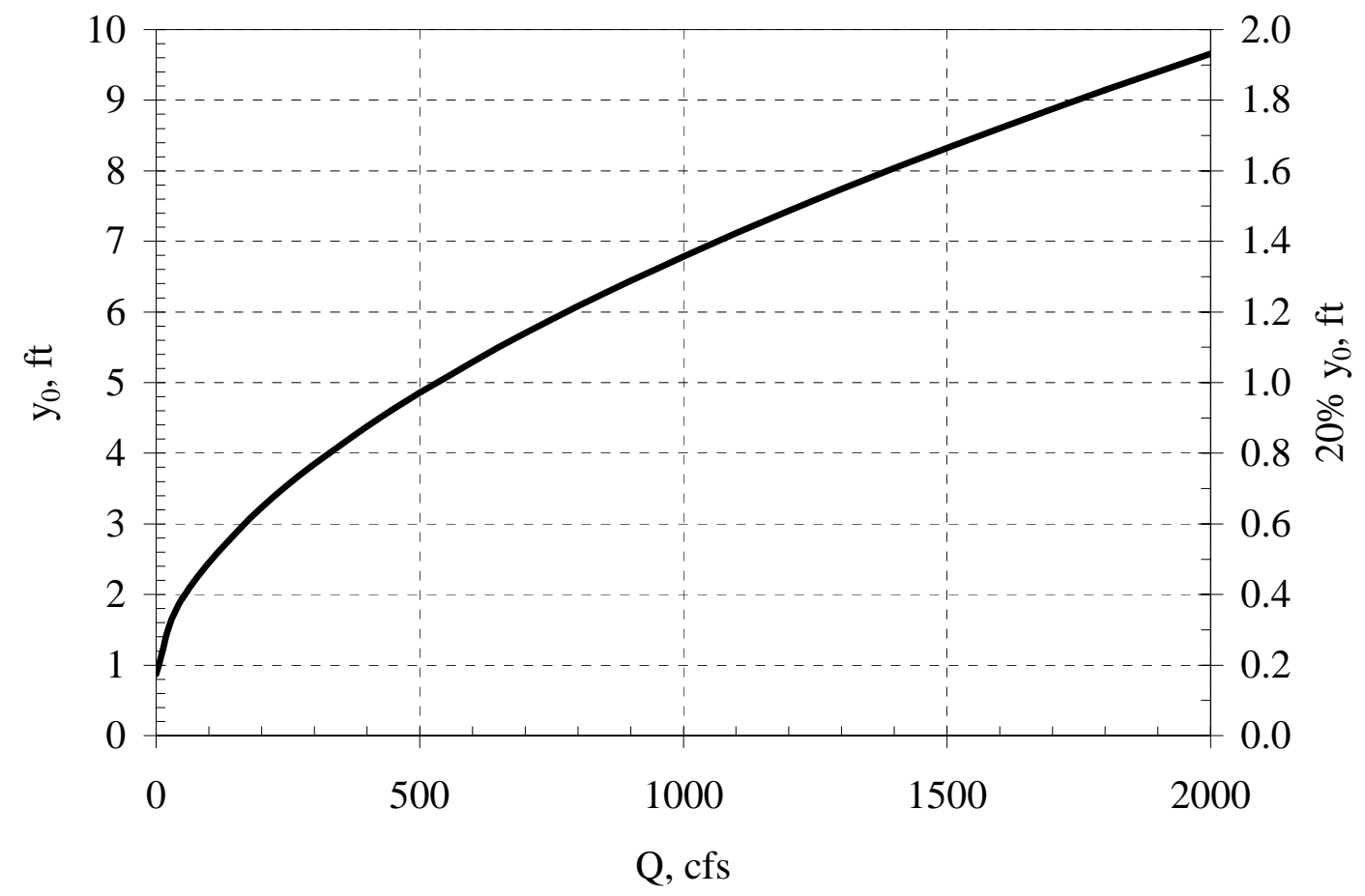

Figure 4.17 Twenty percent depth with increasing discharge 
Figure 4.17 shows that the discrepancy involved with extrapolation of the point samples by spatial integration occurs in a region that cannot be sampled using depthintegrating methods. Furthermore, the spatial integration of the product of the Rouse concentration distribution and the logarithmic velocity distribution to obtain sediment discharge implicitly assumes steady, uniform flow under equilibrium sediment transport conditions. Use of the slope of the energy grade line obtained from the unsteady hydrodynamic model introduces effects of unsteadiness that are not included in the Rouse methodology thus biasing the point-sample integration.

Although the method for spatially extrapolating the point measurements as outlined above overestimates suspended sediment discharge during water discharge less than 200 cfs, it is otherwise effective for predicting suspended sediment discharge. Furthermore, the limitation in the method, namely sampling during low flows with rapidly changing stage, is shared by most other sampling methods including depthintegrating samplers. Numerical techniques also suffer from this limitation since the assumption of steady, uniform flow must be made for calculation. However, the proposed method for vertically and horizontally extrapolating point samples provides a unique means for measuring suspended sediment discharge with an automatic sampler. Calculated bedload discharge can then be added to the measured suspended sediment discharge to obtain total sediment discharge. It has been shown that point sampling can be used in place of depth-integrated sampling after a short calibration period in which both point sampling and depth-integrated sampling are conducted. A series of straightforward numerical techniques yield point samples that are vertically representative of sediment concentration at a single vertical, and lateral variation in 
sediment discharge is identified by comparing measurements at each depth-integrated sampling vertical and applying a correction factor. The method presented can actually provide greater accuracy in some cases due to its inclusion of the unsampled zone neglected by depth-integrating techniques. Because the sampler operates automatically and is programmed to collect samples at a specified time interval, the method provides much greater temporal resolution than any manual techniques.

In addition, an approach for identifying sediment sources using turbidity has been presented to increase the accuracy of automatic point sampling, which stands in contrast to common attempts to replace point and depth-integrating samplers with in situ turbidimeters. Turbidity measurement as presented here provides a method of comparing the sediment that constitutes point samples and depth-integrated samples, and sources of washload can be located and identified through bed and bank sampling.

\subsection{Implementation of Research Findings}

The conclusions of this research may be useful for a municipality or consulting engineer charged with the task of establishing and regulating sediment TMDLs in an urban setting. In addition to the theoretical understanding provided by the data set and its analysis, a pragmatic approach has been developed that optimizes man-hours and project funding and resources. Chapter II provides sufficient background for suspended sediment measurement techniques and establishes automatic programmable point samplers as a convenient and cost-effective option for collecting suspended sediment data. 
The first step in implementing the approach presented here is selecting an appropriate sampling site. A bridge site is ideal because it provides convenient access to sampling equipment and because a bridge is necessary for depth-integrated sampling. The bridge crossing should be perpendicular to the stream reach since a skewed crossing complicates depth-integrating techniques. Cooperation of local property owners and agencies should also be weighed heavily since frequent visits to the site will be necessary. In the particular case of this research, the bridge crossing was within an office park, thereby minimizing sampling restrictions caused by automobile traffic. Heavy vegetation on the stream banks complicates depth-integrated sampling, although bridge sites generally provide sufficient open space. Of particular interest in selecting a sampling site is its proximity to a stream gauging station of an agency such as the U.S. Geological Survey. Gauging stations can provide helpful information such as rainfall data and streamflow parameters, and in some cases this data may be available in realtime.

After the site has been selected, a survey of the sampling cross-section and stream channel and floodplain should be conducted or obtained. Such channel surveys are often available as part of local floodplain maps or flood elevation studies. The survey should include the downstream channel and its floodplain for several thousand feet at regular station intervals. The exact downstream distance may be determined by stage data available downstream, another bridge crossing, or some other boundary condition. The survey data should provide the necessary information of channel thalweg slope and channel dimensions. These survey points are implemented in HEC-RAS to construct the 
numerical model of the stream hydraulics and develop the stage-discharge rating curve as discussed in section 4.6.

The point sampler can be put in place immediately after the site has been selected, as it does not depend on data from the channel survey. The sampler intake strainer should be placed in the channel thalweg so that it will capture the maximum range of flow conditions. Chapter III provides a detailed description of the point sampling apparatus and its installation and use. Once all of the prescribed materials have been collected, installation of the point sampler can be completed in one day's work by two technicians. The exact location of the sampler intake strainer should be carefully measured as part of the channel survey. The sampler should then be programmed according to project goals. Sampler maintenance includes charging the marine battery used to power the sampling unit and routinely checking the intake strainer for clogs or debris that could prevent effective sampling or otherwise damage the sampler tubing.

Bed and bank sediment samples should be collected during periods of low flow. These samples can be collected immediately since they do not depend on the channel survey, although the each sample's upstream location in relation to the point sampler should be noted. Grain size analysis and turbidity measurement may be conducted as prescribed in Chapter III for comparison with storm samples.

Once the site is operational, depth-integrated sampling and velocity measurement may be conducted during storm events of sufficient magnitude. Chapter III provides the sampling scheme utilized in this research and provides references for further guidance for this type of sampling. The velocity data should then be used in conjunction with the 
channel survey data and numerical model (HEC-RAS) to construct the stage-discharge relationship at the sampling cross-section.

Laboratory methods as enumerated in Chapter III provide sediment concentration and turbidity data for storm samples. The sediment concentration data collected with the depth-integrating sampler should be converted to sediment discharge values and plotted to create a sediment-rating curve. Point samples of sediment concentration should also be extrapolated using the Rouse solution as explained in Chapter II and calibrated laterally using the depth integrated samples as described in section 4.9. It is important to note that the storm samples should be analyzed and plotted as soon as possible following the storm event so that gaps in the data set may be identified and targeted in future storm events. Using turbidity data to identify washload sediment is an ongoing process that is relative to annual seasons and changes in the watershed. However, the relationship between turbidity and suspended sediment concentration of the bed and bank sediment samples should provide a useful comparison for subsequent storm sample data. This use of turbidity data will help narrow the range of possible washload sources which will improve calculations of total sediment discharge and assist in allotting allowable contributions of point sediment sources to the stream.

The method outlined above should greatly improve the accuracy and usefulness of automatic point samplers, thereby simplifying the complex task of implementing sediment TMDLs. The research findings presented should provide the appropriate framework for creating a successful sediment TMDL program in urban watersheds. 


\section{CHAPTER V}

\section{CONCLUSIONS AND RECOMMENDATIONS}

\subsection{Conclusions}

Calculating TMDLs for sediment is a complex process that includes multiple sources of error, making it difficult to accurately assess healthy model streams as well as impaired streams. Urban stream hydrology presents a unique set of challenges since the stream's function is permanently altered. When individual storm events are of particular concern due to their role in transporting sediment, automatic point sampling and turbidity have been used to provide the temporal resolution necessary to capture storm events. As discussed in Chapter I, these methods introduce the problems of (1) transforming a point measurement of suspended sediment concentration to a cross-sectional average so that sediment loads can be accurately calculated; and (2) calibrating the correlation between sediment concentration and turbidity. The methodology developed during this project has addressed these concerns and provides an accurate and straightforward approach for use in calculating sediment TMDLs.

Point samples collected over a wide range of storm events in terms of magnitude have been vertically extrapolated by employing the Rouse solution for suspended sediment concentration distribution. The data set produced by vertically extrapolating the Isco point samples from several storm events was compared with depth-integrated samples. Measured sediment discharge of the integrated point samples exhibited close agreement with the measured sediment discharge of the depth-integrated samples. Lateral distribution of measured sediment discharge was quantified by comparing depthintegrated samples taken at each cross-section. This revealed that the average suspended 
sediment discharge at the point sampling vertical was approximately ten percent less than the cross-sectional average. This ten percent difference was applied to the integrated point samples, thereby extrapolating the point samples in the horizontal dimension. This approach yielded point samples that represented the entire cross-section as sampled by the depth-integrating sampler.

A method for using turbidity to improve suspended sediment discharge calculation was also presented. By comparing the turbidity produced by the fine sediment in the point samples with the fine sediment in the depth-integrated samples, it was effectively determined that point sampling accurately captured washload sediment, thereby effectively simplifying sediment discharge calculation. Turbidity analysis used in conjunction with bed and bank sampling can was also utilized to effectively decipher relative sources of sediment in point samples. This process showed that the point sampler collected coarse sediment originating in the stream bed and fine sediment washload from an upstream stream bank.

The point sampling methodology presented here also provides a series of samples corresponding to the complete storm hydrograph. This advantage greatly simplifies field data collection and field personnel requirements. The strengths of this method in particular address the flashy nature of urban streams and concerns that large individual storm events may be responsible for the majority of sediment loads in urban streams. As discussed above, an inherent weakness in the method is the over prediction of suspended sediment discharge during periods of water discharge less than $200 \mathrm{cfs}$. It is also noted that this particular limitation is shared by depth-integrated sampling methods as well and can be minimized through calculation. 
As mentioned in Chapter IV, the ideal means of comparison between point sampling and depth-integrated sampling is the simultaneous collection of both sample types during storm events. Egregious weather conditions prohibited this approach, presenting a possible weakness in point sampling. Although point sampling equipment is not particularly fragile, it is highly susceptible to urban debris transported in streams during storm events of extreme magnitude. Automobile seats and shopping carts were noted near the sampling location following a storm event; no sampling equipment can be expected to withstand such risks. It is also noted that this limitation is even more relevant to depth-integrated sampling since the sampler and the cable by which it is suspended may collect large amounts of debris, sometimes making sampling impossible.

By assessing the in-stream processes in urban streams that govern suspended sediment discharge, a simplified and dependable methodology has been developed and presented whereby automatic point samplers can provide significant insight for the establishment and measurement of sediment TMDLs. In addition, this approach offers little comparative cost and provides unparalleled temporal resolution.

\subsection{Recommended Future Research}

Point sampling and depth-integrated sampling conducted simultaneously over a wide range of storm events would provide considerable insight for improving the methodology presented here. Point sampling performed at several vertical locations relative to the bed would also provide a means of comparison with the Rouse solution for the vertical distribution of suspended sediment. Automatic point sampling concentrated on the rising limb of the hydrograph would provide further insight into the effects of the rapidly changing energy grade line slope on sediment discharge. Automatic samplers 
would provide the potential to sample once per minute and would significantly improve the temporal resolution in this vital period in the storm event. Sampling of the bed and banks could also be conducted during each annual season to analyze potential hysteresis effects caused by weather conditions and changing water temperature. This would also provide information regarding reaches of the stream experiencing aggradation and degradation for comparing sediment loads in several reaches of the stream. 


\section{APPENDIX}

FIELD RECORD OF STORM EVENTS 


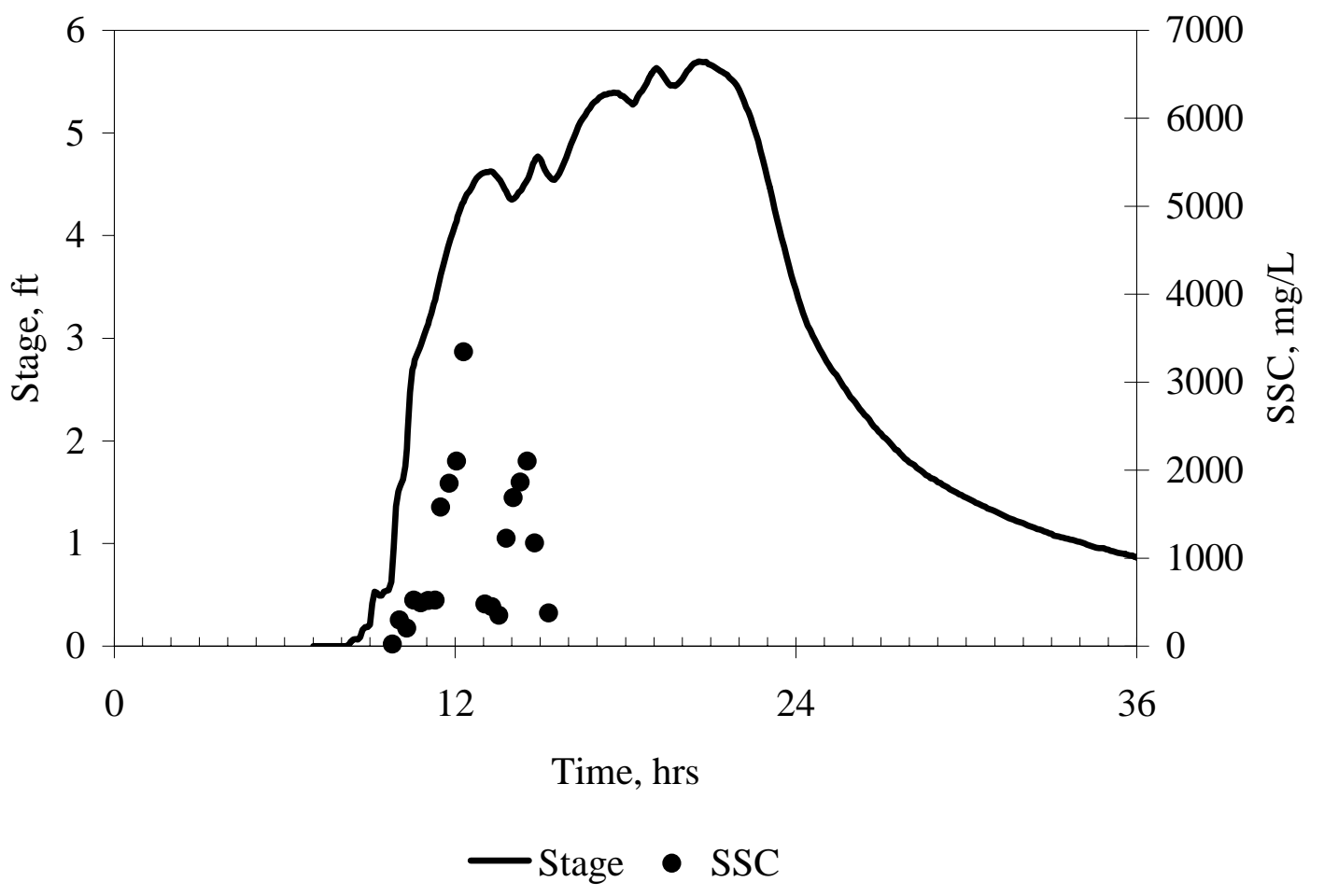

Figure A.1 October 26, 2003 storm hydrograph and point sampled SSC data 


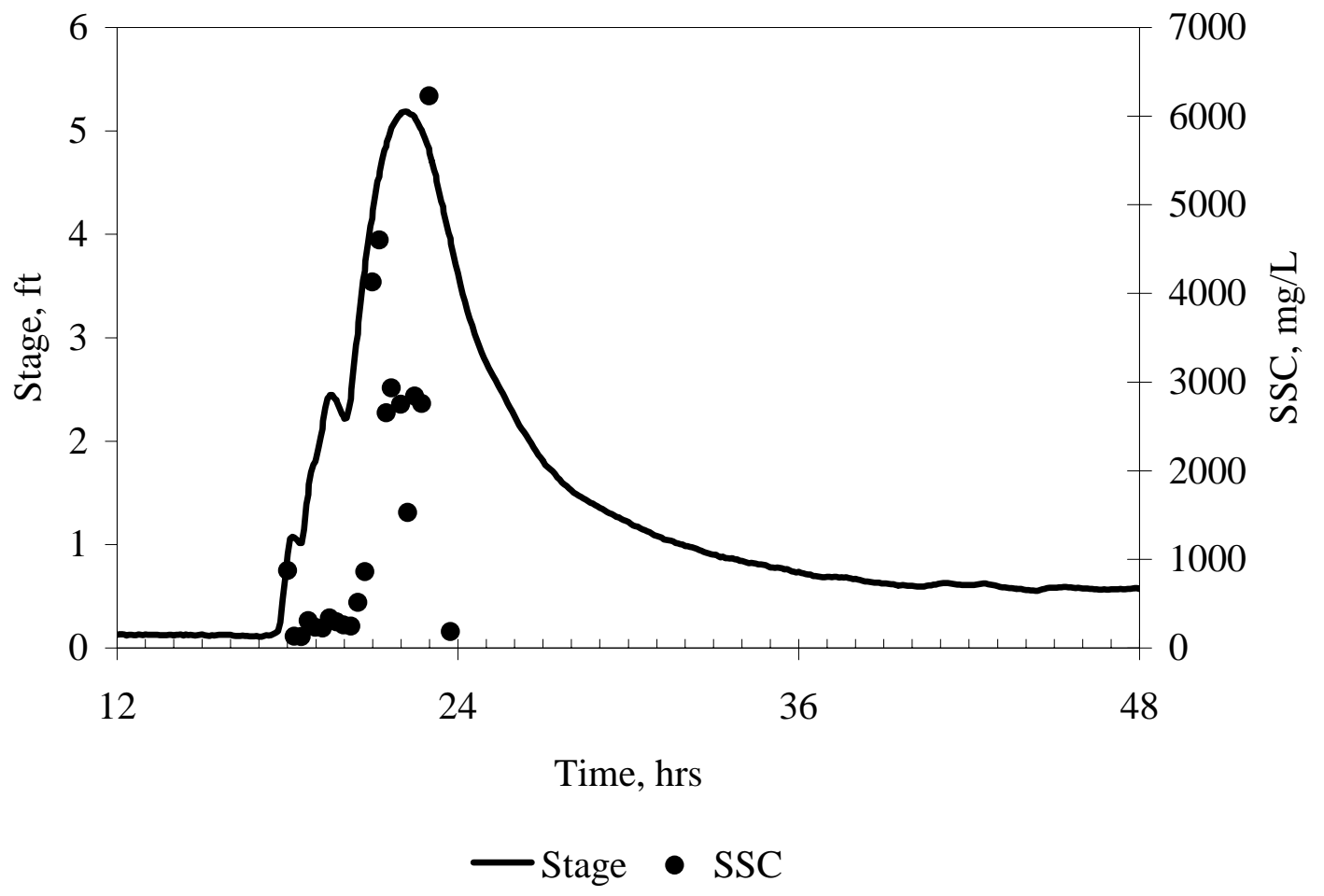

Figure A.2 November 5, 2003 storm hydrograph and point sampled SSC data 


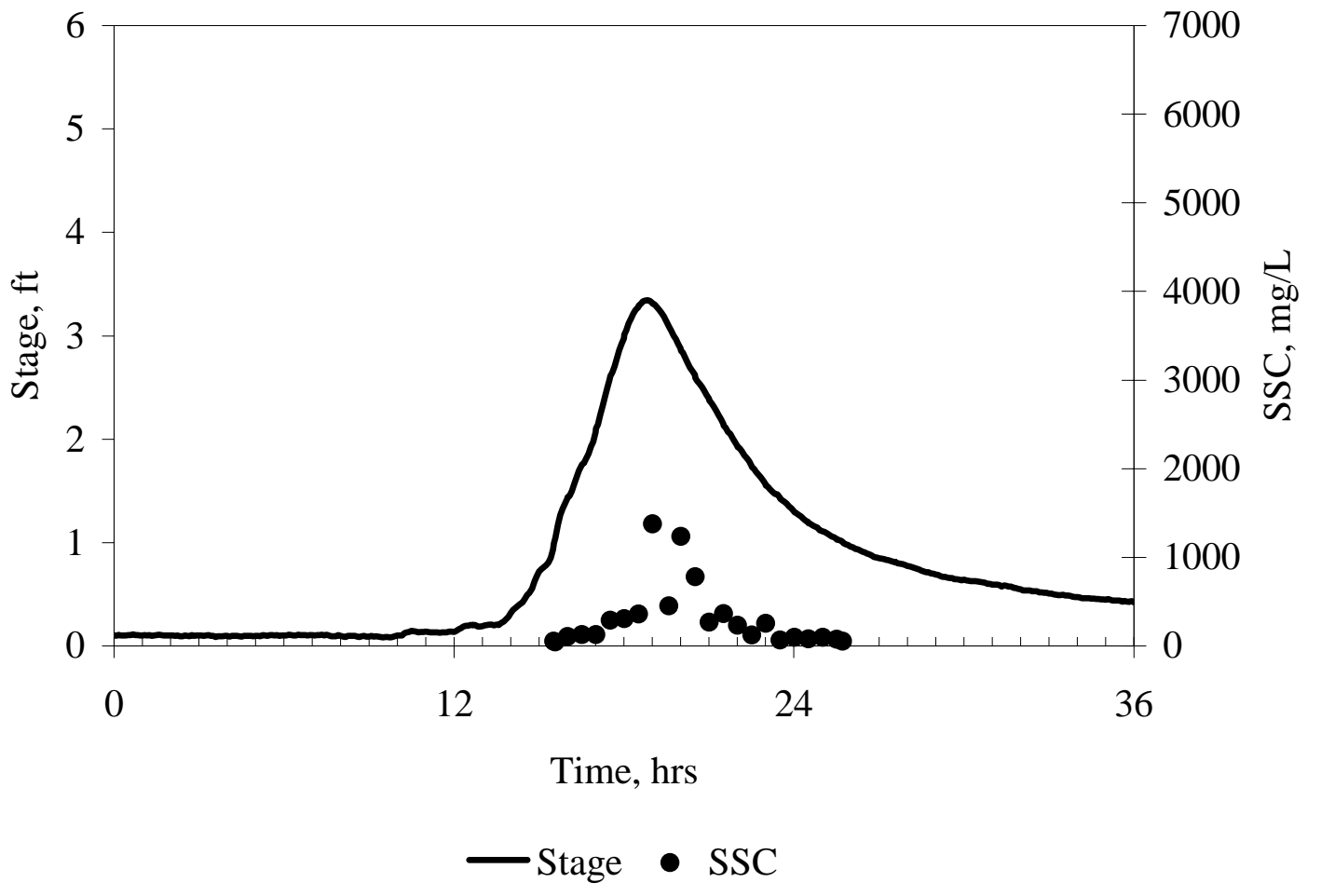

Figure A.3 January 5, 2004 storm hydrograph and point sampled SSC data 


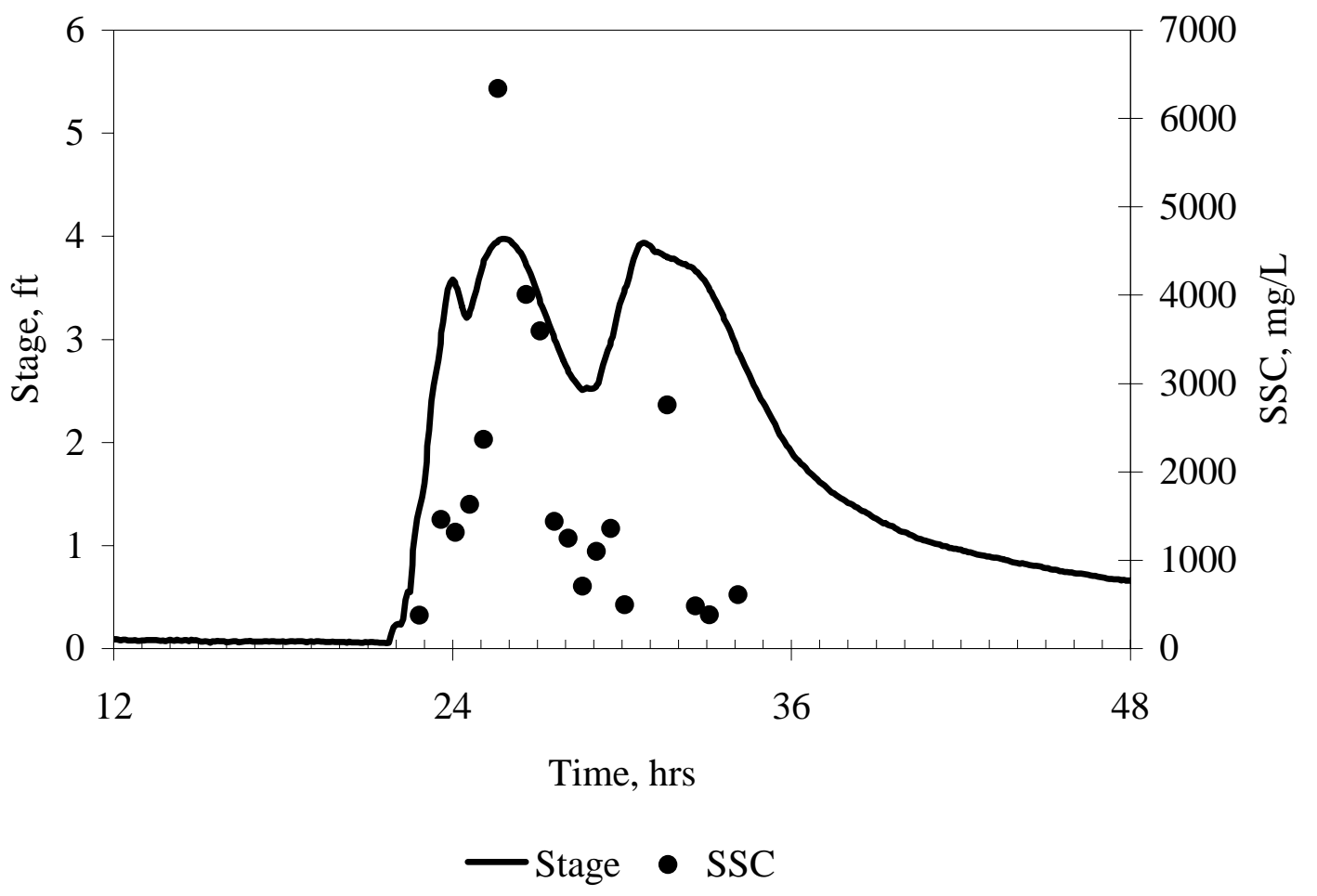

Figure A.4 April 13, 2004 storm hydrograph and point sampled SSC data 


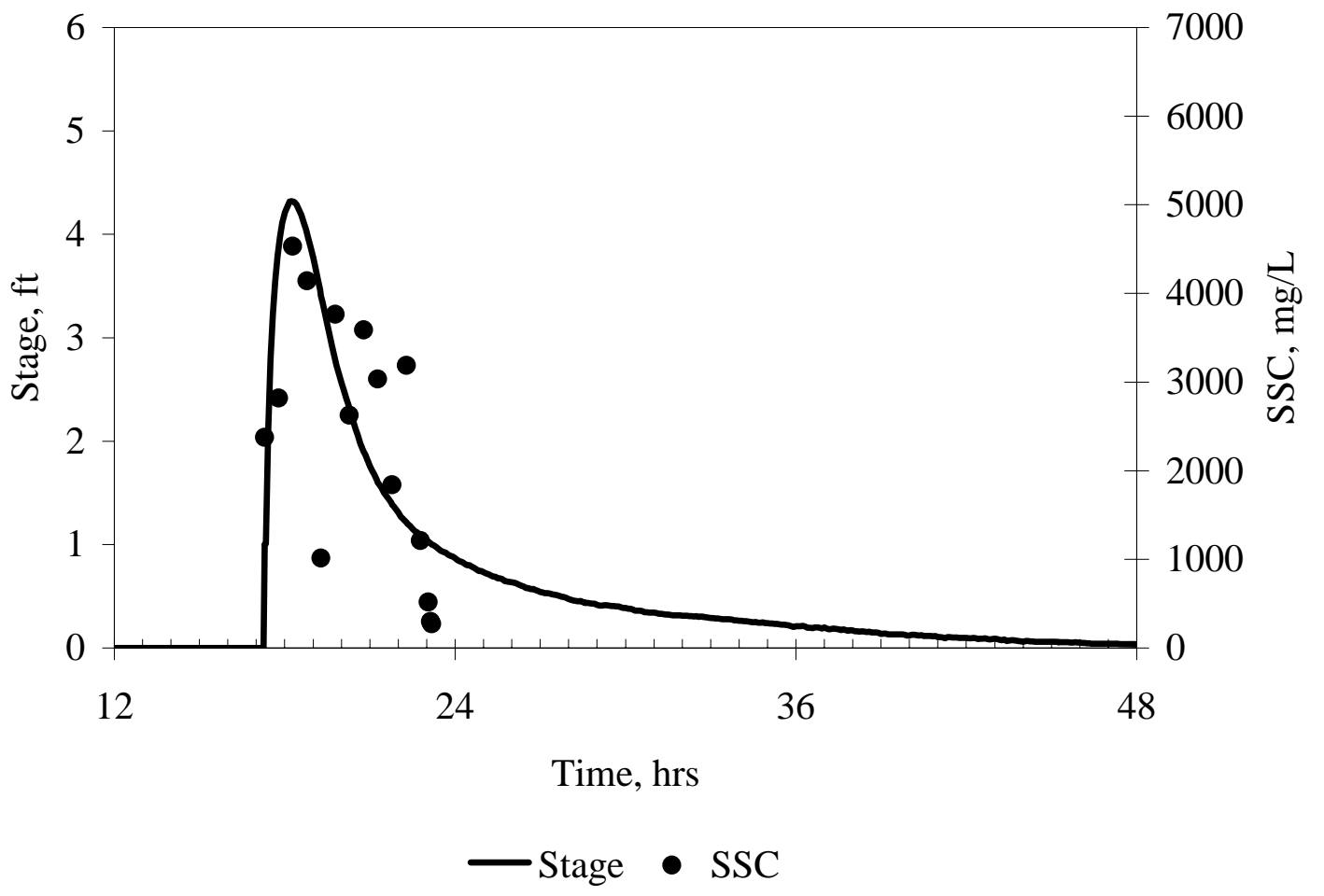

Figure A.5 May 22, 2004 storm hydrograph and point sampled SSC data 


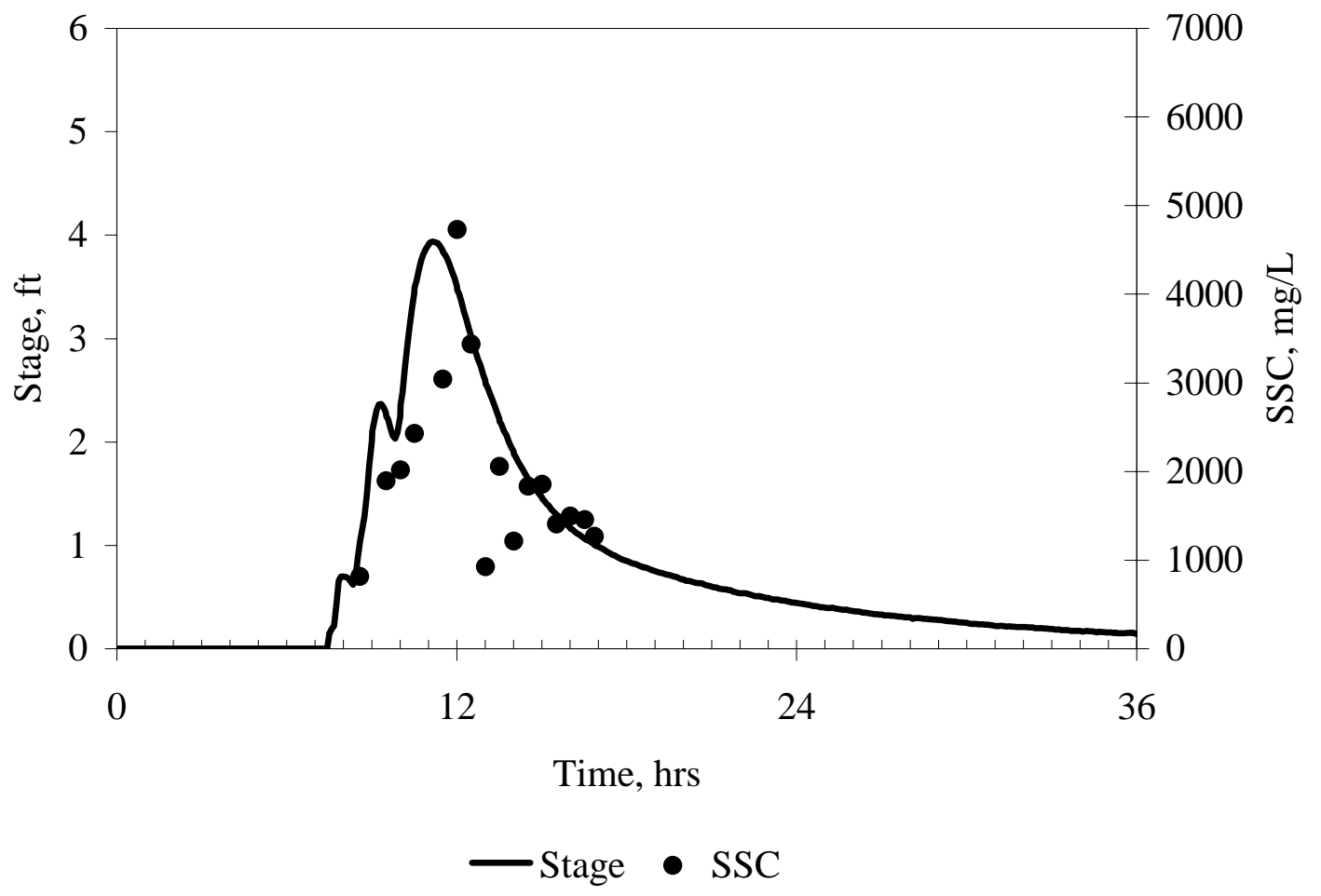

Figure A.6 May 31, 2004 storm hydrograph and point sampled SSC data 


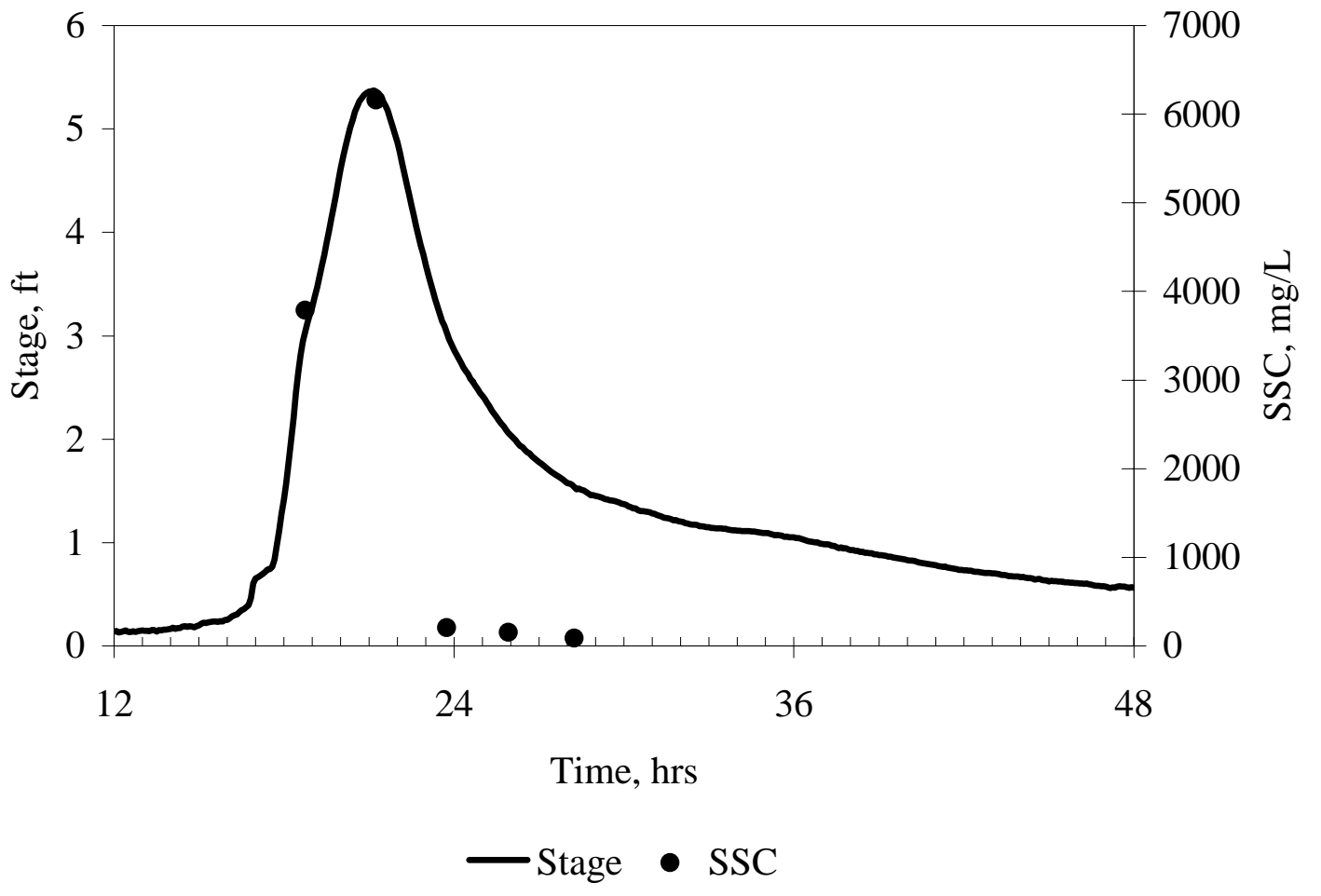

Figure A.7 February 3, 2004 storm hydrograph and SSC data from grouped point samples 


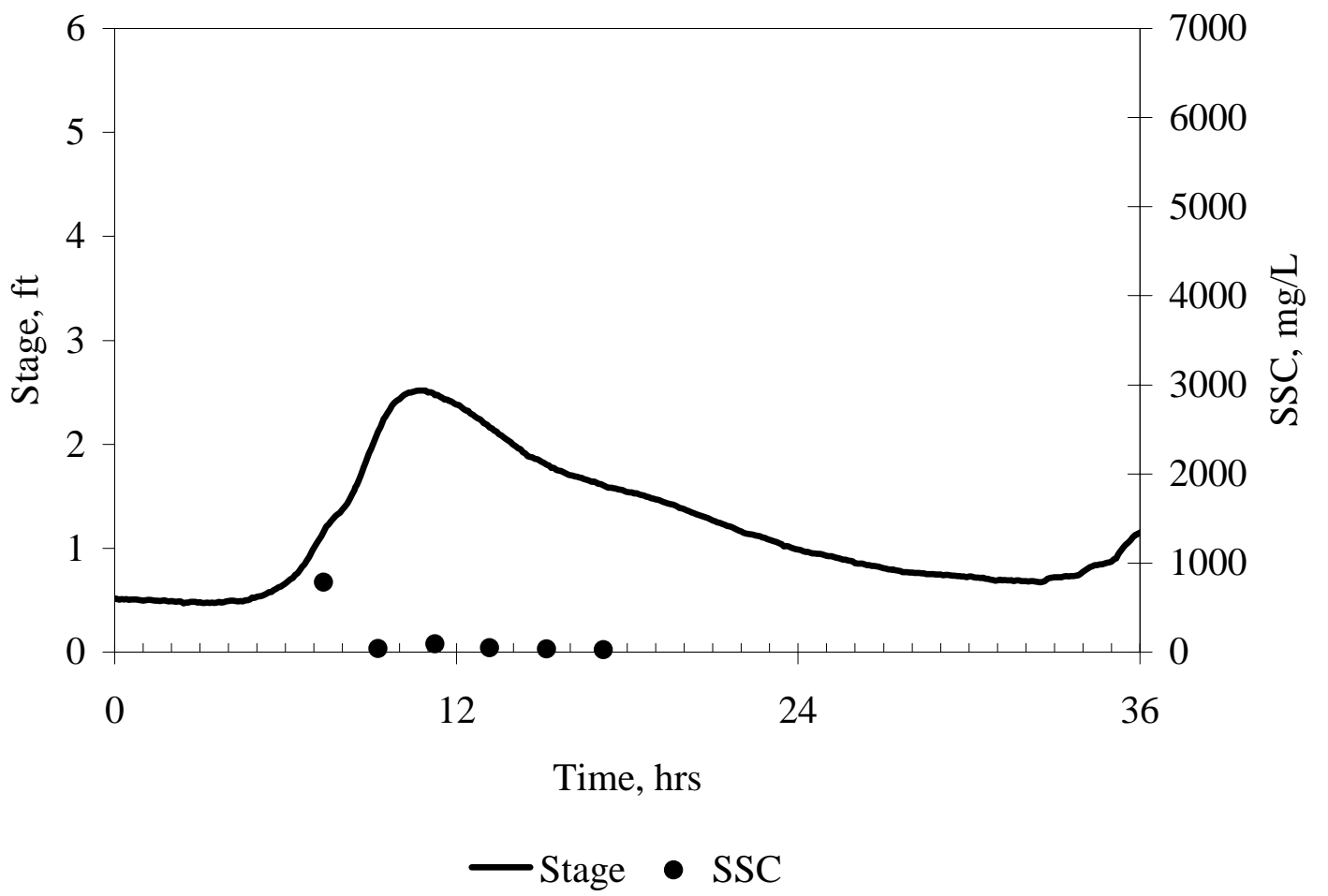

Figure A.8 February 14, 2004 storm hydrograph and SSC data from grouped point samples 


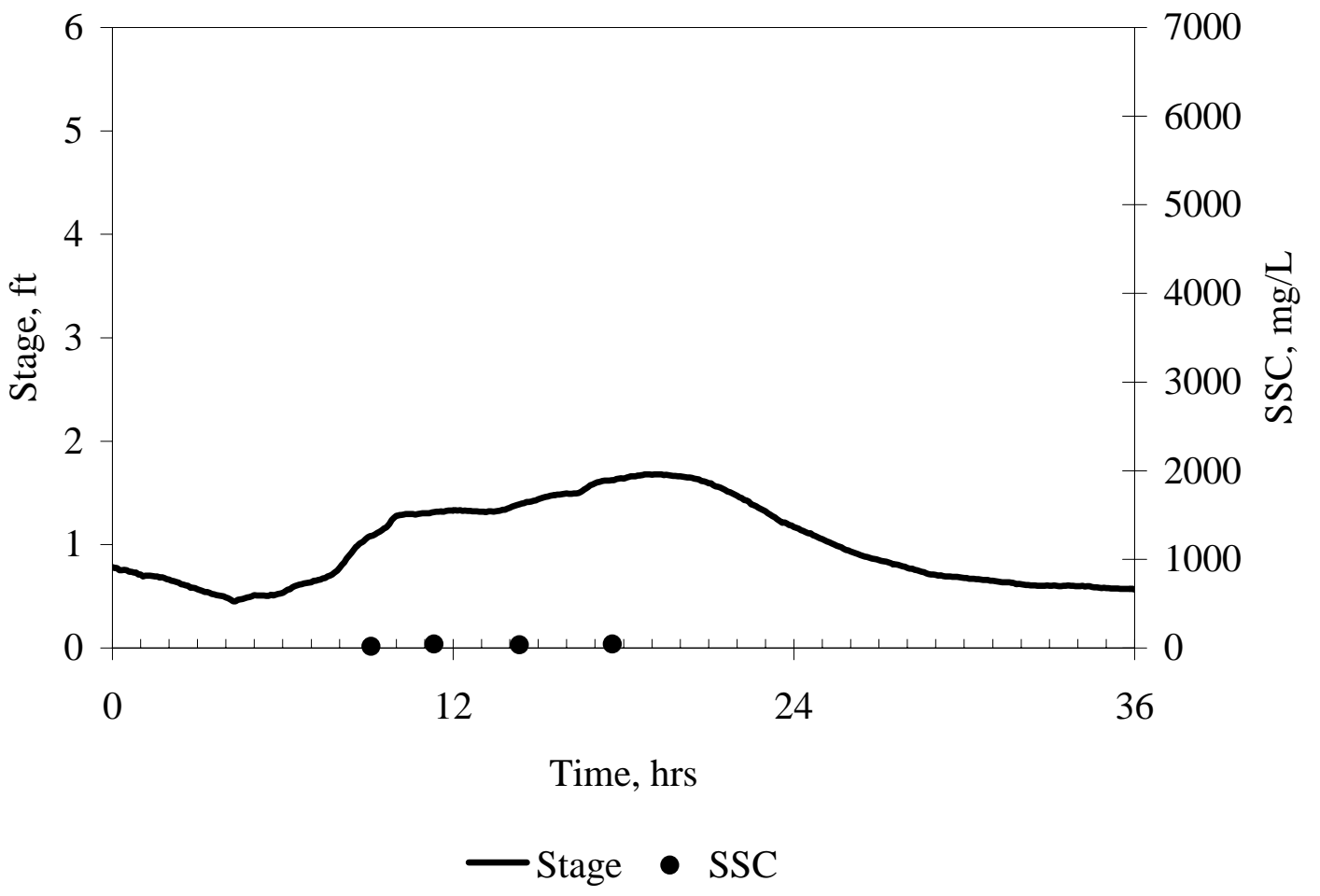

Figure A.9 February 26, 2004 storm hydrograph and SSC data from grouped point samples 


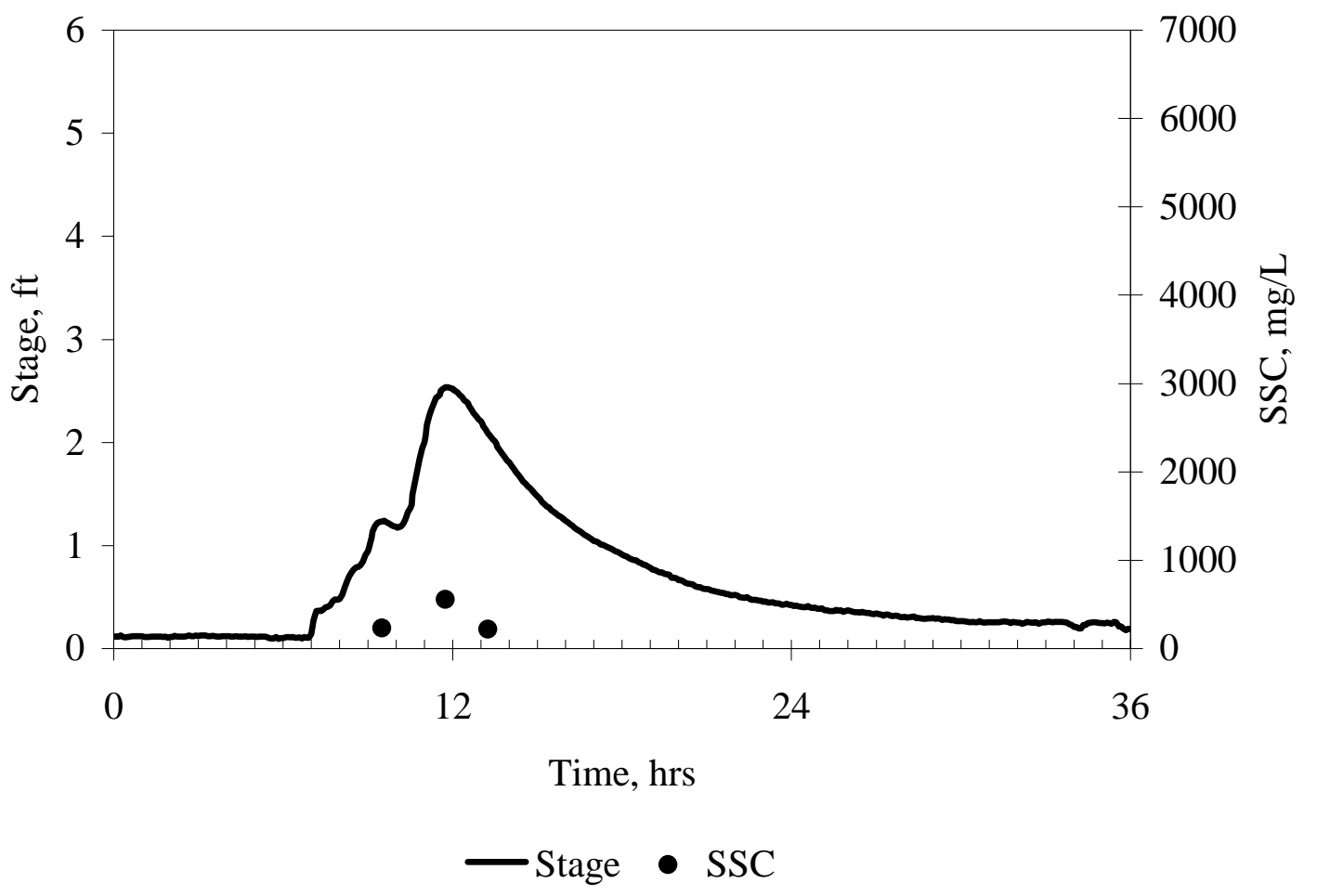

Figure A.10 April 6, 2004 storm hydrograph and SSC data from grouped point samples 


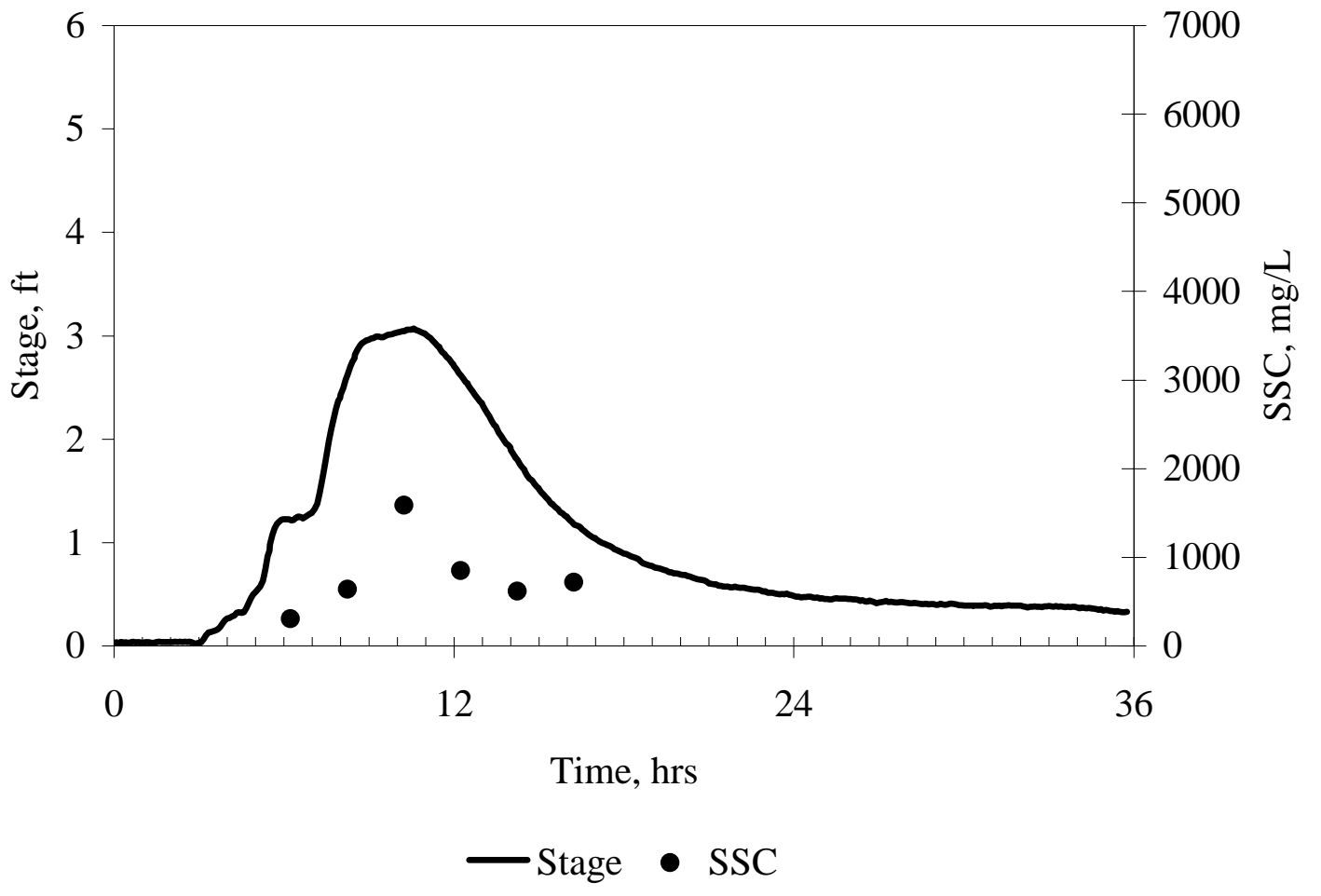

Figure A.11 April 30, 2004 storm hydrograph and SSC data from grouped point samples 


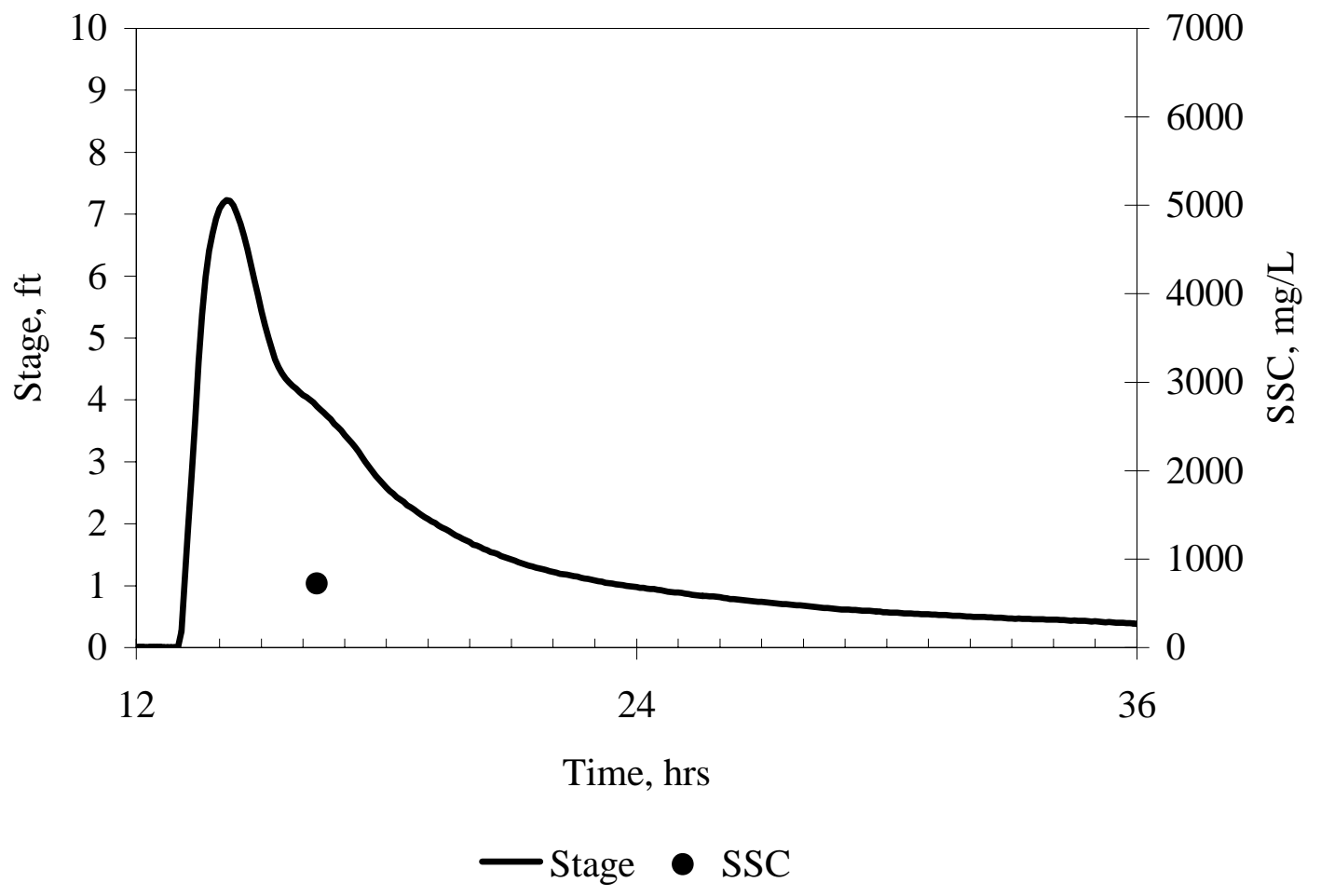

Figure A.12 June 21, 2004 storm hydrograph and cross-sectional SSC data from depth-integrated samples 


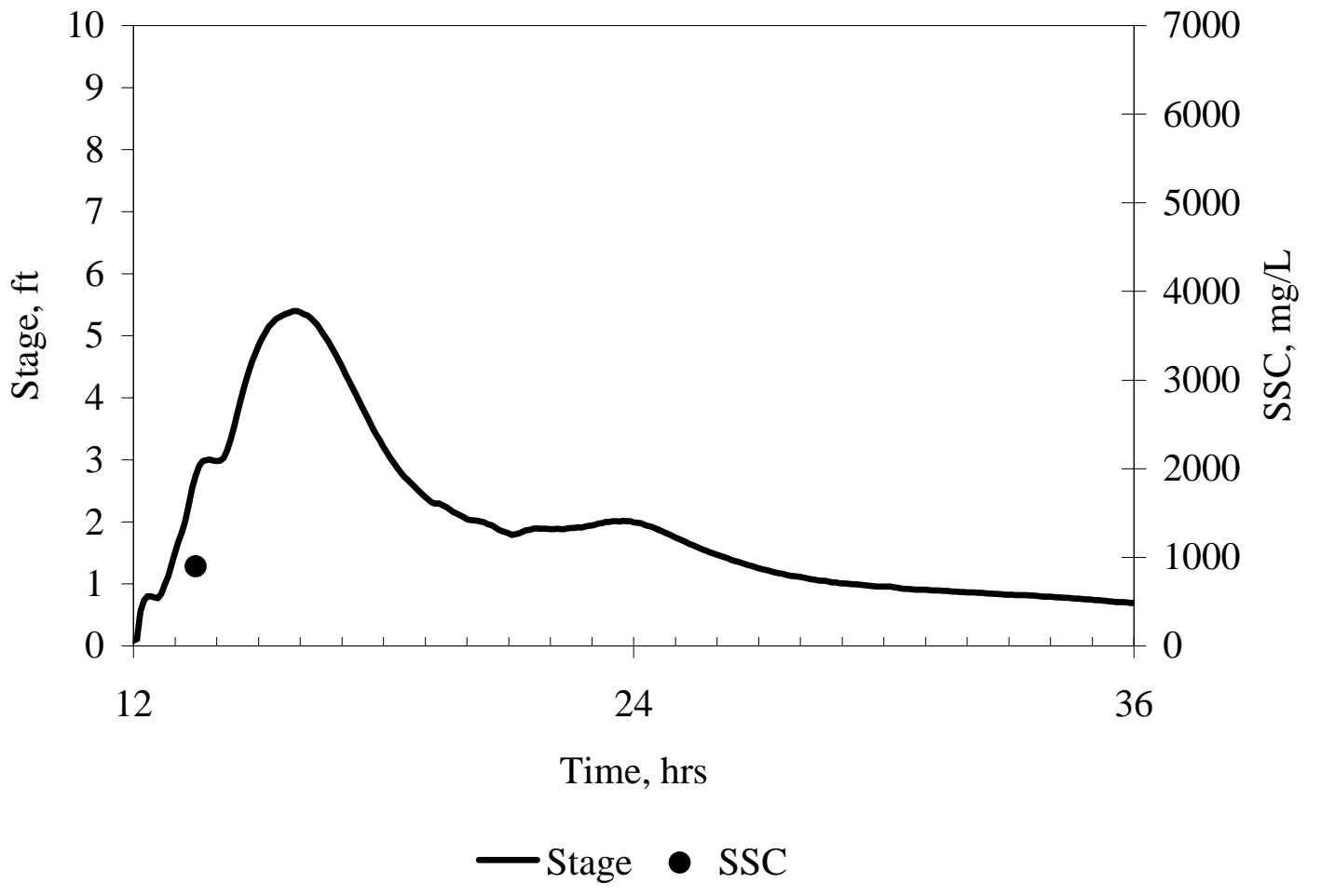

Figure A.13 June 25, 2004 storm hydrograph and cross-sectional SSC data from depth-integrated samples 


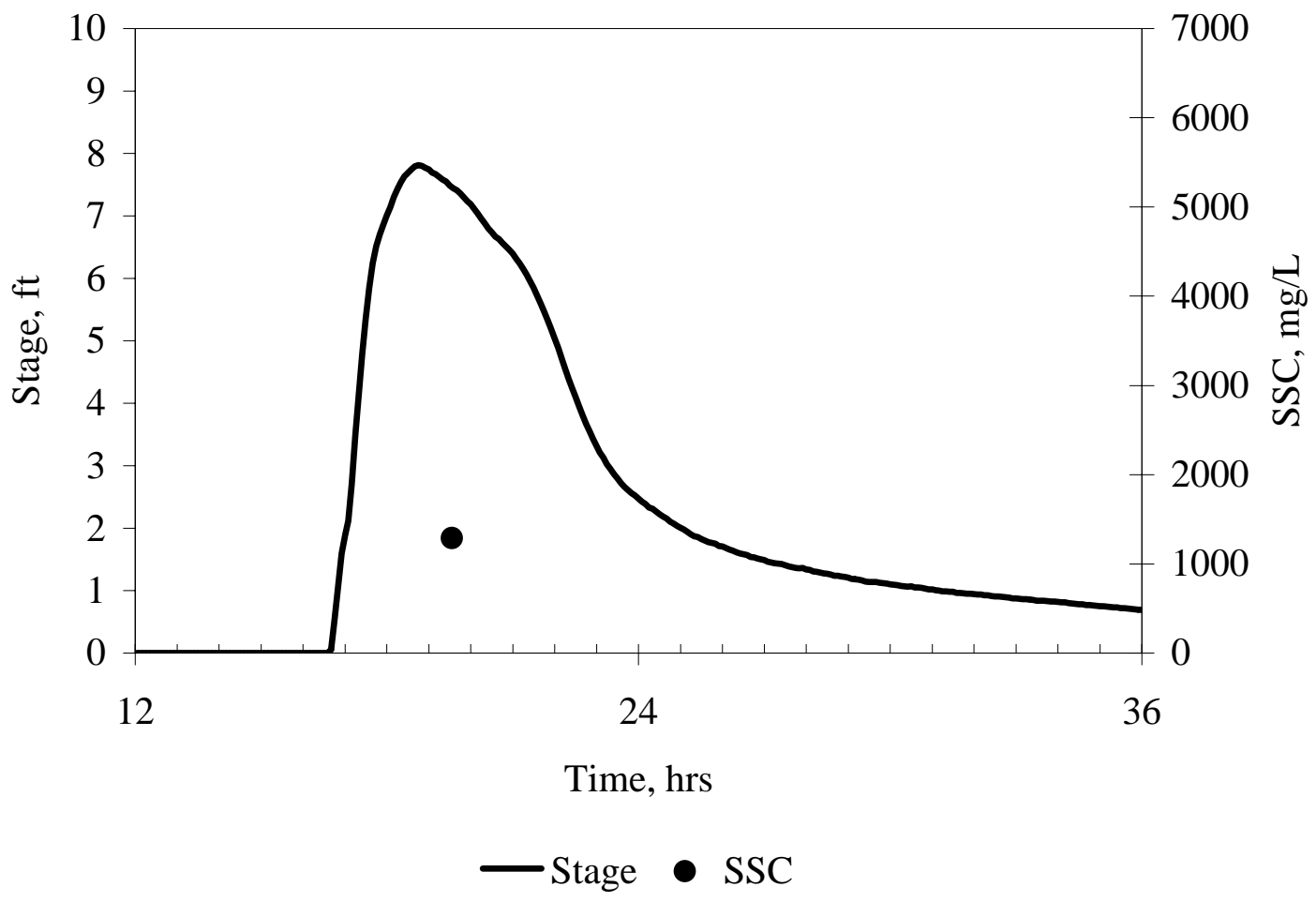

Figure A.14 August 5, 2004 storm hydrograph and cross-sectional SSC data from depth-integrated samples 


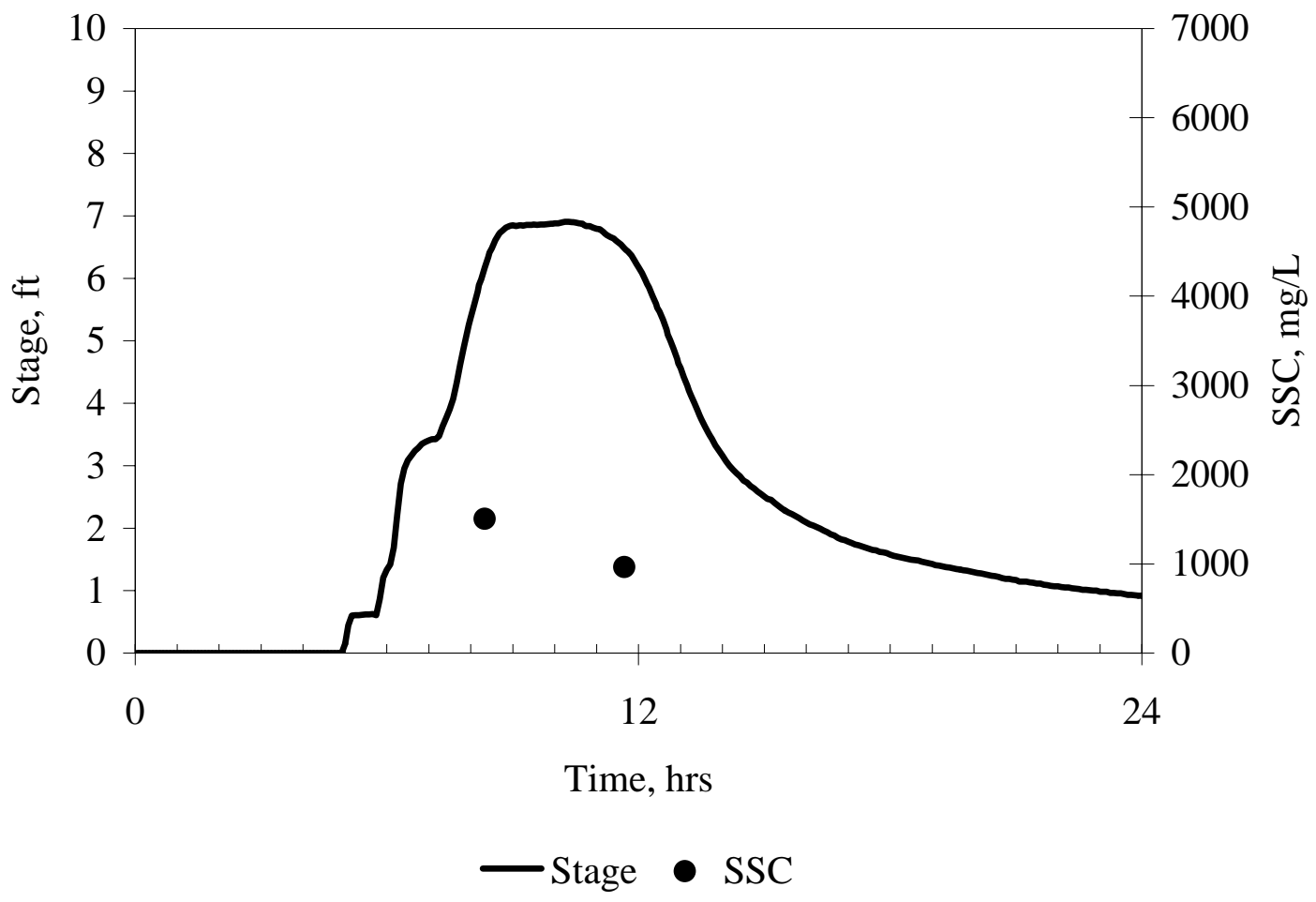

Figure A.15 August 12, 2004 storm hydrograph and cross-sectional SSC data from depth-integrated samples 


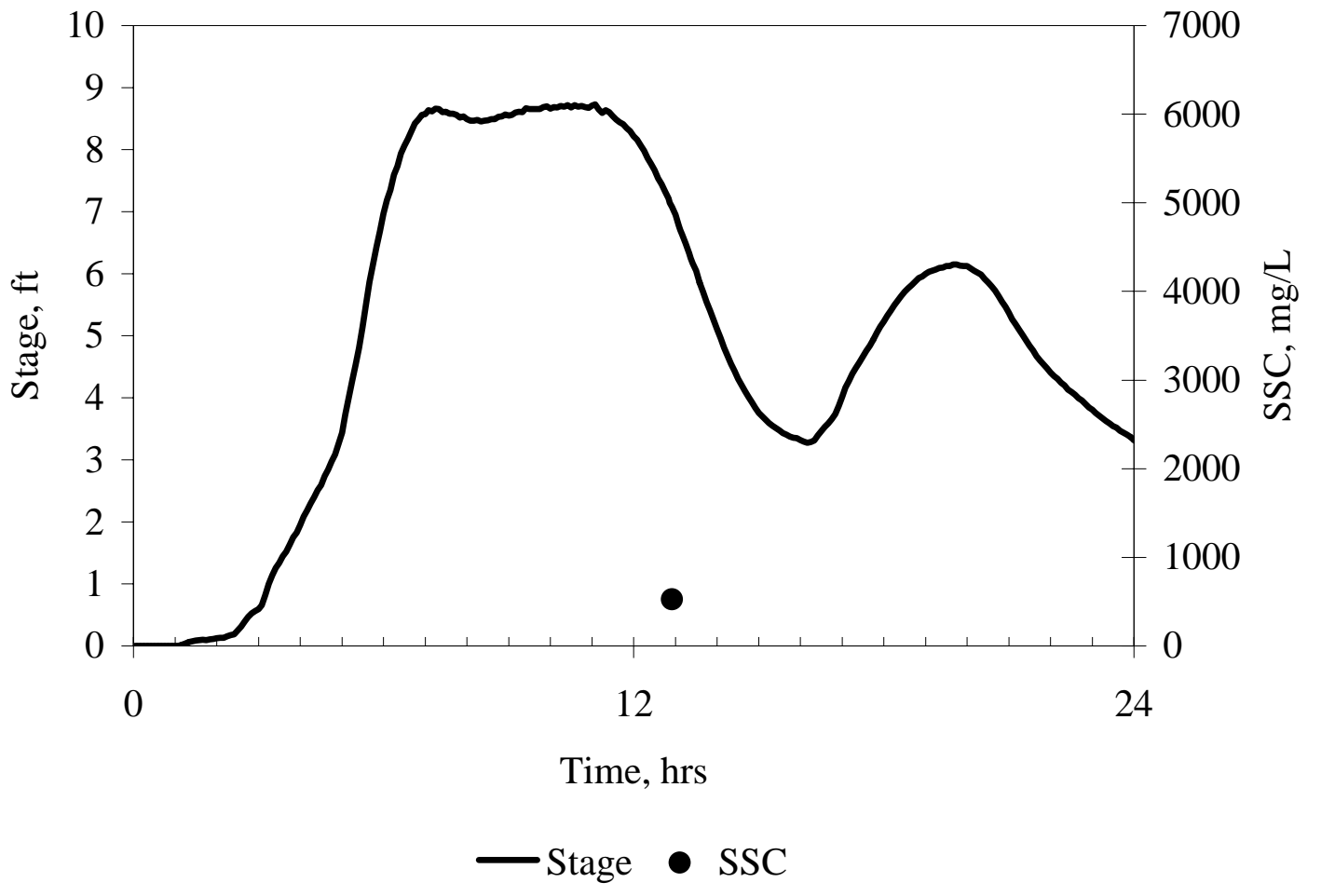

Figure A.16 September 7, 2004 storm hydrograph and cross-sectional SSC data from depth-integrated samples 


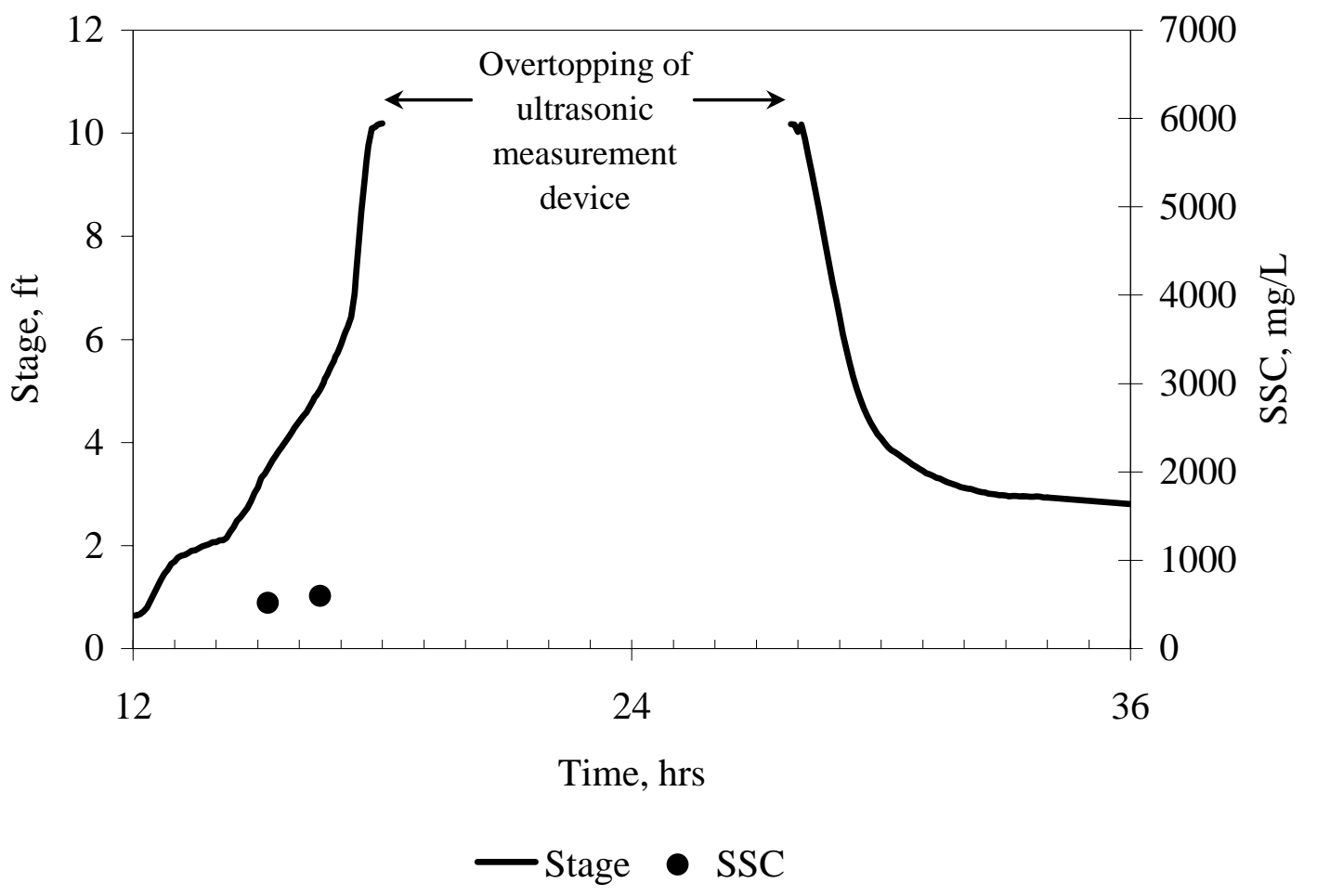

Figure A.17 September 16, 2004 storm hydrograph and cross-sectional SSC data from depth-integrated samples 


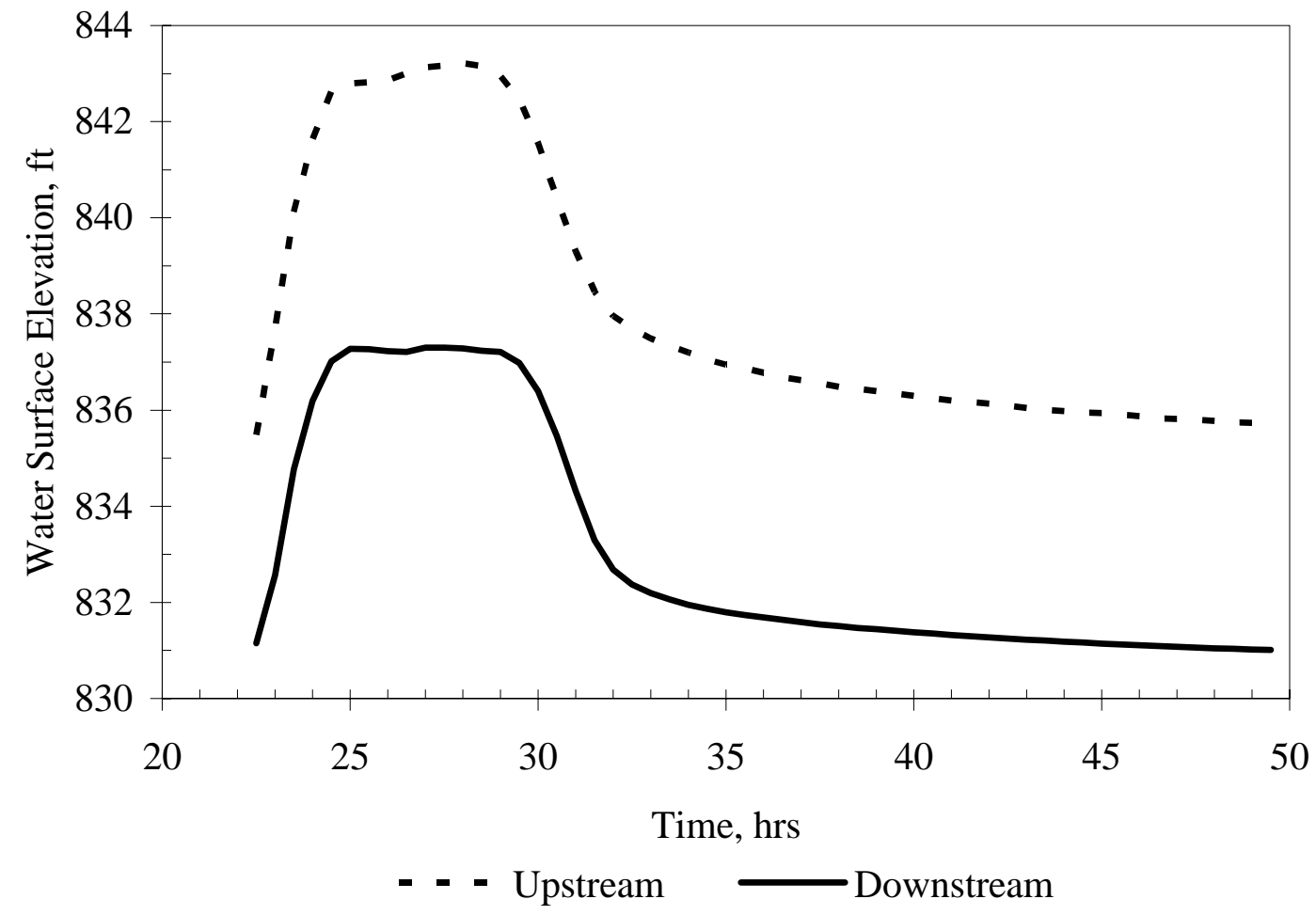

Figure A.18 March 19, 2000 storm hydrographs used to produce the dischargerating curve with HEC-RAS 


\section{REFERENCES}

Agrawal, Y.C. and H.C. Pottsmith. (2002). "New isokinetic version of LISST technology targets needs of the Federal Subcommittee on Sedimentation.” Proc. Turbidity and Other Sediment Surrogates Workshop, Reno, Nevada.

ASTM (American Society for Testing and Materials). (2000). "Standard test methods for determining sediment concentration values in water samples,” D 3977-97, Vol. 11.02, Water (II), 395-400.

ASTM (American Society for Testing and Materials) (2000). "Standard test method for particle-size analysis of soils.” D 422-63.

Brasington, J., and K. Richards (2000). "Turbidity and suspended sediment dynamics in the Nepal Middle Hills.” Hydrological Processes, Vol. 14, pp. 1448-1463.

Buchanan, T.J. and Somers, W.P. (1969). "Discharge Measurements at Gaging Stations.” In Techniques of Water-Resources Investigations, Book 3, Chapter A8, Washington, DC: Government Printing Office, U.S. Geological Survey.

Christensen, V.G., P.P. Rasmussen, and A.C. Ziegler. (2002). "Comparison of estimated sediment loads using continuous turbidity measurements and regression analysis.” Proc. Turbidity and Other Sediment Surrogates Workshop, Reno, Nevada.

Faye, R. E., W.P. Carey, J.K. Stamer, and R.L. Kleckner. (1980). “Erosion, sediment discharge, and channel morphology in the upper Chattahoochee river basin, Georgia.” Geological Survey Professional Paper 1107, U. S. Govt. Printing Office, Washington, D.C.

Gartner, J.W. (2002). "Estimation of suspended solids concentrations based on acoustic backscatter intensity: theoretical background.” Proc. Turbidity and Other Sediment Surrogates Workshop, Reno, Nevada.

Gippel, C.J. (1995). "Potential of turbidity monitoring for measuring the transport of suspended solids in streams.” Hydrological Processes, Vol. 9, pp. 83-97.

Gray, J.R., G.D. Glysson, L.M. Turcios, and G.E. Schwarz. (2000). “Comparability of suspended-sediment concentration and total suspended solids data.” Water Resources Investigation Report 00-4191, Reston, Virginia.

Gray, J.R. (2002). "The need for surrogate technologies to monitor fluvial-sediment transport.” Proc. Turbidity and Other Sediment Surrogates Workshop, Reno, Nevada. 
Grayson, R.B., B.L. Finlayson, C.J. Gippel, and B.T. Hart. (1996). “The potential of field turbidity measurements for the computation of total phosphorous and suspended solids loads.” Journal of Environmental Management, Vol. 47, pp. 257-267.

Green, T.R., S.G. Beavis, C.R. Dietrich, and A.J. Jakeman. (1999). "Relating streambank erosion to in-stream transport of suspended sediment." Hydrological Processes, Vol. 13, pp. 777-787.

Horowitz, A.J., F.A. Rinella, P. Lamothe, T.L. Miller, T.K. Edwards, R.L. Roche, and D.A. Rickert. (1990). "Variations in suspended sediment and associated trace element concentrations in selected riverine cross sections." Environmental Science Technology, Vol. 24, pp. 1313-1320.

Horowitz, A.J. (2002). "The use of rating curves to predict suspended sediment concentration: A matter of temporal resolution." Proc. Turbidity and Other Sediment Surrogates Workshop, Reno, Nevada.

Julien, P.Y. (1995). Erosion and Sedimentation. New York: Cambridge University Press.

Kennedy, E.J. (1984). "Discharge Ratings at Gaging Stations.” In Techniques of WaterResources Investigations, Book 3, Chapter A10, Washington, DC: Government Printing Office, U.S. Geological Survey.

Lewis, J. (2002). "Estimation of suspended sediment flux in streams using continuous turbidity and flow data coupled with laboratory concentrations.” Proc. Turbidity and Other Sediment Surrogates Workshop, Reno, Nevada.

Melis, T.S., D.J. Topping, and D.M. Rubin. (2002). “Testing laser-based sensor for continuous in-situ monitoring of suspended sediment in the Colorado River, Grand Canyon, Arizona.” Proc. Turbidity and Other Sediment Surrogates Workshop, Reno, Nevada.

Pfannkuche, J. and A. Schmidt. (2003). "Determination of suspended particulate matter concentration from turbidity measurements: particle size effects and calibration procedures.” Hydrological Processes, Vol. 17, pp. 1951-1963.

Sturm, T.W. (2001). Open Channel Hydraulics. Textbook Series in Water Resources and Environmental Engineering, McGraw-Hill, New York.

Tarras-Wahlberg, N.H. and S.N. Lane. (2003). "Suspended sediment yield and metal contamination in a river catchment affected by El Nino events and gold mining activities: the Puyango river basin, southern Ecuador.” Hydrological Processes, Vol. 17, pp. 3101-3123. 
U.S. Army Corps of Engineers. (1998). HEC-RAS Hydraulic Reference Manual, Version 2.2. Davis, CA: U.S. Army Corps of Engineers, Hydrologic Engineering Center.

Vanoni, V.A., ed. (1977). Sedimentation Engineering. New York: ASCE Task Committee for the Preparation of the Manual on Sedimentation, ASCE.

Wass, P.D. and G.J.L. Leeks. (1999). "Suspended sediment fluxes in the Humber catchment, UK.” Hydrological Processes, Vol. 13, pp. 935-953.

Weber, D. (2000). Relative Contribution of Sediment from Upland and Channel Erosion, M.S. Thesis, School of Civil and Environmental Engineering, Georgia Tech, Atlanta, GA.

Weigel, J.F. (1984). "Turbidity and suspended sediment in the Jordan River, Salt Lake County, Utah.” Water-Resources Investigations Report 84-4019. 